\title{
Summary of Pilot-Scale Activities with Resorcinol Ion Exchange Resin (U)
}

by

C. A. Cicero

Westinghouse Savannah River Company

RECEIVED

Savannah River Site

Aiken, South Carolina 29808

D. F. Bicklord

T. N. Sargent

M. $K$ Andrews

J. P. Bibler

N. E. Bibler

C. M. Jantzen

DOE Contract No. DE-AC09-89SR18035

This paper was prepared in connection with work done under the above contract number with the U.S.

Department of Energy. By acceptance of this paper, the publisher and/or recipient acknowledges the U.S. Government's right to retain a nonexclusive, royalty-free license in and to any copyright covering this paper, along with the right to reproduce and to authorize others to reproduce all or part of the copyrighted paper. 


\section{DISCLAIMER}

Portions of this document may be illegible in electronic image products. Images are produced from the best available original document. 


\section{DISCLATMER}

This report was prepared as an account of work sponsored by an agency of the United States Government. Neither the United States Government nor any agency thereof, nor any of their employees, makes any warranty, express or implied, or assumes any legal liability or responsibility for the accuracy, completeness, or usefulness of any information, apparatus, product, or process disclosed, or represents that its use would not infringe privately owned rights. Reference herein to any specific commercial product, process, or service by trade name, trademark, manufacturer, or otherwise does not necessarily constitute or imply its endorsement, recommendation, or favoring by the United States Government or any agency thereof. The views and opinions of authors expressed herein do not necessarily state or reflect those of the United. States - Government or any agency thereof.

This report has been reproduced directly from the best available copy.

Available to DOE and DOE contractors from the Office of Scicatific and Technical Information, P. O. Box 62, Oak Ridge, TN 37831: prices available from (615) $576-8401$.

Available to the public from the National Technical Information Service, U. S. Department of Commerce, 5285 Port Royal Rd., Springfield, VA 22161 


\title{
Westinghouse Savannah River Company Savannah River Technology Center
}

WSRC-TR-95-0403

Revision 0

Keywords: 10 w

level mixed wastes,

vitrification, resin

September 30,1995

\section{SUMMARY OF PIIOT-SCAIE ACTIVITIFS WITH RESORCINOT ION EXCHANGE RESIN}

\author{
Compiled by: Connie A. Cicero \\ Contributing Authors: Dennis F. Bickford, \\ Thomas N. Sargent, Mary K. Andrews, Jane P. Bibler, \\ Ned E. Bibler, and Carol M. Jantzen
}

\section{SUMMARY}

The Mixed Waste Focus Area (MWFA) of the Department of Energy (DOE) is currently investigating vitrification technology for treatment of low level mixed wastes (LLMW). They have chartered the Savannah River Technology Center (SRTC) to study vitrification of the wastes through an Office of Technology Development (OTD) Technical Task Plan (TTP). SRTC's efforts have included crucible-scale studies and pilot scale testing on simulated ILMW sludges, resins, soils, and other solid wastes. Results from the crucible-scale studies have been used as the basis for the pilot-scale demonstrations.

As part of the fiscal year (FY) 1995 activities, SRTC performed crucible-scale studies with organic resins. This waste stream was selected because of the large number of DOE sites, as well as commercial industries, that use resins for treatment of liquid wastes. Pilot-scale studies were to be completed in FY 1995, but could not be due to a reduction in funding. Instead, a compilation of pilot-scale tests with organic resins performed under the guidance of SRTC was provided in this report.

The studies which will be discussed used a resorcinol-formaldehyde resin loaded with non-radioactive cesium, which was fed with simulated wastewater treatment sludge feed. The first study was performed at the 
SRTC in the mini-melter, 1/100th scale of the Defense Waste Processing Facility (DWPF) melter, and also involved limited crucible-scale studies to determine the resin loading obtainable. The other study was performed at the DOE/Industrial Center for Vitrification Research (Center) and involved both crucible and pilot-scale testing in the stirMelter ${ }^{\circledR}$ stirred-melter.

Both studies were successful in vitrifying the resin in simulated radioactive sludge and glass additive feeds. The tests in the minimelter could only retain a maximum of 5 grams of resin/100 grams of glass produced, which was nearly identical to the tests at the center which were able to load 4.91 grams of resin/100 grams of glass produced. The slightly lower resin loading in the Center studies was not expected since it was believed that the stir-Melter could more easily incorporate the resin into the glass matrix because of increased air/glass contact and active use of an air sparger.

Future pilot-scale studies will likely be performed with organic resins because of the need to dispose of this growing waste stream. These studies are likely to focus on new technologies that are being developed for pre-treating the resin or on optimization of the glass formula used to entrain the resin, where both should result in higher waste loadings obtainable.

\section{BACKGROUND}

Spent ion exchange resin is a result of many different waste treatment processes. It is used by DOE and commercial facilities for removing unwanted contaminants in liquid or aqueous streams. These contaminants can be either radioactive or hazardous in nature. Thus, the spent resin then becomes either a High Level Waste (HLW), LLMW, Low Level Waste (LLW), or hazardous waste depending on what contaminants it has removed from the waste streams. In some cases, the resins themselves are considered hazardous because of the organic content.

Ion exchange resins are also used in the defense and commercial power reactors to remove anions and cations, particularly low levels of fission products such as $\mathrm{Cs}$ and $\mathrm{Sr}$. Commercial reactors typically use resins with sulfonated groups, and ashes or residues resulting from such resins are usually high in sulfur.

Resorcinol-formaldehyde resin has been proposed for treatment of radioactive wastewater treatment sludges at the Savannah River Site (SRS). This resin was specifically developed for treatment of the supernate from the HLW tanks by J.P. Bibler of SRTC ${ }^{1}$ and it has a Cs capacity that is four times greater than the best commercial resin. 2 The supernate portion of radioactive wastewater treatment sludges usually contains most of the $\mathrm{Cs}$ and thus the radioactivity, so it usually has to be treated to reduce the radioactivity before final treatment. At present, HLW tank supernate at SRS is treated using sodium tetraphenylborate during a precipitation process. This stream is then treated to decrease the organic content by incorporating the hydrolysis of the sodium tetraphenylborate with formic acid to yield 
benzene which is removed through steam distillation. 3 The resulting precipitate hydrolysis aqueous (PHA) product is then sent to the DWPF to be mixed with the sludge portion of the HLW tanks and glass frit. This process has several disadvantages including the presence of large amounts of sodium, potassium, and titanium that are fed to the melter, and, more importantly, regulatory and safety concerns of handling the benzene waste stream.

By using the resorcinol resin to remove the Cs for the SRS HLW process and in other processes, the need for additional benzene destruction equipment is eliminated and the feed can be directly fed into the treatment system without any additional treatment requirements. If vitrification is used, a lower amount of alkali metals is fed to the melter, which increases the reliability of the glass making process because of the affect alkalis have on durability. A final advantage, from a glass processing standpoint, would be the reduction in the amount of titanium fed to the melter which would reduce the potential for the glass to devitrify and for spinels to form in the melter. Another advantage of the resorcinol resin over other resins is that it does not contain sulfur, so when it is destroyed, sulfate salts are not produced as they might be with commercial resins.

The biggest disadvantages of using the resin treatment process at the SRS were not safety or glass quality related. They included the cost and schedule impact for establishing the treatment facilities, and the need for further details on engineering scale-up.

In order for the supernate resin treatment and vitrification destruction process to be considered plausible, demonstrations of the capability to remove the $\mathrm{Cs}$ and vitrify the resulting resin product had to be performed. J.P. Bibler was responsible for proving that the Cs was actually removed from the supernate stream and for providing nonradioactive $C s$ loaded resorcinol resin for crucible-scale vitrification studies. The typical composition of the dried resin after Cs removal from a simulated HLW supernate is given in Table 1.4

$\begin{array}{cc}\text { Table } 1 \text { - Non-Radioactive } & \text { Cs-Loaded Resin Composition } \\ \text { Element } & \text { Ht } 8 \\ \text { C } & 35.5 \\ \text { Na } & 7.0 \\ \text { Cs } & 0.95 \\ O & 45.5 \\ \mathrm{H} & 5.8 \\ \mathrm{~K} & 0.07\end{array}$

In the commercial nuclear power sector, ion-exchange resins generated as wastes require processing prior to disposal. Several volume-reduction methods have been used in the past, but none have offered complete stabilization or large reduction results when a large volume of resin waste is considered. Current practices for storage or disposal are expensive, so if it can be proven that vitrification could successfully incorporate the radioactive components into the glass matrix, destroy 
the organics, and produce an appreciable volume reduction, much benefit would be gained by the commercial nuclear power sector.

\section{RESIN STUDIES AT SRTC}

Once the viability of using the resorcinol resin for removing cs from the supernate was proven, the concept of vitrifying the resin had to be demonstrated. Samples of the non-radioactive Cs loaded resin were obtained for the studies. Samples of simulated radioactive wastewater treatment sludge and a frit glass additive were also obtained, since these two streams would be fed with the resin into the melter for vitrification.

\section{Crucible-scale}

Crucible-scale vitrification studies with the non-radioactive Cs loaded resin were performed by C.M. Jantzen of the SRTC. The main goal of these studies was to determine how the resin would affect the redox of the glass melt. Several trials were performed using varying amounts of resin and nitrate as an oxidizing agent. In these studies, the Cs was intimately mixed with a simulated radioactive sludge and glass frit. The crucibles of the feed were dried and then melted for 4 hours at $1150^{\circ} \mathrm{C}$. After air quenching the samples, the glasses were analyzed for $\mathrm{Fe}^{2+} / \mathrm{Ee}$ ratio.

The compositions of the simulated radioactive sludge and glass frits used in the studies are given in Table 2.4 The simulated radioactive sludge composition is shown on the basis of total solids after drying and is typical of sludges found at the SRS. When the sludge is in the melter feed form, it would also contain soluble formates, nitrates, and nitrites. The frit used in these experiments was Frit 165, which was developed for HLW sludge processing. These two streams were nominally mixed at 28 wt\% sludge oxides and 72 wto frit oxides.

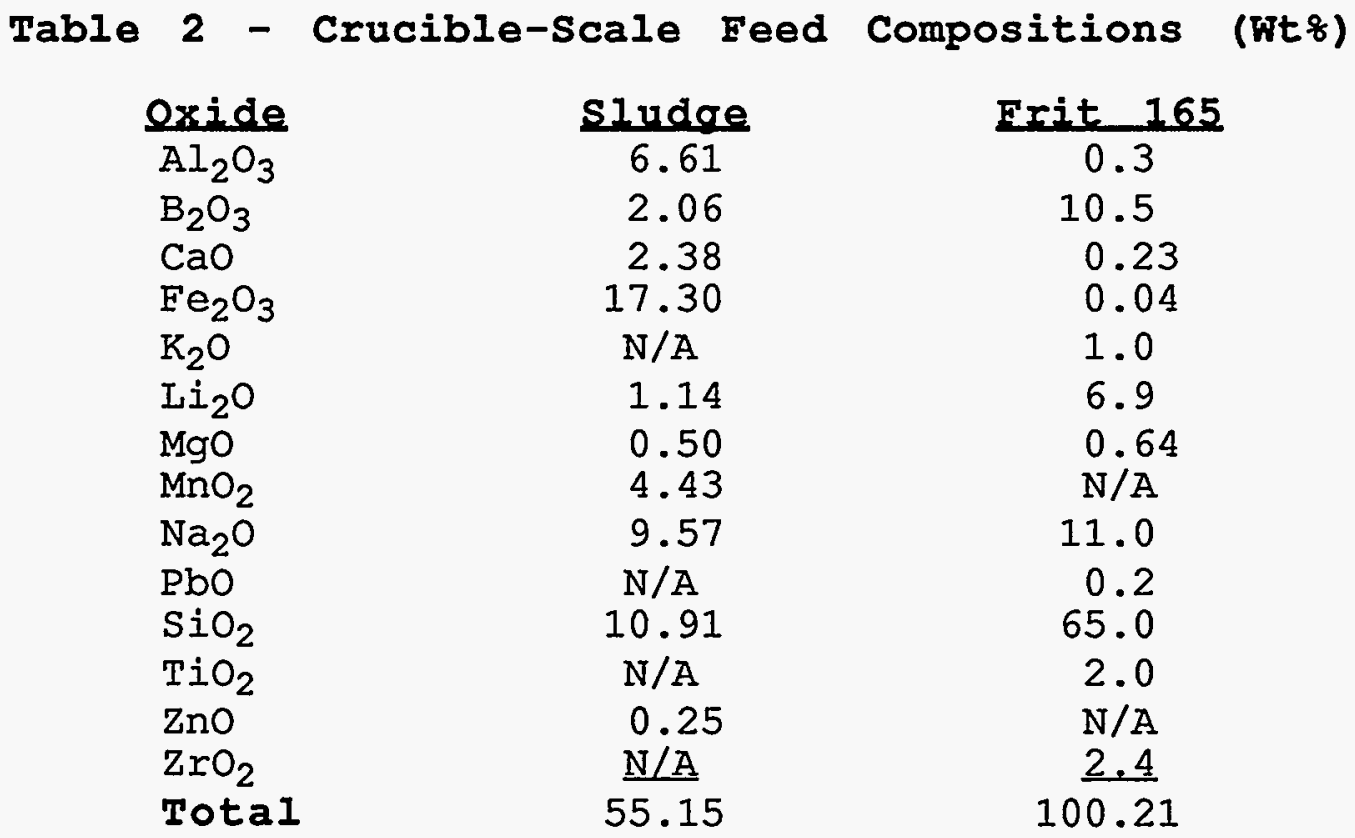


Results of the studies showed that as the resin loading increased, so did the $\mathrm{Fe}^{2+} / \Sigma \mathrm{Fe}$ ratio. Another item noted during the testing was that the presence of nitrates tended to decrease the $\mathrm{Fe}^{2+} / \Sigma \mathrm{Fe}$ ratio.

The maximum loading obtained in these studies was 5 grams of resin per 100 grams of glass produced. The limiting glass property constraint was the glass redox $\left(\mathrm{Fe}^{2+/} / \mathrm{Fe}\right.$ ratio), since ratios below 0.33 are suggested to limit reduction of nickel and other metals. If this upper limit were exceeded, a strong chance of shorting a joule-heated melter exists. 5 The maximum loading suggested still provided an acceptable glass redox.

\section{Pilot-Scale}

For the pilot-scale demonstrations at SRTC, runs were made in the $1 / 100$ th scale joule heated melter. This melter is a ceramic-lined melter that nominally holds $18 \mathrm{~kg}$ of glass in the melt chamber. It normally operates at $1150^{\circ} \mathrm{C}$. Glass is poured from the melter into one liter stainless steel beakers. A small offgas system is also attached to the melter which collects the condensate from the water fed to the melter, as well as entrained particulates.

Three different runs were made for the tests with resorcinol resin, with each run using a total of $120 \mathrm{~kg}$ of feed and producing $30 \mathrm{~kg}$ of glass. In all runs, simulated radioactive sludge and glass frit were used as the feed, at about 42 wt: solids. The composition of the feeds was the same as that given in Table 2 above. The first run was a baseline run and did not contain any resin, while the second and third runs contained resin intermixed in the feed. For the first two runs, the melter was fed for three 16-hour intervals and one 8-hour interval over three days and idled for 8 hours each of the first two days. In the final run, the melter was fed continuously for 53 hours (2.2 days). The intent of the runs was to determine what effect the resin had on the glass product (redox and durability) and on the melter and offgas performance.

In the first and second runs, glass samples were taken once steady-state conditions were obtained, which corresponded to the seventh can collected. For the third run, the glass samples were taken from the third can, which also corresponded to steady state conditions. Since the feed from the second run was still in the melter and was the same composition as the third feed, steady-state was obtained sooner. The composition of the glass samples from each run are given in Table 3.4 The composition for each run was fairly similar, as expected, since they were all the same feed composition. 


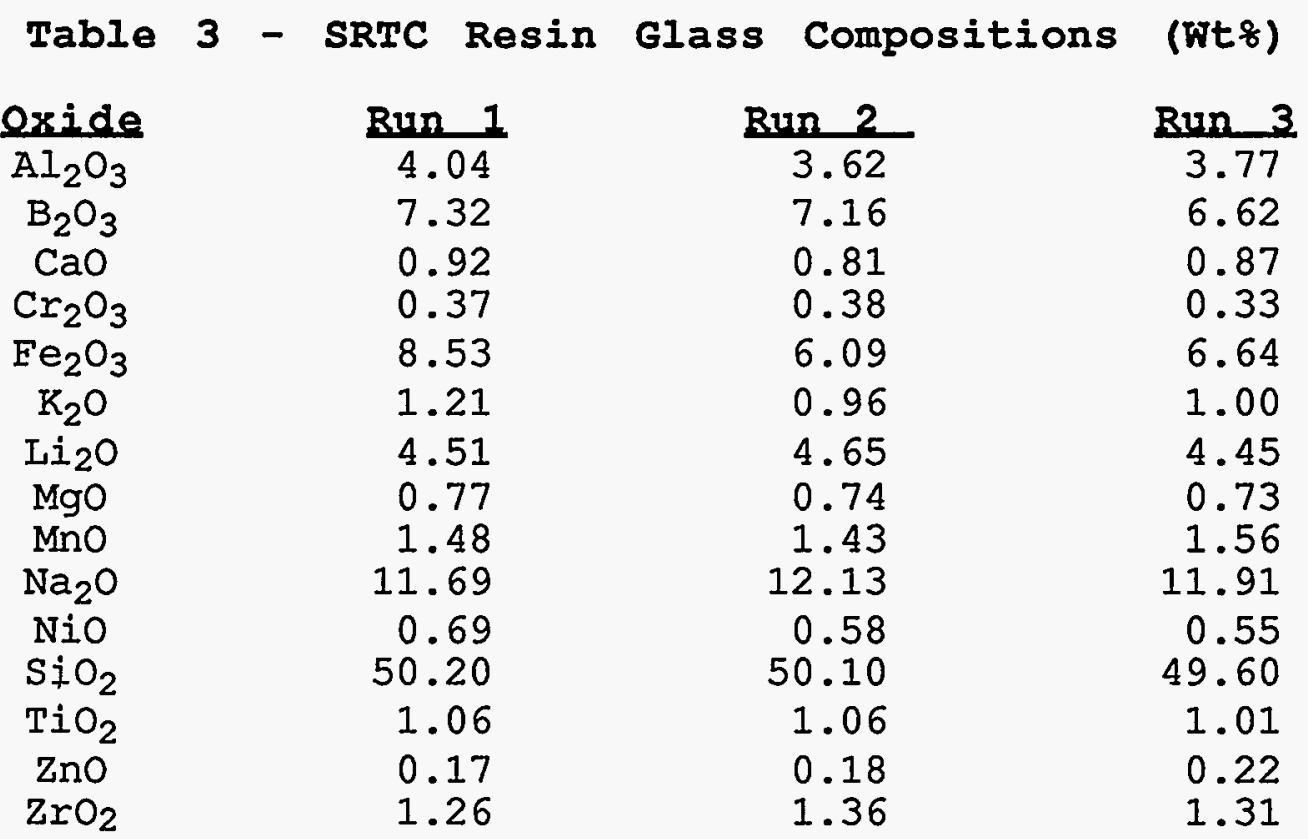

Since the glass redox is such an important criteria for processing organics in a melter, the $\mathrm{Fe}^{2+} / \sum \mathrm{Fe}$ ratio was measured on several glasses from each run using colorimetric analysis. The $\mathrm{Fe}^{2+} / \Sigma \mathrm{Fe}$ ratio results ${ }^{4}$ are given in Table 4, with the first number of the ID indicating the run number and the second number indicating the can number. The $\mathrm{Fe}^{2+} / \Sigma \mathrm{Fe}$ ratios varied from run to run and from can to can as expected because of the introduction of the resin into the glass melt. When resin was present, the ratio increased and the glass was more reduced. The intermittent resin run had the lower ratios, which can be attributed to the allowance of $\mathrm{O}_{2}$ to diffuse back into the melt during the 8-hour idling period. In some cases, the redox ratio was greater than the recommended $0.33,5$ but no evidence of shorting was observed in the melter.

$\begin{array}{cc}\text { Table } 4-\text { SRTC Resin } & \mathrm{Fe}^{2+} / \sum \mathrm{Fe} \\ \text { Glass ID } & \text { Ratio } \\ 1-01 & 0.02 \\ 1-03 & 0.09 \\ 1-07 & 0.12 \\ 1-10 & 0.13 \\ 1-12 & 0.12 \\ 2-01 & 0.07 \\ 2-03 & 0.28 \\ 2-07 & 0.34 \\ 2-10 & 0.35 \\ 2-12 & 0.33 \\ 3-01 & 0.14 \\ 3-03 & 0.34 \\ 3-06 & 0.42 \\ 3-09 & 0.40 \\ 3-12 & 0.44\end{array}$


The Product Consistency Test $(P C T)^{6}$ was performed on the glass samples to determine how the glass performance compared to the DWPE Environmental Assessment (EA) performance criteria ${ }^{7}$ for durability, since these are the only PCT criteria currently established. The PCT is a 7-day crushed glass leach test, which is performed at $90^{\circ} \mathrm{C}$ using deionized water. The resulting leach solution is analyzed for elemental concentrations to determine the durability of the glass. The $\mathrm{pH}$ of the test leachate is also measured since it provides a secondary indication of the glass durability. The data for the SRTC resorcinol resin glasses 4 is given in Table 5. The data shows that the $B$ release and measured $\mathrm{pH}$ increased or glass durability decreased as the $\mathrm{Fe}^{2+/ \Sigma \mathrm{Fe}}$ ratio increased or as more resin was incorporated in the glass matrix. Similar trends were shown for the $\mathrm{Na}$, Ii, and $\mathrm{Si}$ releases, but they were not reported. The reason for the poorer durability of the reduced glasses can be attributed to the role of $\mathrm{Fe}^{2+}$ as network modifier instead of a network former. $\mathrm{Fe}^{3+}$ is a network former. Even though the $\mathrm{B}$ releases and measured pHs were higher for the more reduced glass, they were still well below the EA glass performance criteria7.

$\begin{array}{ccc}\text { Table 5 - SRTC Resin Glass PCT Data (ppm) } \\ \text { Glass ID } & \text { B } & \text { DH } \\ 1-01 & 16.0 & 10.3 \\ 1-03 & 15.7 & 10.2 \\ 1-07 & 18.7 & 10.3 \\ 1-10 & 20.6 & 10.4 \\ 1-12 & 19.3 & 10.4 \\ 2-01 & 15.6 & 10.5 \\ 2-03 & 22.7 & 10.6 \\ 2-07 & 38.3 & 10.7 \\ 2-10 & 36.4 & 10.8 \\ 2-12 & 36.2 & 10.8 \\ 3-01 & 16.1 & 10.3 \\ 3-03 & 22.0 & 10.7 \\ 3-06 & 30.5 & 10.7 \\ 3-09 & 38.6 & 10.9 \\ 3-12 & 42.6 & 10.9\end{array}$

No changes in the melter operating conditions were experienced for the melter when the resin was processed. No effect on the amount of current needed to heat the melter was seen, which suggests that the resin did not produce any conductive species in the melt capable of shorting out the melter. Also, pluggages in the melter feed tube and the offgas system were not observed. Finally, the viscosity of the glass melt did not seem to be affected by the resin addition. ${ }^{4}$

The results from the pilot-scale studies at SRTC indicated that vitrification of resorcinol resin was possible when fed to the melter with simulated radioactive sludge and glass frit feed. The maximum loading obtained in the melter was 5 grams of resin/100 grams of glass produced. Higher waste loadings could have been possible, but were not tested due to the redox limits for the melter. Complete details of the SRTC studies can be found in Attachment I. 


\section{RESIN STUDIES AT THE CENTER}

As part of a graduate student's (T.N. Sargent) thesis project, vitrification of resorcinol resin was investigated at the Center. The thesis involved four different parts, each of which was needed for the final pilot-scale demonstration. The four parts of this project included: crucible studies to determine the reducing potential of the resin and the extent of oxygen consuming reactions; establishment of nominal melter operation parameter values; oxygen transfer tests to approximate the extent of oxygen transfer into the molten glass using an impeller and a combination of the impeller and an external oxygen transfer system; and a pilot-scale test using the stirred melter. ${ }^{8}$ The crucible-scale, oxygen transfer tests, and pilot-scale studies will be summarized in this paper. Complete details of this study can be found in the graduate students thesis, given as Attachment II.

The crucible-scale experiments investigated the effects of organic compound additions on oxidation/reduction shifts and cesium retention for the glass wasteform. By performing the oxygen transfer tests, optimum conditions for operating the melter with resin were determined. The pilot-scale tests, on the other hand, were used to approximate a cesium mass balance around the melter including the feed, exit glass, and offgas streams. A major goal of the pilot-scale efforts was to try to eliminate the crust that forms on top of the melt when resin is fed with the glass feed and to try for more oxidizing conditions in the melter. Both of these would theoretically help lower the cesium volatility.

\section{Crucible studies}

For the crucible studies, reagent grade chemicals were used with a composition similar to the feed used in the SRTC studies. The studies involved filling high purity alumina crucibles with identical amounts of glass forming chemicals. These chemicals were frit, anhydrous borax, ferric oxide, and sodium carbonate. Parameters that were varied. included the amount of organic material, the presence of water, and the inclusion of a sealed lid on the crucible. All of the samples were placed in a pre-heated furnace at $600^{\circ} \mathrm{C}$, and then the furnace

temperature was increased to $1100^{\circ} \mathrm{C}$. The samples were melted at $1100^{\circ} \mathrm{C}$ for three hours and them removed and air quenched. The sealed samples remained sealed during quenching.

The glasses fabricated for the crucible studies were analyzed for $\mathrm{Fe}^{2+/ \Sigma \mathrm{Fe}}$ ratio to determine the redox state and for $\mathrm{Cs}$ content to determine the retention ability. Measured values varied from $0.022-$ 0.833 for the $\mathrm{Fe}^{2+} / \Sigma \mathrm{Fe}$ ratio. The redox values were used to correlate the redox results with the parameters which could affect the final redox state of the glass. The following equations were developed: based on the entire set of crucibles

$$
\begin{gathered}
\mathrm{Fe}^{2+/ \Sigma \mathrm{Fe}}=(1.28 * \mathrm{C})+(0.343 * \mathrm{R})+(0.0292 * \mathrm{~W})+(0.159 * \mathrm{~L}) \\
\text { and for the sealed crucibles only } \mathrm{R}^{2}=0.92, \\
\mathrm{Fe}^{2+/ \Sigma \mathrm{Fe}}=(2.10 * \mathrm{C})+(0.530 * \mathrm{R})+(0.0255 * \mathrm{~W}) \quad \mathrm{R}^{2}=0.96,
\end{gathered}
$$


where $\mathrm{C}$ is the grams of carbon, $\mathrm{R}$ is the grams of resin, $\mathrm{W}$ is the $\mathrm{mL}$ of water, and $I$ is the type of environment ( 1 for a lid, 0 for no $1 i d$ ) .8 It was found that the presence of water hindered the re-oxidation of the glass rather than assisting as an oxygen donor.

The results of the crucible studies indicated that, based solely on the redox ratio limit of $0.337,1.26$ grams of resin could be added to 100 grams of glass in a sealed environment. However, if the crucible was not sealed, 4.91 grams of resin could be added per 100 grams of glass.8 These limits were slightly less than those observed in the SRTC crucible studies ${ }^{4}$.

For all of the glasses fabricated, including those made with carbon, the amount of $\mathrm{Cs}_{2} \mathrm{O}$ measured in the glasses varied from 0.11 - 0.46 wt\% versus a predicted $\mathrm{Cs}_{2} \mathrm{O}$ content of $0.16-0.52$ wt $\%$ This corresponded to a Cs retention range of 59.38 - 97.57\%. The average cesium retention in the crucible melts with resin, as opposed to carbon, was 88.6\% with a standard deviation of $6.6 \% .8$ The results indicated that the final redox ratio and mass of reducing agent did not seem to influence the Cs retention.

\section{Oxygen Transfer Tests}

The oxygen transfer tests were performed to determine the extent of oxygen transfer into the molten glass using an impeller and a combination of the impeller and an external oxygen transfer system. 8 Two of the oxygen transfer tests were batch type experiments using no feed slurry. In these tests, a known amount of glass was placed in the melter, and the impeller agitated the molten glass for several hours to assure equilibrium with the atmosphere. Once at equilibrium, a measured quantity of elemental carbon was added to the melt to increase the $\mathrm{Fe}^{2+} / \sum \mathrm{Fe}$ ratio. After complete reaction of the carbon, glass samples were taken from the melt surface and operational conditions were initiated. Samples were taken periodically for the next several hours. The only difference in the batch tests was that one did not have any water fed to the melter, while the other was fed at a rate of 35-40 $\mathrm{mL} / \mathrm{min} .8$

The second type of oxygen transfer test used continuous slurry flow at a rate of $50 \mathrm{~mL} / \mathrm{min}$ and an exit glass stream was established. Oxygen was also fed to the melter during this test at a rate of $1000 \mathrm{~mL} / \mathrm{min}$. Once successful operation was achieved, non Cs loaded resin was batch fed to the melter in 30 to 100 gram portions to increase the Fe $\mathrm{F}^{2+} / \mathrm{Fe}$ ratio. A total of 300 grams of resin were fed. 8 During this run, the redox state was monitored by periodically sampling the molten glass for colorimetric redox analyses and by using the on-line redox probe. The molten glass samples were taken both from the melt surface and the exit stream. The redox probe was made of a hollow ceramic probe with a zirconium oxide pellet at the tip. This probe contained platinum and rhodium wires which allowed the redox and temperature to be measured. This allowed for a rough correlation between redox probe readings and actual measured redox ratios. 
Equations for determining the amount of recovery time it takes for the melte'r to return to normal operating conditions were derived for both types of oxygen transfer tests. In the first batch mode tests, the approximate oxygen transfer rate was 0.00230 moles $\mathrm{O}_{2}$ per minute with the impeller running. This correlated to an accommodation resin flow rate of 0.1104 grams resin/min. For the second batch mode test where water was added to the feed, the oxygen transfer rate was 0.00153 moles $\mathrm{O}_{2} / \mathrm{min}$ with an equivalent flow rate of resin as 0.0734 grams resin $/ \mathrm{min} .8$ Since the only difference between the two batch tests was the presence of water, it appeared that the presence of water seemed to hinder the re-oxidation of the melt. In the slurry feeding tests, a total of 300 grams of resin was added to the melt. The amount of time it took for the melt to re-oxidize was recorded and during the last 55 minutes the $\mathrm{Fe}^{2+} / \Sigma \mathrm{Fe}$ ratio increased linearly. The approximate oxygen transfer rate was 0.00956 moles $\mathrm{O}_{2} / \mathrm{min}$, which would accommodate a resin feed rate of 0.459 grams of resin $/ \mathrm{min} .8$

\section{Pilot-Scale}

The feed used for the pilot-scale testing at the Center was different than what was used at SRTC or in the crucible studies at the Center. It contained a simulated radioactive sludge portion, frit 202 (borosilicate glass additive), and simulated radioactive supernate material at approximately 35 - 40 wt\% solids. The approximate composition of the three feed portions is given in Table 6.9 The resin used in the testing was loaded with elemental Cs at a mass ratio of $0.16 \mathrm{~g}$ of $\mathrm{Cs} / \mathrm{gram}$ of clean dry resin. The resin was approximately $38.4 \%$ solids.

\section{Table 6 - Center Pilot-Scale Feed Component Compositions (Wt?)}

\begin{tabular}{|c|c|c|c|}
\hline Oxide & sludoe & Supernate & Erit 202 \\
\hline $\mathrm{Al}_{2} \mathrm{O}_{3}$ & 16.86 & 1.20 & $\mathrm{~N} / \mathrm{A}$ \\
\hline $\mathrm{B}_{2} \mathrm{O}_{3}$ & $\mathrm{~N} / \mathrm{A}$ & 29.30 & 8.00 \\
\hline $\begin{array}{l}\mathrm{BaO} \\
\mathrm{CaO} \\
\mathrm{Cr}_{2} \mathrm{O}_{3}\end{array}$ & $\begin{array}{l}0.24 \\
4.39 \\
0.36\end{array}$ & $\begin{array}{l}0.81 \\
0.08 \\
0.02\end{array}$ & $\begin{array}{l}N / A \\
N / A \\
N / A\end{array}$ \\
\hline $\mathrm{Cs}_{2} \mathrm{O}$ & 0.01 & 1.00 & $\mathrm{~N} / \mathrm{A}$ \\
\hline $\mathrm{CuO}$ & 0.18 & 3.80 & $\mathrm{~N} / \mathrm{A}$ \\
\hline $\mathrm{Fe}_{2} \mathrm{O}_{3}$ & 44.12 & 0.81 & $\mathrm{~N} / \mathrm{A}$ \\
\hline $\mathrm{K}_{2} \mathrm{O}$ & 0.39 & 36.92 & $N^{\prime} / A$ \\
\hline $\mathrm{Li}_{2} \mathrm{O}$ & $\mathrm{N} / \mathrm{A}$ & $\mathrm{N} / \mathrm{A}$ & 7.00 \\
\hline $\mathrm{MgO}$ & 0.35 & 0.01 & 2.00 \\
\hline $\mathrm{MnO}_{2}$ & 8.91 & 0.16 & $\mathrm{~N} / \mathrm{A}$ \\
\hline $\mathrm{Na}_{2} \mathrm{O}$ & 12.77 & 18.46 & 6.00 \\
\hline $\mathrm{NiO}$ & 2.65 & 0.05 & $\mathrm{~N} / \mathrm{A}$ \\
\hline $\mathrm{PbO}$ & 0.41 & 0.01 & $\mathrm{~N} / \mathrm{A}$ \\
\hline $\mathrm{SiO}_{2}$ & 4.18 & 0.07 & 77.00 \\
\hline $\mathrm{TiO}_{2}$ & $\mathrm{~N} / \mathrm{A}$ & 7.22 & $\mathrm{~N} / \mathrm{A}$ \\
\hline $\mathrm{ZrO}_{2}$ & 1.41 & 0.02 & $\mathrm{~N} / \mathrm{A}$ \\
\hline
\end{tabular}


As mentioned earlier, the stirred melter was used for the pilot-scale testing because of the unique advantages it offers to vitrification. By using the stirred melter, crust formation on the melt surface could be reduced because the entire melt is agitated by the impeller and the surface is continuously drawn into the melt. The stirring action also helps ameliorate the negative effects of a reduced melt by constantly refreshing the surface layer, which increases oxygen exchange between the melt and the melter head space vapors. Guidance from the results of the crucible-scale studies, as well as the parameter optimization studies were used to perform the pilot-scale studies at the Center.

For the pilot-scale tests, the ion exchange resin and the combined three stream feed were mixed in a bucket and fed directly to the melter for 20 hours at a rate of $51 \mathrm{~mL} / \mathrm{min}$ using a peristaltic pump. The resin and slurry were mixed at a ratio of 295 grams of the wet loaded resin to 11.312 L of slurry.8 Two samples of this feed were taken for chemical composition analyses. The feed was not started until the melter reached the set-point temperatures, which were $1070^{\circ} \mathrm{C}$ for the melter and $1045^{\circ} \mathrm{C}$ for the auxiliary temperature controllers. A gas sparging system was inserted into the molten bath for the duration of the tests. The oxygen gas was expelled directly under the impeller at a rate of $1200 \mathrm{~mL} / \mathrm{min}$ at STP. 8 The redox probe described above was also used during the test to continuously monitor the glass redox, with readings recorded every few minutes. Glass samples were taken from the exit stream approximately every thirty minutes and at the end of the run.

The analytical results for the chemical composition of the feed to the melter 8 are contained in Table 7 . The loss on ignition for the samples was $63.00 \%$ for the initial feed and $66.50 \%$ for the final feed. 8 Results indicated that the composition of the feed to the melter changed over the length of the run. Neither of the results reflects the predicted $\mathrm{Cs}_{2} \mathrm{O}$ content of 0.396 wt\%. This error was partially attributed to analytical error in dissolving and analyzing the samples and also to incomplete mixing in the bucket.

\begin{tabular}{lcc}
\multicolumn{1}{c}{ Table 7 - Resin Feed Analyses } & (Wt8) \\
Oxide & Initial & Final \\
$\mathrm{Al}_{2} \mathrm{O}_{3}$ & 2.95 & 3.35 \\
$\mathrm{~B}_{2} \mathrm{O}_{3}$ & 7.77 & 7.60 \\
$\mathrm{CaO}$ & 1.02 & 1.26 \\
$\mathrm{Cr}_{2} \mathrm{O}_{3}$ & 0.13 & 0.16 \\
$\mathrm{Cs}_{2} \mathrm{O}$ & 0.26 & 0.55 \\
$\mathrm{Fe}_{2} \mathrm{O}_{3}$ & 12.05 & 14.20 \\
$\mathrm{~K}_{2} \mathrm{O}$ & 2.39 & 2.90 \\
$\mathrm{Ii}_{2} \mathrm{O}$ & 4.85 & 4.50 \\
$\mathrm{MgO}$ & 1.55 & 1.48 \\
$\mathrm{MnO}_{2}$ & 2.63 & 3.12 \\
$\mathrm{Na}_{2} \mathrm{O}$ & 6.46 & 6.54 \\
$\mathrm{NiO}_{\mathrm{SiO}}$ & 1.11 & 1.30 \\
$\mathrm{Total}$ & $\underline{54.35}$ & $\underline{50.75}$ \\
& 97.51 & 97.68
\end{tabular}


Redox measurements taken with the redox probe did not correlate well with the analytical results. These results were not used. However, none of the samples analyzed exceeded 0.33 for the $\mathrm{Fe}^{2+} / \Sigma \mathrm{Fe}$ ratio and the average after approximately one hour was 0.176 .8

Four of the glass samples taken during melter operation were analyzed to assist in determining the Cs retention for the glass. The results are shown in Table 8 and are identified by their time of sampling into the run.8 The glass analyses results were fairly consistent over the length of the run. The $\mathrm{Cs}_{2} \mathrm{O}$ concentration changed the most, and it increased as more feed was fed to the melter. This behavior was predicted since the glass used to start the melter did not contain any resin.

\section{Table 8 - Center Resin Glass Compositions (wt $f$ )}

\begin{tabular}{|c|c|c|c|c|}
\hline Oxide & 0 min. & $627 \mathrm{~min}$ & $920 \mathrm{~min}$. & $1385 \mathrm{~min}$ \\
\hline $\mathrm{Al}_{2} \mathrm{O}_{3}$ & 3.09 & 3.05 & 3.04 & 3.07 \\
\hline $\mathrm{B}_{2} \mathrm{O}_{3}$ & 7.90 & 7.75 & 7.76 & 7.80 \\
\hline $\begin{array}{l}\mathrm{CaO} \\
\mathrm{Cr}_{2} \mathrm{O}_{3}\end{array}$ & $\begin{array}{l}1.70 \\
0.19\end{array}$ & $\begin{array}{l}1.24 \\
0.17\end{array}$ & $\begin{array}{l}1.23 \\
0.17\end{array}$ & $\begin{array}{l}1.24 \\
0.17\end{array}$ \\
\hline $\mathrm{Cs}_{2} \mathrm{O}$ & 0.00 & 0.24 & 0.30 & 0.35 \\
\hline $\mathrm{Fe}_{2} \mathrm{O}_{3}$ & 12.00 & 12.25 & 12.50 & 12.57 \\
\hline $\mathrm{K}_{2} \mathrm{O}$ & 2.43 & 2.70 & 2.76 & 2.76 \\
\hline $\mathrm{Li}_{2} \mathrm{O}$ & 4.75 & 4.79 & 4.82 & 4.80 \\
\hline $\begin{array}{l}\mathrm{MgO} \\
\mathrm{MnO}_{2}\end{array}$ & $\begin{array}{l}1.56 \\
2.64\end{array}$ & $\begin{array}{l}1.53 \\
2.74\end{array}$ & $\begin{array}{l}1.56 \\
2.80\end{array}$ & $\begin{array}{l}1.56 \\
2.80\end{array}$ \\
\hline $\mathrm{Na}_{2} \mathrm{O}$ & 6.69 & 6.69 & 6.73 & 6.76 \\
\hline $\begin{array}{l}\mathrm{NiO} \\
\mathrm{SiO}_{2}\end{array}$ & $\begin{array}{r}1.15 \\
54.10 \\
\end{array}$ & $\begin{array}{r}1.18 \\
52.70 \\
\end{array}$ & $\begin{array}{r}1.20 \\
53.55 \\
\end{array}$ & $\begin{array}{r}1.21 \\
53.67 \\
\end{array}$ \\
\hline Total & 98.19 & 97.01 & 98.38 & 98.73 \\
\hline
\end{tabular}

A complete offgas system is connected to the stirred melter. As gasses rose through the riser pipe, they were passed through a combination venturi scrubber/spray quencher, bubbled into a bubbler tank, and then traveled through a counter-current scrubber packed with 0.5 inch Raschig rings.8 The scrubber solution was continuously pumped from a reservoir through the column and back into the reservoir. During the melter demonstration, samples from the scrubber and the bubbler were taken approximately every hour. After steady state conditions were reached in the melter (three melter volume turn-overs), the EPA Modified Method 5 Sampling Train and the EPA Multiple Metals Sampling Train were used to take samples of the offgas. Final samples of the scrubber and bubbler solution were also taken for analyses.

Using the results from the feed stream, glass, and offgas analyses, a mass balance for $\mathrm{Cs}$ was performed around the whole system. Due to the inconsistencies in the feed analyses, a range of values for the amount of Cs actually fed to the melter had to be used. The total Cs fed to the melter was 88.18 grams, with a total glass retention of 82.17 grams $(82.3-93.2 \%)$. The total amount of Cs exiting in the offgas deposits was 0.14 grams, which was about $0.14-0.16 \%$ of the total Cs fed to the 
melter. The total amount of $\mathrm{Cs}$ captured in the bubbler solution was 2.07 grams or 2.1 - $2.4 \%$ of the total Cs fed to the melter. The total Cs captured in the scrubber solution was 0.215 grams or $0.22-0.24 \%$ of the total Cs fed to the melter. 8 A summary of the mass balance numbers can be found in Table 9 .

Table 9 - Cesium Mass Balance

$\begin{array}{ccc}\text { Iocation } & \text { Grams of Cs } & \text { of of Total Cs } \\ \text { Feed Stream } & 88.18-99.83 & \text { N/A } \\ \text { Exit Glass } & 82.17 & 82.3-93.2 \\ \text { Offgas Deposits } & 0.14 & 0.14-0.16 \\ \text { Bubbler Solution (Volatile) } & 2.07 & 2.1-2.4 \\ \text { Scrubber Solution } & 0.22 & 0.22-0.24 \\ \text { Unaccounted Cs } & 15.23-3.58 & 4.00-15.24\end{array}$

Multiple metals sampling train analysis revealed that less than half of the Cs present in the offgas exists in the volatile form. Several other metals partitioned significantly in the volatile form including $15.2 \%$ lead, $25.4 \% \mathrm{Cr}, 14.5 \% \mathrm{Na}, 10.7 \% \mathrm{Ca}, 15.0 \% \mathrm{Ii}$, and $18.5 \% \mathrm{~K}$. The semivolatile organic compounds found in the offgas included benzoic acid, naphthalene, phenanthrene, fluorene, fluoranthrene, and pyrene. 8 This is feasible since the resin is polymer based on resorcinol which is aromatic and all of these were aromatic based.

At a feed rate of 0.50 grams of dry resin per minute, it appeared that there would be no significant problems associated with an over reduced melt.

\section{CONCLUSIONS}

A brief summary of the findings of the SRTC studies summarized in this paper follows:

- For the crucible studies performed at the SRTC, a maximum resin loading of 5 grams of resin/100 grams of glass produced was found.

- In the pilot-scale studies performed at SRTC, resin loadings obtained in the crucible studies were obtained without any significant impact on glass quality or melter operating conditions.

A brief summary of the findings and recommendations of the Center studies summarized above follows:

- For the crucible studies, the average Cs retention was 88.6\% with a standard deviation of $6.6 \%$. No apparent correlation existed between the redox state of the glass and the Cs retention.

- Based on a limited amount of data, the addition of water seemed to result in a more reduced final glass sample. 
- It was determined that slurry feed rate and melter temperature were the two most important operational parameters in achieving successful melter operations. optimum parameters were defined for the stirred melter.

- The oxygen transfer rates under batch type conditions using impeller agitation was 0.0023 moles $\mathrm{O}_{2} / \mathrm{min}$, with water it dropped to 0.00153 moles $\mathrm{O}_{2} / \mathrm{min}$. Under slurry feeding conditions with oxygen sparging, a feed rate of 0.00956 moles $\mathrm{O}_{2} / \mathrm{min}$ was obtained, which is the equivalent of 0.45 grams of dry resin/min.

- Between 82.3 and $93.2 \%$ of the Cs fed to the melter during the pilot-scale testing was retained in the glass.

- The particulate loading during the pilot scale experiment was approximately $433 \mathrm{mg}$ per cubic meter of offgas at an average temperature of $664^{\circ} \mathrm{C}$. The primary elements found were $\mathrm{C}$, $\mathrm{B}$, $\mathrm{Fe}, \mathrm{Na}, \mathrm{Mn}, \mathrm{K}, \mathrm{Ca}$, and $\mathrm{Al}$.

- Dilution air pulled thought the offgas treatment system should be minimized in order to allow for accurate calculations of offgas components.

- The rate of oxygen transfer into the glass melt should be maximized so that the corresponding feed rate of resin can also be maximized.

- Offgas sampling should be done at other locations along the offgas treatment system such as downstream from the scrubber and between the bubbler solution tank and the scrubber in order to calculate other values such as scrubber efficiencies.

\section{ACKNOWLEDGEMENTS}

Funding for the summation part of this research and development work was provided by the Department of Energy - Office of Technology Development under the auspices of the Mixed Waste Focus Area and Technical Task Plan SR1-3-20-04. This Technical Task Plan also provided the funding for the studies at the Center. Funding for the studies at the SRTC was provided by the Department of Energy under contract DE-AC09-89SR18035.

\section{REFERENCES}

1. J.P. Bibler and R.M. Wallace, "Testing a New Cesium-Specific Ion Exchange Resin for Decontamination of Alkaline High-Activity Waste", Proceedings of Waste Management '90, edited by R.G. Post, Tucson, AZ (1990), pp. 747-751.

2. R.M. Wallace and J.P. Bibler, "An Improved Method for Decontaminating Soluble High-Ievel waste Using Ion Exchange", DPST-88-789, E.I. du Pont Nemour \& Co., Aiken, SC (1988). 
3. W.D. Pearson, "Savannah River Site High Level Waste Program and the Defense Waste Processing Facility", Proceedings of the Fifth International symposium on Ceramies in Nuclear and Hazardous waste Management, Cincinnati, OH (1991), pp. 3-10.

4. N.E. Bibler, J.P. Bibler, M.K. Andrews, and C.M. Jantzen, "Initial Demonstration of the Vitrification of Nuclear Waste sludge Containing an Organic Cs-Loaded Ion Exchange Resin", WSRC-MS-91465, Westinghouse Savannah River Company, Aiken, SC (1991).

5. W.G. Ramsey, C.M. Jantzen, and D.F. Bickford, "Redox Analyses of SRS Melter Feed Slurry; Interactions Between Nitrate, Formate, and Phenol Based Dopants", Proceedings of the Fifth International Symposium on Ceramics in Nuclear and Hazardous Waste Management, Cincinnati, OH (1991) pp. 259-266.

6. N.E. Bibler and C.M. Jantzen, "The Product Consistency Test and Its Role in the Waste Acceptance Process", Proceedings of Waste Management 189, edited by R.G. Post, Tucson, AZ (1989) pp. 743-749.

7. C.M. Jantzen, N.E. Bibler, D.C. Beam, C.I. Crawford, and M.A. Pickett, "Characterization of the Defense waste Processing Facility (DWPF) Environmental Assessment (EA) Glass Standard Reference Material", WSRC-TR-92-346, Westinghouse Savannah River Company, Aiken, SC (June 1, 1993).

8. T.N. Sargent, Jr., "Vitrification of Cesium-Contaminated Organic Ion Exchange Resin", Graduate thesis presented to Clemson University - Environmental Systems Engineering (August 5, 1994).

9. R.E. Schumacher, "DWPF Batch 1, Waste Glass Investigations", Proceedings of the Fifth International symposium on Ceramics in Nuclear and Hazardous Waste Management, Cincinnati, OH (1991) pp. 453-463. 
ATTACHMENT I - SRTC RESORCINOL RESIN PAPER 


\section{INITIAL DEMONSTRATION OF THE VITRIFICATION OF HIGH-LEVEL NUCLEAR WASTE SLUDGE CONTAINING AN ORGANIC CS-LOADED ION EXCHANGE RESIN}

N. E. BIBLER, J. P. BIBLER, M. K. ANDREWS, and C. M. JANTZEN Westinghouse Savannah River Co., Aiken, SC, 29802

\section{ABSTRACT}

When immobilizing into borosilicate glass the radionuclides in the caustic high-level radioactive wastes stored in the USA, the soluble fission product $\mathrm{Cs}-137$ has to be removed from supernates of the wastes. In the current processes zeolites or an organic precipitant will be used to remove the Cs. These are then treated further and mixed with the radioactive sludges and vitrified into a borosilicate glass. This paper describes the vitrification of a mixture resulting from using a new process to remove Cs from the caustic supernate. A resorcinol based organic ion exchange resin is used. This resin was then mixed with sludge and frit and vitrified. Using an organic ion exchange resin rather than zeolite or the organic precipitant has certain advantages. For example, use of the zeolite increases the amount of glass to be made and use of the organic precipitant produces benzene as a secondary waste stream. Results in the paper indicate that a mixture of the resin, sludge and frit can be successfully vitrified in a joule-heated, slurry fed melter. However, when resin is present in the feed, the glass becomes less durable due to the increased amount of $\mathrm{Fe}$ (II) caused by reduction of $\mathrm{Fe}$ (III) in the melt. Based on the durabilities of other waste glasses, this glass is still suitable as a canistered wasteform.

\section{INTRODUCTION}

At the Hanford, West Valley, and the Savannah River Site (SRS), high-level radioactive nuclear wastes will be immobilized into borosilicate glass for permanent disposal in a geologic repository. At all three sites, the wastes are stored as caustic slurries in million gallon underground tanks. Since the slurries are caustic, most of the fission products and the transuranic waste radionuclides are precipitated in a sludge as hydrous oxides; however, since $\mathrm{Cs}$ is soluble in caustic slurries, most of the radioactive Cs-137 is in the supernate along with high concentrations of $\mathrm{Na}^{+}$ions $(-4 \mathrm{M})$ added as $\mathrm{NaOH}$. Consequently, $\mathrm{Cs}-137$ has to be removed from the supernate and consolidated with the sludge in order to immobilize all the radioactivity into the glass. At Hanford and West Valley, an inorganic zeolite mineral is used in the reference process to remove Cs. This zeolite will be mixed with sludge and an appropriate frit and then fed into a melter at $1150^{\circ} \mathrm{C}$. The supernates at Savannah River Site (SRS) are too caustic to allow the use of zeolite. Cesium will be precipitated as cesium tetraphenylborate (CsTPB). Potassium is also precipitated from the supernate as KTPB. The tetraphenylborate precipitates will then be decomposed by hydrolysis. This produces benzene which is removed in order to reduce the amount of carbon going into the melter. The product of this hydrolysis will be mixed with the sludge and frit and then fed to a melter.

Recently, an organic ion exchange resin has been developed that can successfully compete with high concentrations of $\mathrm{Na}^{+}$ions in the caustic supernates and remove the $\mathrm{Cs}^{1}{ }^{1}$ This resin has been tested on both actual and simulated radioactive supernates. ${ }^{1}$ As a second generation process at SRS, we are investigating the possibility of using this resin to remove $C s$ and then mixing the Cs-loaded resin with sludge and frit and feeding the mixture directly into a melter to make glass. The resin will be incinerated in the melter and the residual $\mathrm{Cs}$ immobilized in the borosilicate glass. This process has advantages over both the zeolite and the CSTPB precipitation processes. Becâuse the resin is burned and zeolites are not, this process would produce less glass than the zeolite process. There are two apparent advantages over the CsTPB process. First, the resin process does not produce a secondary waste stream as does the CsTPB process. In the CsTPB process, benzene is produced by the hydrolysis process and 
has to be stored or destroyed. Second, with the resin process, the need for the complicated hydrolysis process is eliminated altogether. However, as with any new process, integration of the ion exchange streams with other streams in the process and the burning of the spent resin in the melter has to be demonstrated on a pilot scale before the actual performance of the overall process can be accurately assessed.

This paper describes three kilogram scale melter runs designed to test whether a durable glass could be made by feeding a slurry of sludge, frit, and the organic resin to a joule-heated melter. Because the organics in the feed might reduce redox elements such as $\mathrm{Fe}$, the redox of the final glass was measured by determining the $\mathrm{Fe}(\mathrm{IM})$ content of the glass. The durability of the glass was measured by the Product Consistency Test (PCT). Another goal was to determine if the presence of resin significantly altered the performance of the melter and offgas system. Each melter run used nominally $120 \mathrm{~kg}$ of slurry, lasted three days and produced nominally $30 \mathrm{~kg}$ of glass. Prior to using the large melter, small scale crucible tests were performed to determine how the resin will affect the redox of the melt.

\section{EXPERIMENTAL}

The melter was a ceramic-lined, joule-heated melter that held nominally $18 \mathrm{~kg}$ of glass in its melt chamber. Feed for the melter was a slurry (nominally 58 weight percent water) containing the sludge, frit and resin. The melt was at $1150^{\circ} \mathrm{C}$. During the feeding process as the slurry fell on the top surface of the melt, water was flashed off, any organic present was incinerated, sludge was dissolved in the melt, and the frit was melted. Molten glass was poured from the bottom of the melt into one liter stainless steel beakers. The off-gas system collected the condensate from the water fed to the melter, as well as particulates entrained in the off-gas.

Three melter runs were performed. Each run contained the same simulated sludge and frit. Resin was added to the feed for the second and third run. For the first two runs the melter was fed for three 16-hour intervals and one 8-hour interval over three days. The melter idled for 8 hours each of the first two days. The first run contained only frit and sludge and was performed to determine the quality of the glass when resin was not in the feed. The second run was identical to the first except that resin had been added to the feed. In the third run, the melter was fed continuously for 53 hours or 2.2 days. Each run produced 12 cans of glass with each can holding approximately $2 \mathrm{~kg}$.

The durability of the glass was determined by subjecting samples of the glass from various cans to the PCT. ${ }^{2}$ This is a crushed glass leach test at $90^{\circ} \mathrm{C}$ using deionized water. The crushed glass (100-200 mesh) is leached for 7 days and the amount of soluble elements (B, $\mathrm{Na}, \mathrm{Li}$, and $\mathrm{Si}$ ) released to the solution measured to determine the durability of the glass. The final $\mathrm{pH}$ of the leachate was also measured and is an indication of the durability of the glass. Crushed glass was obtained by grinding pieces of glass that were taken from the liter stainless steel cans using a hammer and chisel. The grinder contained a tungsten carbide blade to prevent iron contamination of the glass.

The redox property of the glass was measured by determining the Fe(II) content of the glass. A colorimetric technique was used after $\mathrm{HF} / \mathrm{HCl}$ dissolution of crushed samples of glass. 4

\section{RESULTS AND DISCUSSION \\ Preliminary Crucible Tests}

To determine how the resin would affect the redox of the glass melt, small crucible tests were performed using varying amounts of resin and an oxidizing agent, nitrate ions. In 
these tests, the mixture of resin, sludge, and frit was dried and then melted for four hours at $1150^{\circ} \mathrm{C}$. The glass was quenched and the Fe(II) content of the glass measured. The results of these tests indicated that with increasing amounts of resin in the feed, more $F e(I)$ was present in the glass. The results also showed that both $\mathrm{NaNO}_{3}$ and $\mathrm{HNO}_{3}$ were effective in lowering the amount of $\mathrm{Fe}$ (II) formed. $\mathrm{HNO}_{3}$ was more effective than $\mathrm{NaNO}_{3}$. The crucible tests indicated that at a ratio of 5 grams of resin per 100 grams of glass, the $\mathrm{Fe}(\mathrm{II}) / \mathrm{Fe}$ (total) ratio should be $\sim 0.3$. This value has been proposed as an upper limit on the amount $F e(I I)$ that should be present in the nuclear waste glasses that will be produced at SRS. ${ }^{4}$ This upper limit is based on the standard state calculation of the stability of nickel sulfide in the melt ${ }^{5}$ If nickel sulfide forms, it is conductive and may create an electrical short and damage the melter electrodes. For the resin runs, it was decided to use enough resin to approach this upper limit, thus, 5 grams of resin were used for every 100 grams of glass expected in the run.

\section{Melter Feed Composition}

Table I shows the major composition (on the basis of total solids in the slurry after it is dried) of the simulated nuclear waste sludge used in this study. This composition is typical i for the sludges that will be processed at SRS. When the sludge is present as melter feed, it

TABLE I. MAJOR COMPONENTS IN A DRIED SRS SIMULATED SLUDGE

\begin{tabular}{cccc} 
Element & $\begin{array}{c}\text { Weight } \\
\text { Percent }\end{array}$ & Element & $\begin{array}{c}\text { Weight } \\
\text { Percent }\end{array}$ \\
\hline $\mathrm{Fe}$ & 12.1 & $\mathrm{Na}$ & 7.1 \\
$\mathrm{Si}$ & 5.1 & $\mathrm{Al}$ & 3.5 \\
$\mathrm{Mn}$ & 2.8 & $\mathrm{Ca}$ & 1.7 \\
$\mathrm{~B}$ & - & $\mathrm{Li}$ & 0.53 \\
$\mathrm{Mg}$ & 0.64 & $\mathrm{Zn}$ & 0.20
\end{tabular}

will be in a slurry that contains soluble formates, nitrates, and nitrites. Formate is alded to adjust the rheology of the sludge and reduce $\mathrm{Hg}$ which is distilled from the sludge prior to feeding it into the melter. Nitrates and nitrites are present in the original sludge while it is stored in the waste tanks. Nominal concentrations of these anions are $1.2 \mathrm{M}$ for formate, $0.4 \mathrm{M}$ $*$ for nitrate, and $0.1 \mathrm{M}$ for nitrite. The frit used was Frit 165 . Its composition is given in Table II. The final glass is 28 weight percent sludge oxides and 72 weight percent frit oxides.

\section{TABLE II: OXIDE COMPOSITION OF FRIT 165}

\begin{tabular}{|c|c|c|c|}
\hline & Weight & & Weight \\
\hline Qxide & Percent & Oxide & Percent \\
\hline $\mathrm{SiO}_{2}$ & 65.0 & $\mathrm{Na}_{2} \mathrm{O}$ & 11.0 \\
\hline $\mathrm{B}_{2} \mathrm{O}_{3}$ & 10.5 & $\mathrm{Lin} O$ & 6.9 \\
\hline $\mathrm{ZrO}_{2}$ & 2.4 & $\mathrm{TiO}_{2}$ & 2.0 \\
\hline $\mathrm{K}_{2} \mathrm{O}$ & 1.0 & $\mathrm{MgO}$ & 0.64 \\
\hline $\mathrm{PbO}_{2}$ & 0.2 & $\mathrm{CaO}$ & 0.23 \\
\hline & 0.3 & $\mathrm{Fe}_{2} \mathrm{O}_{3}$ & 0.04 \\
\hline
\end{tabular}

- The elemental composition of the Cs-loaded resin is given in Table III. Prior to putting the resin into the melter feedtank, the resin was saturated with Cs by removing Cs from a simulated radioactive caustic supernate. The composition of this supernate was 4.0 $\mathrm{M} \mathrm{NaNO}_{3}, 1.5 \mathrm{M} \mathrm{NaOH}$, and $2.5 \times 10^{-4} \mathrm{M} \mathrm{CsNO}_{3}$. The Na form of the resin was used. To have enough resin for both runs, approximately $3 \mathrm{~kg}$ of dry resin were needed. This amount of resin was used to remove the Cs from 1700 liters of simulated supernate. The only pretreatment of the resin prior to adding it to the melter feedtank was to filter it from the supernate and air dry. (Air drying would probably not be necessary during large scale 


\section{TABLE III: ELEMENTAL COMPOSITION OF DRIED CS SPECIFIC \\ ION EXCHANGE RESIN AFTER REMOVING Cs FROM A SIMULATED HLW SUPERNATE}

\begin{tabular}{cc} 
& Weight \\
Element & Percent \\
\hline $\mathrm{C}$ & 35.5 \\
$\mathrm{Na}$ & 7.0 \\
$\mathrm{Cs}$ & 0.95
\end{tabular}

\begin{tabular}{cc} 
Element & $\begin{array}{c}\text { Weight } \\
\text { Percent }\end{array}$ \\
\hline $\mathrm{O}$ & 45.5 \\
$\mathrm{H}$ & 5.8 \\
$\mathrm{~K}$ & 0.07
\end{tabular}

processing.) The correct amount of dried resin was then mixed with the sludge and frit slurry in the melter feedtank.

Addition of the resin adds negligible amounts of alkali metals to the glass. For example, based on the composition in Table III, the presence of the resin adds only $\sim 0.4$ weight percent $\mathrm{Na}$ and 0.004 weight percent $\mathrm{K}$ to the glass. The amount of $\mathrm{Cs}$ added is even lower.

\section{Effect of Resin on Melter Operation}

When resin was present in the feed, no differences in melter operation were evident. There was no effect of resin on the required amount of current to pass through the electrodes in order to maintain the melt at $1150^{\circ} \mathrm{C}$. This suggests that the resin did not produce any conductive species in the melt which would short out the electrodes. The presence of the resin also did not introduce any adverse effects such as pluggage of the melter feed tube or off-gas system. Finally there was no apparent affect on the pourability (viscosity) of the glass melt.

\section{Final Glass Compositions}

The composition of a sample of glass from each of the three runs is given in Table IV. For the sludge only run (Run 1) and the intermittent sludge-resin run (Run 2), the samples were taken from the seventh can collected. For the continuous resin run, the sample was taken from the third can collected. Except for the Fe(II) and Fe(III) contents, the compositions are

$\approx$ similar. This is expected because the only difference in the feed was whether resin was present or not. When resin was present, the amount of Fe(II) increased which indicates that the glass is in a more reduced state. Further, in the melter run where the melter had been fed continuously for 2.2 days, the amount of $\mathrm{Fe}$ (II) increased the most (see Table IV).

\section{Effect of Resin on Glass Redex and Durability}

Table $\mathrm{V}$ summarizes the results for the redox ratios $(\mathrm{Fe}(\mathrm{m}) / \mathrm{Fe}$ (total)) and the durabilities for samples of glass from five of the twelve cans collected in each of the three melter runs. The cans were collected in the numerical sequence given by the sample numbers in the first column of Table V. For example, Sample 2-07 was from the 7th can collected in the second run (the intermittent resin run). As each run progressed (run times given in column 2), the glass became more reduced (the iron redox ratio increased) and less durable as measured by the-PCT. Lower durabilities are indicated by the increased $\mathrm{pH}$ values (Column 4) and $\mathrm{B}$ concentrations (Column 5 ) in the PCT tests. Similar trends were indicated by the $\mathrm{Na}, \mathrm{Li}$, and $\mathrm{Si}$ leached from the glass in the PCT tests. The $\mathrm{pH}$ increases are due to hydronium ions in the leach water exchanging with alkali ions in the glass. An increase in the $\mathrm{Fe}(\mathrm{II})$ in the glass decreases its durability because $\mathrm{Fe}$ (II) acts as a network modifier in the glass, while Fe(III) can be a network former. In the sludge only run, reduction in the melt was caused by formic acid. When resin was present, increased reduction was caused by the organic resin. 
TABLE IV: COMPOSITIONS OF THREE GLASSES FROM THREE MELTER RUNS TESTING THE EFFECT OF ORGANIC RESIN ON SLUDGE VITRIFICATION

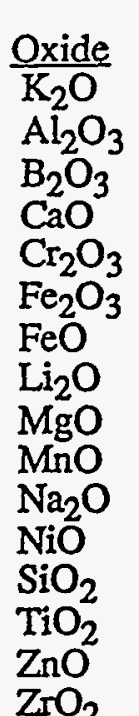

\begin{tabular}{|c|c|c|}
\hline \multicolumn{3}{|c|}{ Composition (weight percent) } \\
\hline Glass-1-07a $^{\mathrm{a}}$ & Glass-2-07b & Glass-3-03c \\
\hline 1.21 & 0.96 & 1.0 \\
\hline 4.04 & 3.62 & 3.77 \\
\hline 7.32 & 7.16 & 6.62 \\
\hline .92 & .81 & .87 \\
\hline .37 & .38 & .33 \\
\hline 8.53 & 6.09 & 6.64 \\
\hline 1.05 & 2.82 & 3.15 \\
\hline 4.51 & 4.65 & 4.45 \\
\hline 0.77 & 0.74 & 0.73 \\
\hline 1.48 & 1.43 & 1.56 \\
\hline 11.69 & 12.13 & 11.91 \\
\hline 0.69 & 0.58 & 0.55 \\
\hline 50.2 & 50.1 & 49.6 \\
\hline 1.06 & 1.06 & 1.01 \\
\hline 0.17 & 0.18 & 0.22 \\
\hline 1.26 & 1.36 & 1.31 \\
\hline
\end{tabular}

aGlass from Can 7 of the intermittent sludge only run. bGlass from Can 7 of the intermittent sludge-resin run. cGlass from Can 3 of the continuous sludge-resin run.

TABLE V: IRON REDOX RATIO AND PCT RESPONSE FOR GLASS SAMPLES FROM VITRIFICATION OF A SLURRY OF FRIT, SIMULATED HLW SLUDGE AND AN ORGANIC ION EXCHANGE RESIN

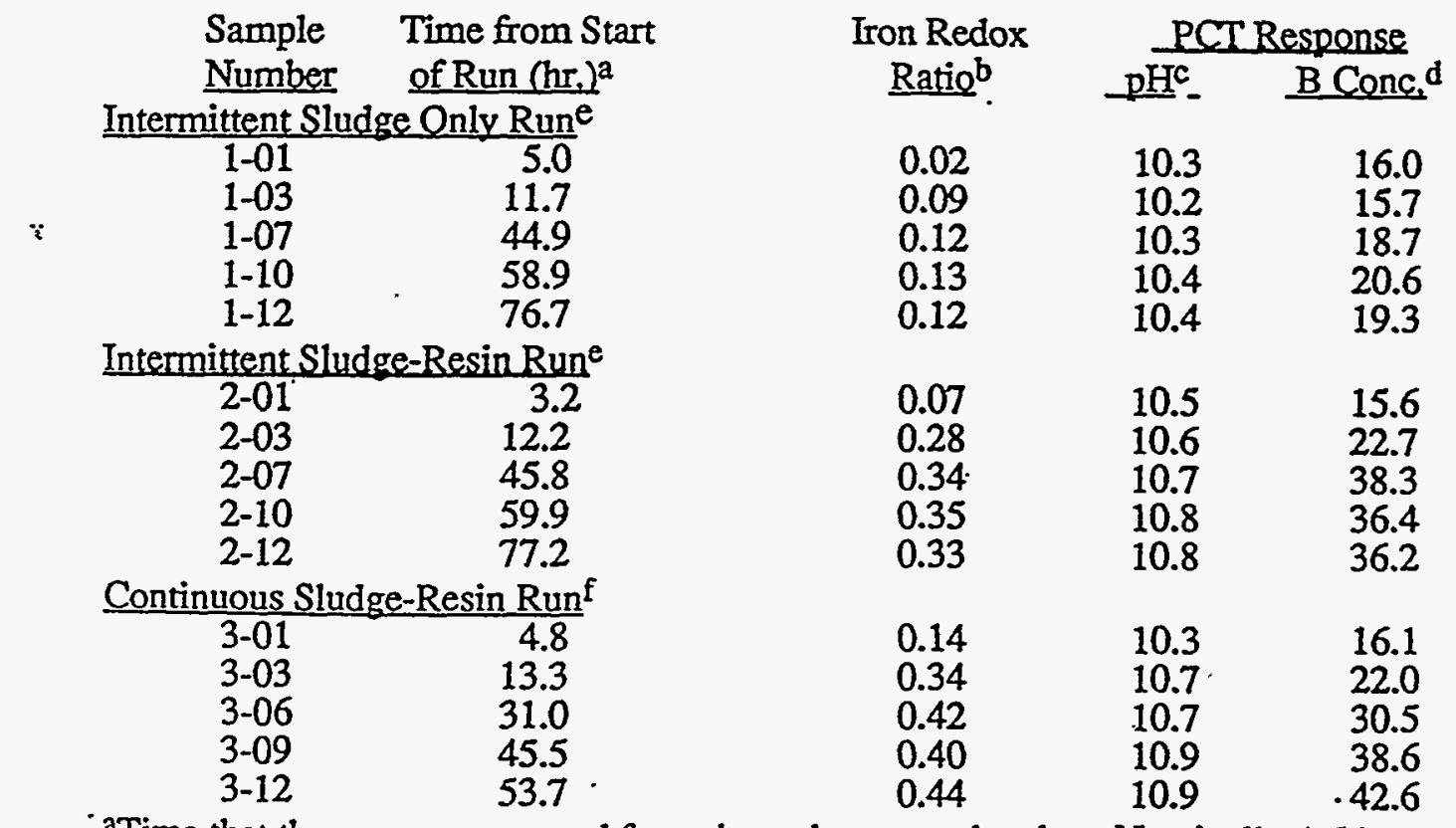

- aTime that the can was removed from the melter pour chamber. Nominally 4-5 hours were required to fill a can.

bMeasured $\mathrm{Fe}(\mathrm{II}) / \mathrm{Fe}$ (total) ratio in the glass.

${ }^{\mathrm{c}}$ Final $\mathrm{pH}$ in the PCT leach test. Initial $\mathrm{pH}=6.5$.

dFinal boron concentration (ppm) in the PCT leach test. Initial $=0.0$.

Melter was fed and glass poured for three 16 hour and one 8 hour intervals with 8 hour intervals in between. Total time $=3.2$ days.

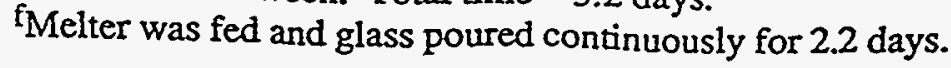


The glass collected in the first can from each run is more oxidized and more durable than the glass collected later in the runs. This is because the melter idled at $1050^{\circ} \mathrm{C}$ for several days between runs. During this idling period, $\mathrm{O}_{2}$ diffused into the melt and reoxidized the $\mathrm{Fe}$. Thus, the glass collected in the first can in the next run would be from this oxidized meit. The most reduced glass had a redox ratio of 0.44 and resulted from the continuous resin run (Run 3 ). In the two resin runs, the redox ratio of the glass in many cans exceeded the upper limit of 0.3 proposed $^{4}$ for this ratio. However, during these runs, there was no indication of electrical shorting in the melter. We are now examining the glass by scanning electron microscopy to see if any reduced metals are present. The final redox ratios in the intermittent resin run were not as high as the continuous resin run. During the intermittent run, $\mathrm{O}_{2}$ diffused into the melt during the 8 hours per day when the melter was idling. Consequently, the melt did not become as reduced as in the continuous run.

The acceptability of the glass from this process as a waste form for SRS radioactive waste can be assessed by comparing its durability with that of the glass which has been qualified in the DWPF Environmental Assessment (EA glass). Preliminary PCT results 6 with the EA glass indicate a $\mathrm{B}$ concentration nominally $10 \mathrm{X}$ higher than the highest $\mathrm{B}$ concentration in Table $\mathrm{V}$. On this basis, it can be concluded that glass prepared by vitrification of waste containing an organic ion exchange resin would be acceptable as a canistered waste material.

\section{CONCLUSIONS}

1. An organic ion excharge resin can be mixed with simulated high-level radioactive waste sludge and frit and then successfully vitrified in a slurry fed, joule-heated melter.

2. The resin does not significantly affect the operation of the melter and off-gas system. However, this will have to be further tested with longer runs and a larger melter.

3. The resin causes the glass to become more reduced which decreases its durability. However, when comparad to preliminary PCT results with the DWPF EA glass, this glass is acceptable for the immobilization of radioactive waste.

\section{FUTURE WORK}

The advantages of using an organic ion exchange resin for removing Cs from caustic supernates justify further tests to refine the vitrification process. Efforts will be made to adjust the melter feed to produce a more oxidized and durable glass. For example, based on the crucible tests, if nitric rather than formic acid is used to adjust the rheology of the sludge, the glass will be more oxidized. Further, it may be possible to reduce the amount of resin in the feed and still have enough resin to remove Cs-137 from the supernates. Lastly, methods of eluting the $\mathrm{Cs}$ off the resin need to be investigated.

\section{ACKNOWLEDGMENT}

- This work was done under Contract No. DE-AC09-89SR18035 with the U.S. Department of Energy. 


\section{REFERENCES}

1. J. P. Bibler and R. M. Wallace, "Testing a New Cesium-Specific Ion Exchange Resin for Decontamination of Alkaline High-Activity Waste," Proceedings of Waste

Management ' 90 , edited by R. G. Post, Tucson, AZ, (1990), pp. 747-751.

2. N. E. Bibler and C. M. Jantzen, "The Product Consistency Test and Its Role in the Waste Acceptance Process," Proceedings of Waste Management '89, edited by R. G. Post, Tucson, AZ, (1989)pp.743-749.

3. C. J. Coleman, E. W. Bauman, and N. E. Bibler."Colorimetric Determination of $\mathrm{Fe}$ (II)/Fe(III) Ratio in Radioactive Glasses," Broceedings of the Intemational High-Level Radioactive Waste Management Conference (American Nuclear Society, Inc., La Grange Park, IL, 1992), p. 557-561.

4. D. F. Bickford A. A. Ramsey C. M. Jantzen AND K. G. Brown, "Control of Radioactive Waste Glass Melters: I. Preliminary General Limits at Savannah River," I. Am. Ceram. Soc.. 73, pp. 2896-2902 (1990).

5. D. F. Bickford and R. B. Diemer, Jr., "Redox Control of Electric Melters with Complex Feed Compositions, Part. I," L. NonCryst. Solids. 84, pp. 276-284 (1986).

6. N. D. Hutson, C. M. Jantzen, and D. C. Beam, "A Pilot Scale Demonstration of the DWPF Process Control and Product Verification Strategy," Proceedings of the Intemational High-Ievel Radioactive Waste Management Conference, (American Nuclear Society, Inc., La Grange Park, IL, 1992), pp. 524-532. 
ATTACHMENT II - CENTER RESORCINOL RESIN THESIS 
August 5, 1994

To the Graduate School:

This thesis entitled "Vitrification of Cesium-Contaminated Organic lon Exchange Resin" and written by Thomas N. Sargent, Jr. is presented to the Graduate School of Clemson University. I recommend that it be accepted in partial fulfillment of the requirements for the degree of Master of Science with a major in Environmental Systems Engineering.

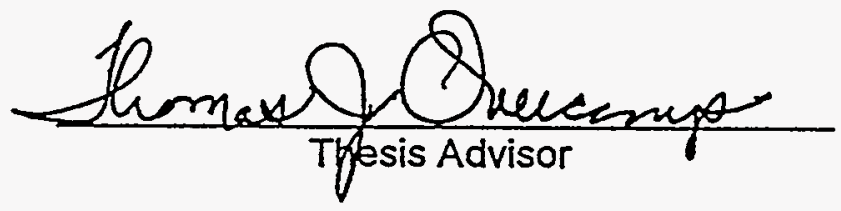

We have reviewed this thesis and recommend its acceptance:

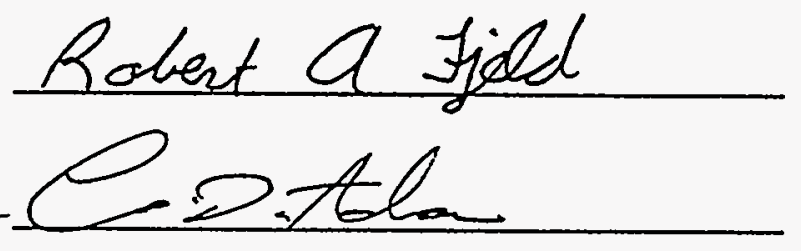

Accepted for the Graduate School:

A. Deutagne Brooks 
VITRIFICATION OF CESIUM-CONTAMINATED ORGANIC

ION EXCHANGE RESIN

\author{
A Thesis \\ Presented to \\ the Graduate School of \\ Clemson University
}

\begin{abstract}
In Partial Fulfillment
of the Requirements for the Degree

Master of Science

Environmental Systems Engineering
\end{abstract}

by

Thomas N. Sargent, Jr.

August 1994 


\section{ABSTRACT}

Vitrification has been declared by the Environmental Protection Agency (USEPA) as the Best Demonstrated Available Technology (BDAT) for the permanent disposal of high-level radioactive waste. Savannah River Site currently uses a sodium tetraphenylborate (NaTPB) precipitation process to remove Cs-137 from a wastewater solution created from the processing of nuclear fuel. This process has several disadvantages such as the formation of a benzene waste stream. It has been : proposed to replace the precipitation process with an ion exchange process using a new resorcinol-formaldehyde resin developed by Savannah River Technical Center (SRTC). Preliminary tests, however, showed that problems such as crust formation and a reduced final glass wasteform exist when the resin is placed in the melter environment. The newly developed stirred melter could be capable of overcoming these problems. This research explored the operational feasibility of using the stirred tank melter to vitrify an organic ion exchange resin. Preliminary tests included crucible studies to determine the reducing potential of the resin and the extent of oxygen consuming reactions and oxygen transfer tests to approximate the extent of oxygen transfer into the molten glass using an impeller and a combination of the impeller and an external oxygen transfer system. These preliminary studies were used as a basis for the final test which was using the stirred tank melter to vitrify nonradioactive cesium loaded organic ion exchange resin. Results from this test included a cesium mass balance, a characterization of the semi-volatile organic compounds present in the off gas as products of incomplete combustion (PIC), a qualitative analysis of other volatile metals, and observations relating to the effect the resin had on the final redox state of the glass. 


\section{DEDICATION}

This thesis is dedicated to my wonderful wife, Heather, who in the last eighteen months has taught me the true definitions of love, patience, and support. 


\section{ACKNOWLEDGMENTS}

I could not have finished if it were not for the support I received from each member of my family back in Stone Mountain, GA. It was obvious they wanted me to finish as much as I did. Thanks Mom, Dad, Rebecca, and Jonathan!

The friendships I have made while at Clemson are irreplaceable. I am extremely thankful to anyone who ever played on our ESE intramural sports team, Activated Sludge. I would especially like to thank everyone in my Bible study; Tim and Julfe $K$., Tom and Holly S., Burt and Ashley R., Ed G., David and Cathy B., Matt M., and Mark C., for the prayers and support I felt when I was completing my work. They made me feel God's presence even when things did not look real positive. The support and assistance given to me by everyone in the vitrification group; Paul F., Debbie S., Rob W., and $\mathrm{Ken} H$, cannot go without mention.

I would also like to express my gratitude to my major advisor, Dr. Thomas J. Overcamp, who provided technical guidance during the research. I am extremely grateful to David Bennert for all that I learned from him during this project. Thanks for convincing me to stay with the project.

I am also grateful to Bill Dunn who I'll never forget and who helped me in so many ways that I couldn't possibly list them here.

Thanks go to the Department of Energy and Westinghouse Savannah River Site for funding this research.under technical task plan number SR1-3-20-04. I would especially like to recognize Dennis Bickford for providing invaluable guidance and insight during the entire project and Connie Cicero for everything she did as well. 
TITLE PAGE

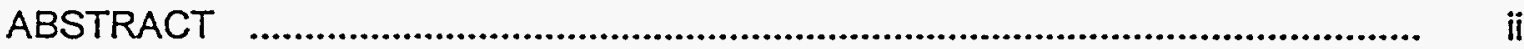

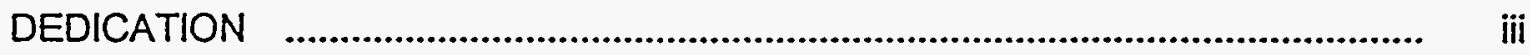

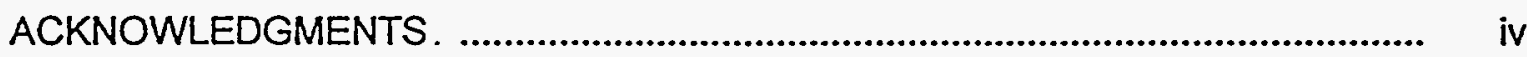

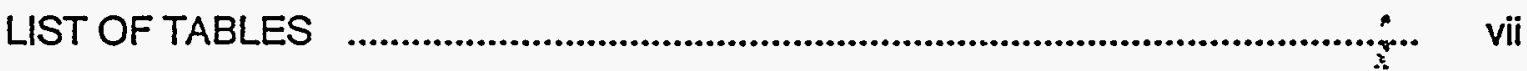

LIST OF FIGURES

\section{CHAPTER}

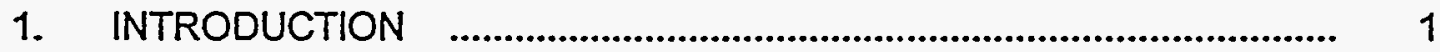

2. BACKGROUND AND LITERATURE REVIEW

The Vitrification Process ........................................................ 4

Savannah River Site High Level Waste Program $\quad$......................... 5

The lon Exchange Process $\quad$........................................................ 7

The lon Exchange Resin ........................................................... 8

Studies of Vitrification of H-Area Ion Exchange Resin ................. 8

Vitrification with Organic Compounds ......................................... 10

Redox Control of Glass ............................................................. 10

Cesium Volatility .......................................................................... 11

3. EXPERIMENTAL OBJECTIVES …................................................... 13

4. MATERIALS AND METHODS

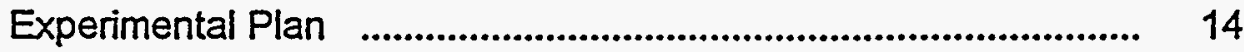

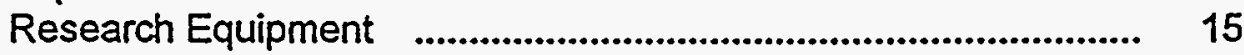

Research Chemicals .................................................................. 22

Phase I: Crucible Study _........................................................ 24

Phase I: Analytical Methods .................................................... 26

Phase II: Operational Parameters $\quad$.............................................. 27

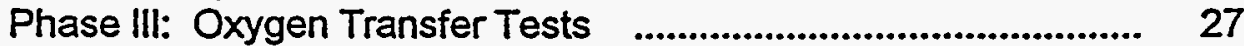

Phase IV: Vitrification of lon Exchange Resin .......................... 30

Phase IV: Analytical Methods .................................................... 32 
Table of Contents (Continued)

Page

5. " RESULTS AND DISCUSSION ....................................................... 34

Phase l: Crucible Studies ...................................................... 34

Phase Il: Establishing Operational Parameters ........................ 44

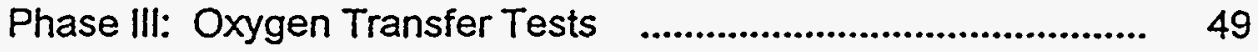

Phase IV: Vitrification of lon Exchange Resin ......................... 53

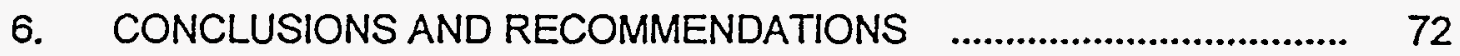

APPENDICES $\quad$.................................................................................... 75

A. Sample Calibration Curve for Fe(II)/Fe(total) Redox Analysis................ 76

B. Field Data Sheets from Off Gas Sampling.......................................... 77

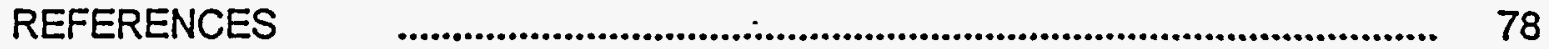




\section{LIST OF TABLES}

Table

Page

I. Approximate Composition of the Slumy Components

Used in Phases 11,111 , and IV.

II. Phase II Operational Parameters Matrix............................................. 28

III. Operating Conditions for Phase III Oxygen Transfer Tests ...................... 29

IV. Basic Matrix for Phase I Crucible Study Experiments............................. $\quad 34$

V. Crucible Contents for Phase I Crucible Study Experiments..................... 36

VI. Final $\mathrm{Fe}(\mathrm{II}) / \mathrm{Fe}$ (total) Values for Phase I Crucible Experiments................. 38

VII. Cesium Retention in Phase I Crucible Experiments ................................ 44

VIII. Phase II Final Operating Conditions ............................................... 45

IX. Phase IV CELS Feed Analysis Results ............................................ 57

X. Phase IV Semi-Quantitative Analysis of Feed ............................... 57

XI. Phase IV CELS Analysis of Exit Glass Samples Taken at Different Times ......................................................................... 60

XII. Phase IV CELS Oxide Analysis, Semi-Quantitative Analysis, and Loss on Ignition Results of Off Gas Deposits

XIII. Phase IV SRS Results of Bubbler and Scrubber Solution Analyses for Cesium

XIV. Phase IV Cesium Mass Balance Summary .......................................... 66

XV. Phase IV Multiple Metals Sampling Train Results ................................ 70

XVI. Phase IV Modified Method 5 Sampling Train Results.............................. 70

B-I. Field Data Sheet for Multiple Metals Sampling Train............................... 77

B-11. Field Data Sheet for Modified Method 5 Sampling Train ........................ 77 


\section{LIST OF FIGURES}

Figure

Page

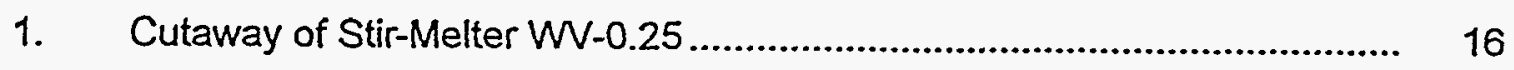

2. Feed System Used in Phases $\|$ and III .............................................. 18

3. Feed System Used in Phase IV ......................................................... 18

4. Off Gas Treatment System............................................................... 21

5. Comparison of Experimental Values with Predicted Values for the Entire Set of Crucibles in Phase 1 ............................................ 41

6. Comparison of Experimental Values with Predicted Values for the Sealed Set of Crucibles in Phase 1

7. Correlation Between Grams of Reducing Agent as Resin and Final $\mathrm{Fe}(\mathrm{II}) / \mathrm{Fe}$ (total) Ratio in Glass for Entire Set of

Crucibles in Phase 1

8. Recovery Curve for Phase III Batch Test One...................................... 52

9. Recovery Curve for Phase III Batch Test Two...................................... 54

10. Recovery Curve for Phase III Continuous Feed Test ............................. 54

11. Phase IV CELS Analysis Results for $\mathrm{Cs}_{2} \mathrm{O}$ in Glass ............................. 60

12. Phase IV Results from Bubbler Solution Analysis ................................ 64

13. Phase IV Results from Scrubber Solution Analysis ................................ 65

14. Phase IV Fe(II)/Fe(total) Ratio Results ............................................... 71

A-1. Sample Calibration Curve for Fe(II)/Fe(total) Redox Analysis ................. 76 


\section{CHAPTER 1}

\section{INTRODUCTION}

Vitrification, the conversion of a material or materials into a glass or glass-like substance, has been declared the Best Demonstrated Available Technology (BDAT) for the treatment of high-level radioactive waste (HLW) (FR, 1990). It has also been chosen for treatment of high level wastes in Germany, France, Great Britain, and Japan (Wicks, 1989). It involves subjecting materials capable of forming a glass or glass-like substance to temperatures above $1000^{\circ} \mathrm{C}$ so that they may form a glass. One way this is done is in an electrically heated glass melter with either alloy or ceramic lining. This is known as ex situ vitrification. The original waste can be bound into a glass matrix which is extremely leach resistant and has usually undergone an extremely beneficial volume reduction from a practical and economic standpoint.

High-level radioactive waste (HLW) is the waste product resulting from the processing of nuclear fuel. Currently, there are approximately $120,000 \mathrm{~m}^{3}$ of HLW stored in two tank farms with a total of 51 carbon steel tanks at the Savannah River Site (SRS). After ten to twenty years of aging, one of the major sources of beta and gamma radiation is cesium-137. Because of it's alkali nature, cesium-137 is soluble in water which can result in a cesium-contaminated waste salt solution. The current method used by SRS to remove this radioactive ion from solution is precipitation using sodium tetraphenylborate (NaTPB) (Wallace, 1988). This process, however, produces a large amount of organic material which puts a burden on a glass melter. A process step perfórmed prior to melter processing is used to decrease the amount of organic compounds in the meiter feed. This step incorporates the hydrolysis of the TPB with formic acid to yield benzene which can be removed through steam distillation. Although the process is able to remove approximately 90 percent of the organic 
material, it is very complex and has several disadvantages. These disadvantages include the presence of large amounts of sodium, potassium, and titanium that are fed to the melter, and the regulatory and safety concerns of handling the benzene waste stream.

Although ion exchange was proposed to replace the sodium tetraphenylborate precipitation process, it was discarded due to major additions in processing space required for the operating equipment. A new resin has been developed, however, which is capable of removing cesium under SRS HLW storage conditions (Wallace, 1988). This proposed process carries several advantages which could outweigh the necessary modifications in the tank farm program. Two of these advantages are a lower amount of alkali metals fed to the melter, which would increase the reliability of the glass making process, and the absence of boron in the resin which would allow the boron content of the glass to be more easily regulated. One method suggested for disposal of the used resin is to feed it along with frit and other necessary additives directly into the existing Defense Waste Processing Facility (DWPF) melter at the SRS. Preliminary tests, however, (Bibler, 1991) showed that problems exist when the resin is placed in the melter environment. First, the resin has the tendency to accumulate on top of the melt in a crust. This increases the time for the feed to become incorporated in the melt and allows more time for cesium to volatilize instead of becoming immobilized in the melt. Second, the organic resin causes significant reducing conditions in the melt which could increase the volatility of alkali metals such as cesium and can result in a less durable glass.

The newly developed stirred tank melter may be capable of overcoming both of these problems. The melter used for these experiments is the Stir-Melterm WW-0.25 designed and fabricated by Stir-Melter, Inc. It's design includes an impeller that enters the melt from the top. Since the entire melt is agitated by the impeller, the crust formation is decreased by continuously drawing the surface into the melt. The impeller 
agitation can also ameliorate the negative effects of a reduced melt by constantly refreshing the surface layer and thereby increasing oxygen exchange between the melt and vapors above the melt. A more oxidized melt could lower the amount of cesium volatilized as well as other metals (Bickford, 1994).

This research focused on the vitrification of the ion exchange resin developed at the SRS. The goal of this research was to provide a basis for determining the feasibility of vitrifying the organic ion exchange resin proposed to decontaminate aqueous solutions containing cesium-137. The research was conducted in four phases. The first phase involved several crucible level experiments. This phase investigated the effects of organic compound additions on the formation of a glass wasteform. These effects included oxidation/reduction shifts and cesium retention. It also examined the reducing effectiveness of the ion exchange resin in comparison to elemental carbon. The goal of the second phase was to establish nominal melter operation parameter values. This phase determined acceptable valués for operational parameters such as impeller height, impeller rotational speed, and melter temperature which needed to be maintained in order to sustain satisfactory melter production rate and operating conditions. which indicate successful operation of the melter. The third phase was oxygen transfer tests. This phase examined the rate of oxygen transfer into the molten glass through combinations of impeller agitation, an extemal air sparger, and water in the feed. The fourth and final phase was the actual vitrification of the resin using the stirred melter. The primary goal of this phase was to approximate a cesium mass balance around the melter including the feed, exit glass, and off gas streams. The test program for this phase also included gas sampling for semi-volatile organic compounds, other volatile metals in addition to cesium, and total particulate matter. 


\section{CHAPTER 2}

\section{BACKGROUND AND LITERATURE REVIEW}

\section{The Vitrification Process}

Vitrification is the process of tuming a material or materials into a glass or glasslike substance. It is a general term covering all glass making operations from the creation of bottle glass to the treatment of radioactive, hazardous, and mixed wastes. Mixed wastes are those which have both a hazardous element or compound and the radioactive elements and are often the most difficult to treat successfully. In the environmental engineering realm, the term vitrification specifically covers the process in which a wide variety of waste streams are converted into a durable glass wasteform (USEPA, 1992).

Glass melter designs combine many of the characteristics of flásh boilers, calciners, incinerators, and electrically heated glass melters (Bickford, 1986). The melter acts as a flash boiler when a slurry feed containing organic compounds is . exposed to the $500^{\circ} \mathrm{C}$ to $900^{\circ} \mathrm{C}$ surface of the glass pool. Volatile organic compounds present in the feed can be considered to boil off at the same temperature as water. These compounds can be collected in an off gas treatment system and destroyed effectively (Bickford, 1986). Calcination occurs as the solids in the feed settle into the melt pool and are further heated. The formates and hydroxides of cations such as $\mathrm{Al}$, $\mathrm{Na}$, and $\mathrm{Ca}$ are converted to oxides which are then incorporated in the glass matrix. Several of these cations are common components in hazardous waste streams and thus decrease the amount of additives needed for successful vitrification (Bickford, 1986). When organic contaminants are subjected to typical vitrification temperatures of over $1000^{\circ} \mathrm{C}$, they are destroyed either by pyrolysis or combustion. Some of the 
heavier organic compounds are pyrolyzed within the melt. The majority of the combustion generally occurs in the plenum above the melt or in a secondary combustion chamber. Destruction efficiencies of over 99.999 percent have been reported in vitrification systems for compounds such as chlorobenzene, phenol, and carbon tetrachloride (Armstrong, 1985; USATHMA, 1988; Klingler, 1989).

The melters are electrically heated by passing a current through electrodes submerged in the molten glass. The heat caused by the resistance of the glass to the current allows the molten glass to maintain a melting temperature. Resistance heaters are also used in some cases to provide extra heat when needed (Bickford, 1986).

\section{Savannah River Site High Level Waste Program}

At the SRS, the high-level radioactive waste (HLW) residue of over 30 years of reprocessing irradiated nuclear fuels for national defense purposes is currently stored in 51 carbon steel tanks located in two tank farms and totals approximately 120 thousand cubic meters. This HLW at SRS is the residue of chemical reprocessing of uranium fuel and targets after irradiation in nuclear reactors. HLW contains most of the fission products of irradiation, including the intense beta and gamma radiation emitters Cs-137 and Sr-90 (Pearson, 1991).

The HLW produced is first transferred from the separation facilities, where it was generated, to waste receipt tanks. While in these tanks, the waste divides into three parts. First, a metal oxide sludge settles out. This sludge consists of metal oxides of aluminum, iron, and manganese. It makes up approximately 10 percent of the waste volume and has the majority of the radioactivity since it includes most of the fission products and some actinides that were not recovered in the reprocessing facility. The overlying layers are a salt solution and a salt cake. The salt solution and cake are primarily sodium nitrate, sodium nitrite, and sodium hydroxide. It is also highly radioactive because it contains cesium-137 (Pearson, 1991). 
The metal oxide sludge, salt solution, and salt cake are allowed to remain in the receipt tanks undisturbed for at least one year in order for the shçt-lived isotopes to decay and for the metal oxides to settle. After one year, the salt solution and salt cake are decanted off and concentrated into a salt cake. This cake is allowed to decay for several more years before further processing (Pearson, 1991).

Tank sludges high in aluminum are leached with $\mathrm{NaOH}$ to dissolve most of the aluminum. Approximately 75 percent of the hydrated aluminum is dissolved resulting in a volume reduction of about 50 percent (Pearson, 1991). All sludges are washed with water to decrease the volume by removing the soluble salt content. It is currently thought that this washed sludge will be stored at 10 to 19 weight percent solids and fed to the Defense Waste Processing Facility (DWPF) melter. The DWPF is a treatment facility designed for the processing and immobilization of High-Level Radioactive Waste (Pearson, 1991).

The current method to remove the radionuclides from the salt solution and salt cake is through the addition of sodium tetraphenylborate solution (Bibler, 1991). This produces insoluble tetraphenylborate salts of cesium, ammonium, and potassium. A small amount of sodium titanate slumy is also added to adsorb any residual plutonium or strontium. The resultant slurry, composed of tetraphenylborate salts and used sodium titanate, is then processed under continuous filtration until it is 10 weight percent solids. It is then washed to a low soluble salt level and pumped to the DWPF (Pearson, 1991).

Before vitrification, the tetraphenylborate salts are processed to remove most of the organic carbon. This is accomplished by the addition of formic acid which converts the phenyl groups to an immiscible benzene phase. The benzene is removed through steam distillation and incinerated. The remaining aqueous phase solution contains the cesium and other metals as formate salts, boric acid, formic acid, phenol, and phenylboric acid. This solution is known as Precipitate Hydrolysis Aqueous (PHA) 
product. The solution along with the insoluble titanate is collected and fed to the Sludge Receipt and Adjustment Tank (SRAT) (Pearson, 1991).

The SRAT is fed by the washed sludge slurry and the precipitate hydrolysis product. Mercury is reduced to its elemental state in the SRAT through the addition of formic acid and removed with steam distillation. The SRAT slumy is then mixed with borosilicate glass frit and concentrated to 45 weight percent by boiling. It is transferred to the Melter Feed Tank and then fed to the melter (Pearson, 1991).

The decontaminated salt solution from the waste processing steps will be mixed with cement, flyash, and slag to produce saltstone which will be disposed of as:a LowLevel Radioactive Waste (LLW) at SRS (Pearson, 1991).

\section{The lon Exchange Process}

A cation exchange resin has been developed recently by SRS whose cesium capacity was four times greater than the best commercial resin (Wallace, 1988). It can potentially reduce the complexity of the decontamination process. The Cs removal could occur in the tank farm area, the Sr removal in a sodium-titanate ( $\mathrm{Na}-\mathrm{Ti}$ ) column, and mercury removal in a resin column. Spent Sr titanate could be fed with the Cs resin to the melter.

The potential advantages of the ion exchange process are (Wallace, 1988)

1. The need for the acid hydrolysis process would be eliminated;

2. The alkali elements going to the melter as part of the PHA product would be eliminated. This would greatly increase the reliability of the glass making process;

3. The amount of titanium going to the meiter would be decreased by about a factor of 10 . This will significantly reduce the possibility of devitrification in the glass product, and of spinel formation in the melter;

4. No boron is introduced to the glass making process by the spent resin. Thus, the boron content in the glass can be controlled by regulating borosilicate glass additions; 
5. The volume of waste sent to the Saltstone facility, where decontaminated salt solution is immobilized by mixing with cement, slag, and flyash, should be less for the ion exchange process (Pearson, 1991);

6. Problems associated with the generation of organic compounds in the TPB precipitate process would be eliminated;

7. The need for a holding tank regulated under the Resource Conservation and Recovery Act (RCRA), an incinerator, and mercury removal processes to handle the benzene waste stream created through the formic acid hydrolysis would be eliminated.

The possible disadvantages of the ion exchange process are (Wallace, 1988)

1. The cost and schedule of the tank farm program would be impacted;

2. Engineering aspects of the ion exchange process, such as resin transport have not been evaluated in detail.

\section{The lon Exchange Resin}

The resin which is being proposed to replace the tetraphenylborate process for cesium removal is a resorcinol-formaldehyde cation exchange resin (Bibler, 1987). It is prepared by condensing the potassium salt of resorcinol with formaldehyde in an aqueous solution. This results in a gel which is dried at approximately $100^{\circ} \mathrm{C}$. The sample can be prepared in three separate forms distinguished by the exchangeable cation. Initially, the resin is present in the potassium form. The hydrogen form is prepared by washing the resin present in the potassium form in a dilute solution of nitric acid. A combination potassium/sodium form is prepared by rinsing the potassium resin with $2 \mathrm{M} \mathrm{NaOH}$ solution.

\section{Studies of Vitrification of lon Exchange Resin}

Bibler (1991) used a ceramic-lined joule heated melter with a capacity of $18 \mathrm{~kg}$ of glass for their demonstrations of the vitrification of the same organic ion exchange resin used in this study. The melter was fed with a 58 wt\% slumy containing ground borosilicate glass, sludge, and resin. The ground glass was frit 165 developed at SRS. 
The sludge was a "typical" composition for sludges which will be processed at SRS. The anions in the sludge were primarily nitrates, nitrites, and formates. The resin was 0.95 weight percent cesium. The melter operating temperature was $1150^{\circ} \mathrm{C}$. It was reported that during the feeding phase, the slurry "fell on the top surface of the melt, water was flashed off, any organic present was incinerated, sludge was dissolved in the melt, and the frit was melted." The molten product was collected in stainless steel beakers through an overflow drain. The off gas system was able to collect condensate from the water fed to the melter as well as particulate matter entrained in the off gas.

Three runs were performed using this melter. The first run used a combination of sludge and frit, while the second and third runs used a mixture of frit, sludge, and resin. The schedule for the first two runs consisted of pouring for sixteen hours during the first two days and eight hours during the third day with the melter idling for the remaining hours of each day. The schedule for the third run was one run with a duration of fiftythree hour (2.2 days). Each run collected 12 cans of glass with each can holding approximately $12 \mathrm{~kg}$.

Bibler concluded that no effects on melter operation were caused by resin addition to the feed. This included no shorting out of the melt due to conductive species, no pluggages in the off gas system, and adequate pourability of the melt. The resin did, however, have an effect on the final glass compositions. The sample for each run had very similar compositions except for the relative amounts of $\mathrm{Fe}(\mathrm{II})$ and Fe(III). Whenever resin was present, the Fe(ii) concentration was higher, indicating the glass was in a more reduced state. The amount of $\mathrm{Fe}(\mathrm{II})$ was highest during the third run. This was because the other two run schedules included an idling time where oxygen had a chance to diffuse into the melt and reoxidize the melt. Samples were taken several times during the course of the runs. In all cases, the glass became more reduced and less durable as time passed during resin feeding. This inverse relationship between durability and redox state is due to the fact that $\mathrm{Fe}(\mathrm{II})$ acting as a 
network modifier reduces durability while $\mathrm{Fe}($ III) is a network former. However, the glass is still an "acceptable waste form" when "compared to the preliminary results with the DWPF Environmental Assessment (EA) glass."

\section{Vitrification with Organic Compounds}

One possible problem with organic compounds in the melter environment is the formation of soot and tar. Both of these can cause pluggages in off gas system equipment. More importantly, these carbon deposits can cause sulfidization or carburization of melter equipment. Depending on the type of redox environment, alloys can be attacked moderately or severely. Inconel-690 placed in a reducing environment showed "catastrophic" sulfidization (Bickford, 1986).

\section{$\underline{\text { Redox Control of Glass }}$}

Redox control of the glass melt is an important process operation. It is done by balancing the amount of reducing agents and oxidizing agents in the feed and plenum. For a complex feed which includes organic compounds, the redox state of the waste glass is found by balancing the reducing potential of feed organic compounds and the oxidizing potential of the gases above the melt as well as any nitrates or polyvalent elements in the waste (Bickford, 1991). One of the primary tests for excessive amounts of organic compounds in the melter feed is determining the ratio of $\mathrm{Fe}$ (II) to Fe(III) or $\mathrm{Fe}(I I)$ to total iron (Bickford, 1986). Accurate control of the redox state can lead to better metal retention within the melt, a more durable final glass product, more efficient heat transfer within the melt, and a better Destruction and Removal Efficiency (DRE) of organic compounds in the feed.

\section{Cesium Volatility}

Cesium is a semi-volatile metal. This is of concern at nuclear sites because it is primarily present as a radioactive isotope such as Cs-137. There have been several 
efforts to lower the volatility of cesium in a melt. One method was to add soda ash or sodium oxide to the melt to decrease the melting temperature. However, the increased evolution of off gas offset the benefits of the new melt temperature (Spalding, 1989). Current trends in cesium control include either controlling process feed or recycling off gas components. Controlling process feed involves monitoring the constituents in the feed and how they affect cesium volatility, while recycling off gas components such as HEPA filters or scrubber water, minimize the amount of cesium in the secondary off gas system waste stream (USEPA, 1992).

Kamizono (1986) examined the volatility of cesium within a stainiess steel: " canister. The purpose of his study was to look into the safety aspects of HLW vitrification storage. In this experiment, HLW was placed into a canister which was heated in a furnace to $1000^{\circ} \mathrm{C}$ in steps of $25^{\circ} \mathrm{C}$. It was noted that the decay heat did not play an important role in the temperature control of the glass. During the course of heating, air samples were taken into a bottle with a volume of approximately $7 \mathrm{~cm}^{3}$. The normalized concentration of cesium (taken by dividing the airbome concentration by the glass concentration) approached it's maximum value in less than one hour; Kamizono divided the complex release mechanism into two pathways. First, the radionuclide must migrate from within the melt to the melt surface. Second, the radionuclide at the surface reacts with other elements. Cesium has been reported to volatilize as $\mathrm{CsBO}_{2}$ (Asano, 1985). This means that the volatility of cesium at the surface has some relation to the interaction between cesium and boron. The volatility of cesium also increases with increasing temperature with the activation energy equal to approximately $140 \mathrm{~kJ} / \mathrm{mol}$. The temperature range of this study was from $400^{\circ} \mathrm{C}$ to $1000^{\circ} \mathrm{C}$.

When alkali metals are bound in a glass matrix, they begin to act in a non-ideal manner. For example, the activity of cesium oxide when incorporated in a glass is several orders of magnitude lower than when it is existing as a pure element. This 
decreases the volatility of cesium from a glass matrix significantly. If cesium does volatilize, it quickly disassociates into $\mathrm{Cs}^{+}$and $\mathrm{O}_{2}$ (Sanders, 1977). After volatilizing; the vapor pressure of $\mathrm{Cs}^{+}$is approximately 10 times higher than that of $\mathrm{Cs}_{2} \mathrm{O}(\mathrm{Odoi}$, 1979). 
CHAPTER 3

\section{EXPERIMENTAL OBJECTIVES}

The goal of this research was to provide a basis for determining the feasibility of vitrifying a cesium-contaminated organic ion exchange resin. In order to meet this goal, the following research objectives were established:

1. using crucible studies to determine some of the effects such as changes in $\mathrm{Fe}$ (II)/Fe(total) ratio and cesium retention that the addition of organic compounds have on the formation of a glass;

2. determining a range of acceptable values for several operating parameters such as melter temperature and also determining the relative importance of the operating parameters;

3. approximating oxygen transfer rates into a glass melt using different combinations of operating conditions;

4. using pilot scale demonstrations to perform a cesium mass balance around the melter including the feed, off gas, and exit glasś streams;

5. characterizing semi-volatile products of incomplete combustion (PIC) found in the off gas resulting from the vitrification of the resin. 


\section{CHAPTER 4}

\section{MATERIALS AND METHODS}

A pilot-scale stirred tank glass melter fabricated by Stir-Melter, Inc. was used to investigate the potential application of vitrification in the treatment of organic ion exchange resin (Richards, 1991). The experimental system consisted of the melter, two related feed systems, an oxygen sparger, and an off gas treatment system. Three phases of preliminary studies were performed prior to the actual use of a pilot-sciale glass melter for the vitrification of the cesium-contaminated ion exchange resin. "These preliminary studies included crucible studies and oxygen transfer tests.

\section{Experimental Plan}

The research was divided into four phases. The first phase was a crucible study. This phase examined the effect that the addition of an organic material had on the resulting glass wasteform. These effects included cesium retention and final redox state of the melt. The goal of the second phase was to set a range of operational parameters that would allow for successful operation of the melter. A matrix with 12 different combinations of operating parameters was established in order to determine a range of acceptable operating parameters and also to distinguish the relative importance of the operating parameters. The third phase was oxygen transfer tests. Approximate values of the oxygen transfer rate into the molten glass under different combinations of impeller agitation, oxygen sparging, and feed water were calculated based on temporal changes in the $\mathrm{Fe}(\mathrm{II}) / \mathrm{Fe}$ (total) ratio. The fourth phase of research was the vitrification of actual cesium-contaminated ion exchange resin. The results from each of the first three phases of research were used in establishing conditions for the fourth phase. 


\section{Research Equipment}

\section{Stirred Tank Melter}

-The stitred tank glass melter used in this research was the Stir-Melter model WV-0.25. A cutaway of the melter is shown in Figure 1 (Richards, 1991). It is a Jouleheated melter with a power supply rated at $50 \mathrm{~V}$ maximum, 300 Amperes maximum, or $10 \mathrm{~kW}$ total power. The vessel is constructed of inconelm alloy 601 . It is $15.24 \times 15.24$ $\times 30.48 \mathrm{~cm}(6 \times 6 \times 12 \mathrm{in})$. The vessel is surrounded by exterior $7 \mathrm{~kW}$ heating elements which are used for startup and to assist in maintaining melter temperatures if necessary. An impeller extends into the molten glass from above. The height"and rotational speed of the impeller can be controlled. Feed components are fed into the melter through ports located above the melter vessel. The feed materials fall into the vessel and on the molten glass bath where they are rapidly incorporated into the melt through impeller agitation. When the molten glass level reaches 6 inches from the bottom of the vessel, the glass drains from an overflow spout. The molten glass exits from the bottom of the tank, upwards through a channel in the comer of the vessel, over an overflow point located $15.24 \mathrm{~cm}$ (6 in) from the bottom of the vessel, and then downward to an outlet located at the bottom of the melter. There is also an additional water-cooled drain plug located in a lower comer of the vessel adjacent to the overflow channel. This is used when emptying the melter vessel (Richards, 1991).

The melter used in these experiments was also equipped with a drain tube heater. Occasionally, the glass exiting the melter through the overflow drain cooled while passing down the exit tube and caused blockages. A heated rod, placed adjacent to the exit tube, kept the local environment inside the tube at approximately $1000^{\circ} \mathrm{C}$ to aid in maintaining a steady flow of glass. The rod heated the entire drain tube except for the lower two to three inches. In addition to the drain heater, a propane 


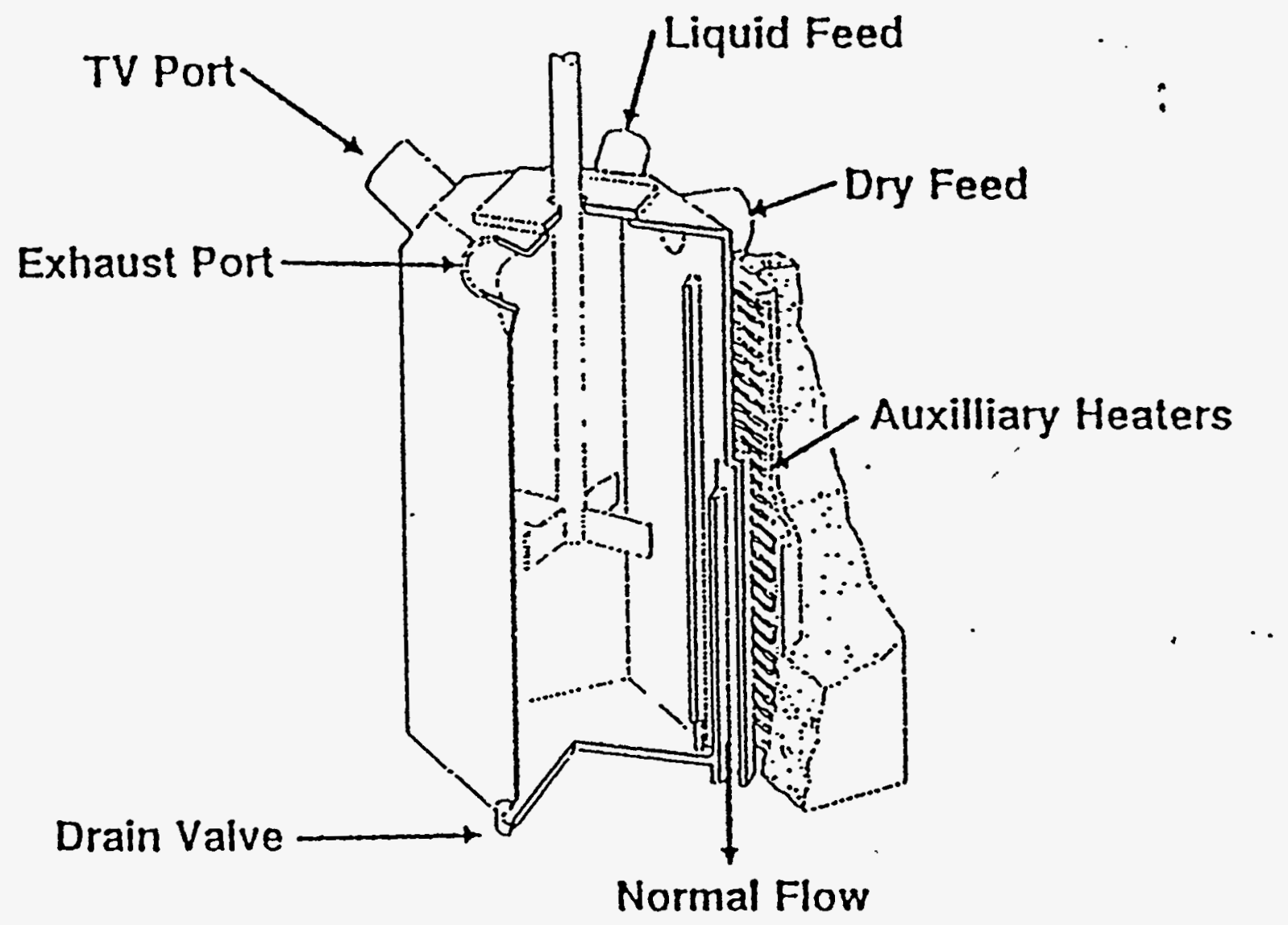

Figure 1. Cutaway of Stir-Melter WV-0.25 (Richards, 1991) 
burner was used to heat the lower few inches of the drain tube so that the exiting glass did not cool as it left the tube.

\section{Feed System}

The feed system used during Phases II and III of the research is shown in Figure 2. It consisted of a large stainless steel mixing tank, a secondary stainless steel vessel, a diaphragm pump, and a peristaltic pump. The slurry mixture was stored in the large mixing tank capable of holding over 55 gallons. This tank was equipped with a large impeller and baffles in order to keep the slurry in suspension. The mixture was pumped with a diaphragm pump into the secondary vessel which was elevated above the large mixing tank on a small stand. The operating volume of the secondary vessel was approximately 3 liters. The slumy entered the secondary vessel tangential to the walls of the vessel creating a swirling motion in the secondary vessel which kept the slurry in suspension. The secondary vessel had two exit ports. The first port was a tube which entered from the bottom of the vessel and ended approximately 3.5 inches from the bottom. When the slurry reached the height of the tube, it would overflow into the tube and drain through a hose back into the large mixing tank. It was installed so that a constant level of slurry was maintained in the vessel to assist in maintaining a steady flowrate. The second port was a small hole in the side located approximately 2.75 inches from the bottom of the vessel. The slurry was pumped from this port using a Cole Parmer peristaltic pump with a Masterflex controller through the water-cooled slurry feed nozzle and into the melter vessel.

The feed system shown in Figure 3 was used during Phase IV research. It was much simpler than that used in Phases II and III. The previous system was not used during Phase IV research because it would have involved either allowing the resin to mix in the large mixing tank or using an auger feeder to feed the resin as a separate feed stream. Both of these circumstances were unacceptable. If the resin was allowed 


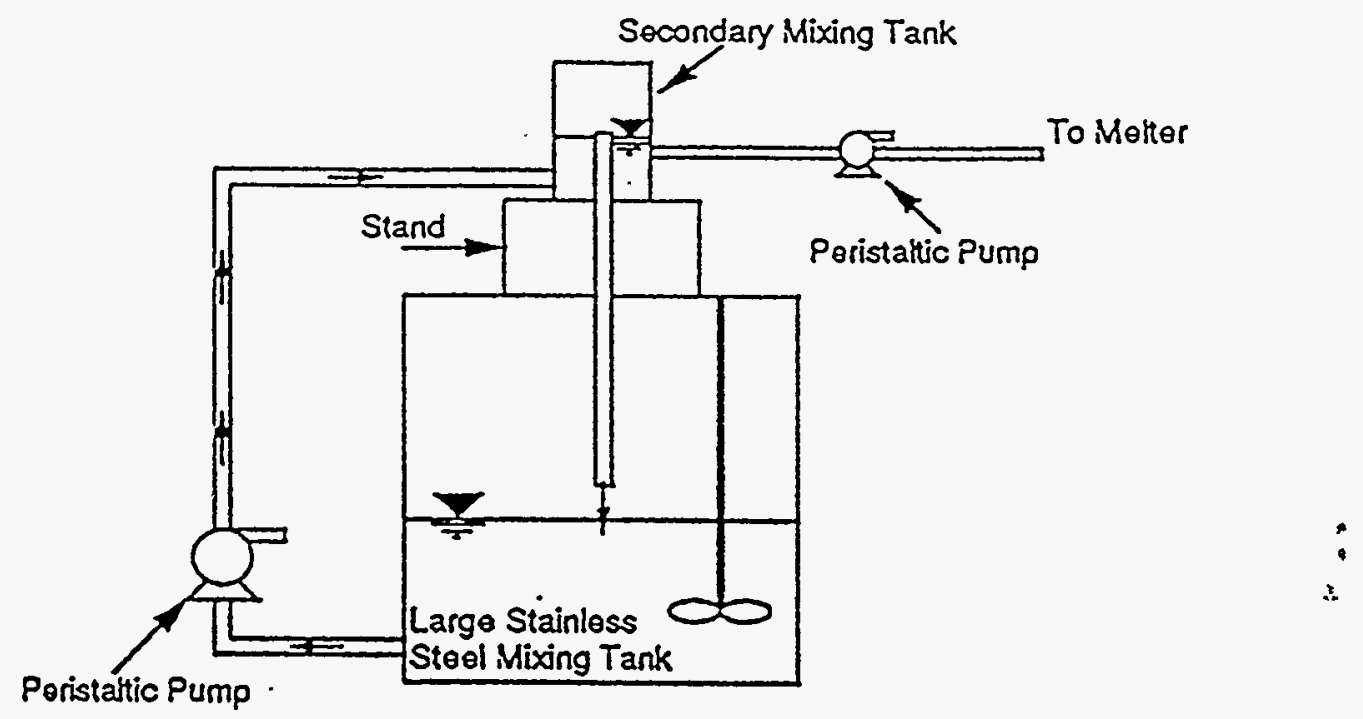

Figure 2. Feed System Used in Phases II and III

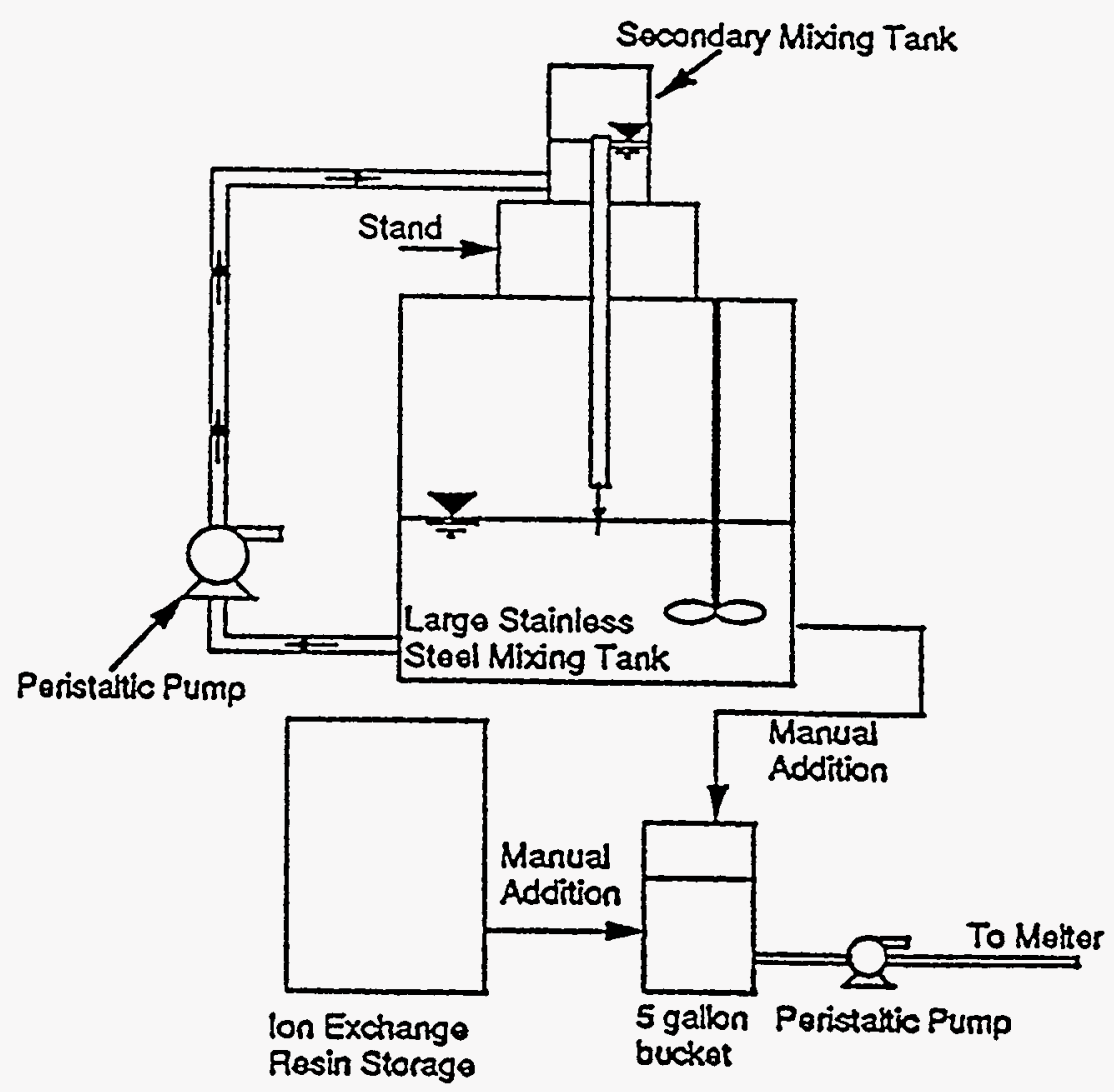

Figure 3. Feed System Used in Phase IV 
to mix in the large mixing tank, the cesium might have disassociated from the resin into thẹ slurry and behaved differently in the melter. Auger feeding of the resin was attempted unsuccessfully. When it was fed in this manner, it became swept up in the off gas before it could reach the melt surface. Therefore, the slurry from the large tank and cesium-contaminated ion exchange resin were mixed in a 5 gallon bucket. The feed to the melter was pumped directly from this bucket into the melter using a Cole Parmer peristaltic pump with a Masterflex controller.

The water-cooled slumy feed nozzle fit directly into the slurry feed port of the melter assembly. The nozzle consisted of two concentric 304 stainless steel tubes. The outer diameters of the two tubes were 0.25 inches and 0.75 inches, respectively. The slurry travelled down the 0.25 inch tube into the melter. The 0.75 inch diameter tube surrounded the smaller tube and was sealed around both ends forming a jacket. This jacket was fed with ambient temperature.cooling water so that the nozzle and slumy did not become too hot and cause a blockage.

\section{Gas Sparging System}

The melter used in this study was also equipped with a gas sparging system consisting of a 0.50 inch 1.D. Inconel 601 tube inserted into the molten bath. The gas was supplied from an ordinary gas cylinder. The gas travelled from the cylinder through a calibrated Gilmont flowmeter before being expelled directly under the impeller. The flowrate of the gas was controlled using a needle valve.

\section{Redox Probe}

The redox probe was a hollow ceramic probe with a zirconium oxide pellet at the tip. It was manufactured by C.S.I.R.O. in Australia under U.S. Patent \# 4,046,661 (Arculos, 1981). Inside the ceramic probe was a type $R$ thermocouple consisting of platinum and rhodium wires. Another platinum wire ran down the outside of the 
ceramic probe and wrapped around the zirconium oxide pellet. Redox measurements were taken by reading the voltage across the two platinum wires. Temperature measurements were made simultaneously by reading the voltage across the thermocouple wires and using a thermocouple table specific to the $R$ type thermocouple (Bums, 1993).

\section{Off Gas Treatment System}

The off gas treatment system is shown in Figure 4. A $5 \mathrm{hp}$ blower (not shown in figure) created a negative pressure in the headspace of the melter and pulled gases evolved from the feed and air inleakage through a 2 inch riser pipe. The gas then passed through a combination venturi scrubber/sqpray quencher. Approximately one liter per minute of water was added through the quench in order to decrease the temperature and scrub some of the larger particles. The gas then was bubbled into a bubbler tank with an operational volume of approximately 92 liters through a perforated pipe. The water level in the tank was controlled to approximately 15 inches using a tube which entered through the top and was connected to a continuously operating peristaltic pump. The tube stopped approximately 15 inches from the bottom of the tank as shown in the figure. Thus, when the water level in the tank reached 15 inches, it was pumped from the tank. The gas then travelled through a countercurrent scrubber packed with 0.50 inch Raschig rings. The scrubber column contained 5 feet of packing and was 6 inches in diameter. The scrubber solution was continuously pumped from a reservoir at a rate of approximately 1 to 2 gallons per minute which had an operational volume of approximately 325 liters through the column and back into the reservoir.

\section{Temperature Control}

Watlow brand temperature controllers were used to control the power supplied by the glass melter. Both the melter heating circuit (Joule) and the auxiliary heating circuit 


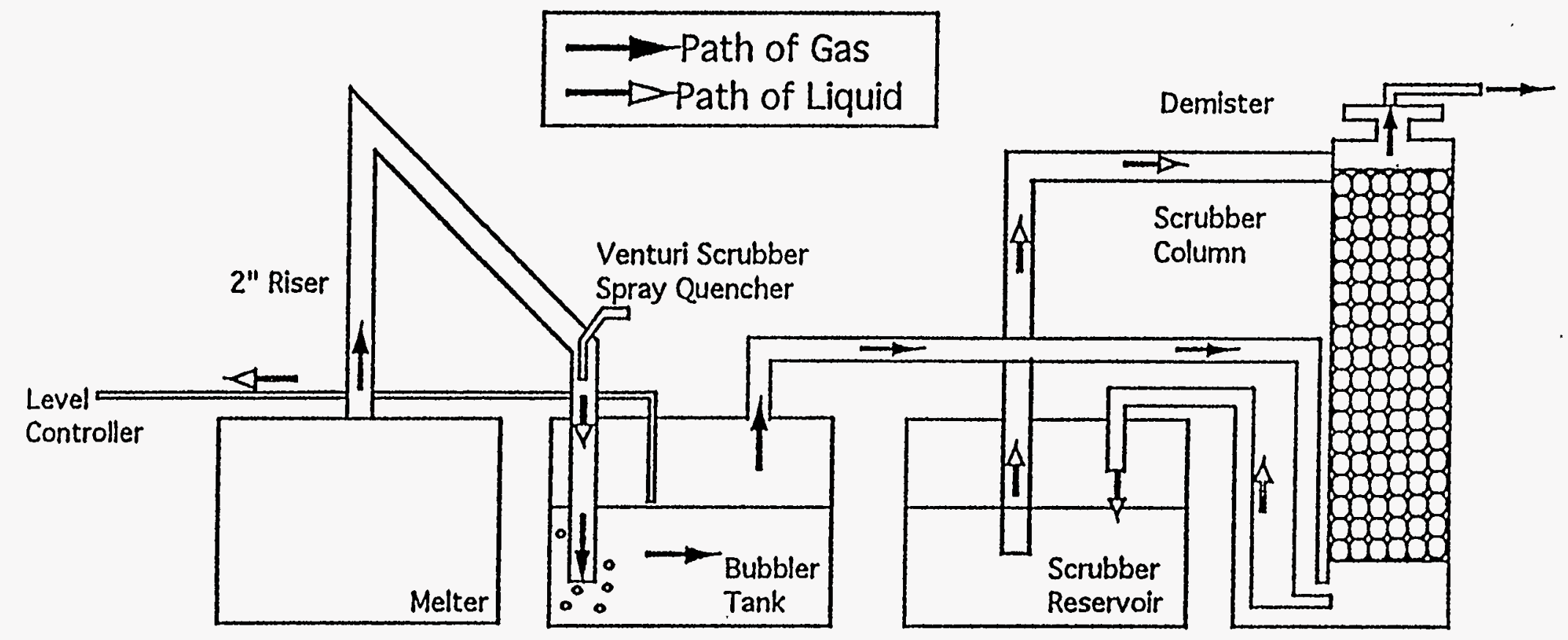

Figure 4. Off Gas Treatment System 
were controlled by a Watiow controller to a user defined temperature setpoint. In addition to the setpoints, the user could also define the percentage of the maximum power available to be used by the melter in each heating circuit. Type $S$ thermocouples were used in controlling each heating circuit. The thermocouples were placed so that they measured the temperature next to the vessel wall. The thermocouple used by the melter controller measured the temperature near the bottom of the vessel. The thermocouple used by the auxiliary controller measured the temperature approximately 6 inches above the melter thermocouple. Typically, the melter controlier was supplied with a higher setpoint than the auxiliary controller so that the glass was predominantly heated using Joule heating.

\section{Research Chemicals}

\section{Slumy}

The slurry provided by SRS used in Phases II, III, and IV of this research was a HLW surrogate of what would actually be fed to DWPF melter. The slurry was approximately 35 to 40 weight percent solids. It was made of three components: The first component was a surrogate metal oxide sludge similar to what would be found at the bottom of the waste tanks at SRS. The second component was frit 202, which is a borosilicate glass frit designed by SRS for the vitrification of HLW. The third component was simulated PHA material. If the ion exchange process actually replaced the NaTPB precipitation process, the simulated PHA material would not be present in the slurry. PHA was present because an existing surrogate containing the PHA material was available, and it was decided that the small amount of PHA material existing in the slumy would not significantly affect this study. No external organic material such as carbon or resin was present in the slurry except for the small amount of formic acid contributed by the simulated PHA material: An approximate oxide 
composition of each of the three primary components of the slurry is shown in Table I (Schumacher, 1991).

During Phase IV the slurry was premixed with the resin before being fed to the melter. This mixture was analyzed by Coming Engineering Laboratory Services (CELS). Results of these analyses are provided in Chapter 5.

\section{Ion Exchange Resin}

The ion exchange resins used in the study were provided by SRS. It was made available in two forms. The first form was ion exchange loaded with elemental çêsium. The mass ratio of cesium in the loaded form of resin was 0.16 grams of cesium per gram of clean dry resin. It was approximately $38.4 \%$ solids but had no free standing water in the container. This resin was used in both Phases I and IV. The second resin was not loaded with cesium and was basically dry. This resin was used in Phase III.

\section{Miscellaneous Chemicals}

The carbon used in Phase I and Phase III was granulated activated carbon supplied by Calgon (CAS\# 7440-44-0). The ferric oxide used in the crucible study was $99+\%$ pure and supplied by Harcross Pigments (Lot number F8090). The sodium carbonate used in the crucible study was technical grade, mined. It was supplied by General Chemical. The glass frit used in the crucible study was supplied by Bassichi's Co. (Lot number CBF-230). The anhydrous borax used in the crucible study was 99.5\% pure on a metals basis and supplied by Johnson Matthey (Lot number H10C05). The cesium carbonate used in the crucible study was $99 \%$ pure on metals basis and supplied by Johnson Matthey (Lot number 129C06). 


\section{Phase 1: Crucible Study}

\section{Sample Preparation}

Each of the chemicals used in the crucible study was dried in a $101^{\circ} \mathrm{C}$ to $103^{\circ} \mathrm{C}$ oven for more than 24 hours prior to the crucible study. After they were removed from the oven, they were stored in a desiccator until used in the experiments.

\section{Experimental Procedure}

High purity alumina crucibles were filled with identical amounts of glass forming chemicals. Each crucible contained approximately 20 grams of frit, 2.5 grams of anhydrous borax, 2.5 grams of ferric oxide $\left(\mathrm{Fe}_{2} \mathrm{O}_{3}\right)$, and 2.5 grams of sodium carbonate $\left(\mathrm{Na}_{2} \mathrm{CO}_{3}\right)$. The type and amount of organic material, the presence of water, and the inclusion of a sealed lid were altered for each crucible. The parameters used for each crucible set are defined in Chapter 5. Cesium carbonate was added to those samples using elemental carbon as the carbonaceous material to provide cesium for the cesium retention study. Water was added to some of the crucibles to examine it's effect on the final redox state of the glass. All samples were ground and stirred using a mortar and pestle to assure uniform blending of the components. Crucibles were sealed, as required, with a commercial ceramic sealant. .

A furnace capable of maintaining $1100^{\circ} \mathrm{C}$ was preheated to $600^{\circ} \mathrm{C}$. After the samples were placed in the furnace at $600^{\circ} \mathrm{C}$, the temperature was increased to $1100^{\circ} \mathrm{C}$. The samples were maintained at $1100^{\circ} \mathrm{C}$ for three hours. The crucibles were then removed from the furnace and air quenched. The sealed samples remained sealed during quenching. 
Table I

Approximate Composition of the Slumy Components

Used in, Phases II, III, and IV

\begin{tabular}{cccc}
\hline \hline Oxide & $\begin{array}{c}\text { Sludge } \\
\text { (weight percent) }\end{array}$ & $\begin{array}{c}\text { PHA } \\
\text { (weight percent) }\end{array}$ & $\begin{array}{c}\text { Frit 202 } \\
\text { (weight percent) }\end{array}$ \\
\hline $\mathrm{Al}$ & 16.86 & 1.20 & \\
$\mathrm{Ba}$ & 0.24 & 0.81 & 8.00 \\
$\mathrm{~B}$ & & 29.30 & \\
$\mathrm{Ca}$ & 4.39 & 0.08 & \\
$\mathrm{Cr}$ & 0.36 & 0.02 & \\
$\mathrm{Cs}$ & 0.01 & 1.00 & $: 3.00$ \\
$\mathrm{Cu}$ & 0.18 & 3.80 & 2.00 \\
$\mathrm{Fe}$ & 44.12 & 0.81 & \\
$\mathrm{~K}$ & 0.39 & 36.92 & 6.00 \\
$\mathrm{Li}$ & & & \\
$\mathrm{Mg}$ & 0.35 & 0.01 & \\
$\mathrm{Mn}$ & 8.91 & 0.16 & \\
$\mathrm{Na}$ & 12.77 & 18.46 & \\
$\mathrm{Ni}$ & 2.65 & 0.05 & \\
$\mathrm{~Pb}$ & 0.41 & 0.01 & \\
$\mathrm{Si}$ & 4.18 & 0.07 & \\
$\mathrm{Ti}$ & & 7.22 & \\
$\mathrm{Zr}$ & 1.41 & 0.02 & \\
\hline
\end{tabular}




\section{Phase 1: Analytical Methods}

\section{Recovery of Glass Samples}

The glass from each crucible was removed by breaking the crucible with a hammer over a stainless steel tray. Prior to analysis, it was powdered to approximately 100 mesh using an agate ball mill. The powdered glasses were stored in labelled plastic vials.

\section{Redox Ratio Analysis}

The redox analysis for $\mathrm{Fe}(11) / \mathrm{Fe}$ (total) ratio in waste glass followed the same procedure as that developed at Savannah River Site (Baumann, 1987). This method involved placing pulverized glass in a sulfuric/hydrofluoric acid mixture in the presence of ammonium vanadate. As the $\mathrm{Fe}(\mathrm{II})$ ions entered solution, they reacted with the $\mathrm{VO}_{2}{ }^{+}$ion to produce $\mathrm{Fe}(\mathrm{III})$. After the glass dissolved, boric acid was added to complex the fluoride. A buffered Ferrozine solution was used to raise the $\mathrm{pH}$ and "regenerate" the original $\mathrm{Fe}(I I)$. The solution turned a magenta color due to the formation of a ferrous-Ferrozine complex. The absorbance of this solution was determined colorimetrically at $562 \mathrm{~nm}$. Ascorbic acid was then added to reduce all $\mathrm{Fe}$ to $\mathrm{Fe}$ (II). The resulting Fe(II) formed more of the ferrous-Ferrozine complex. A new absorbance was read and the $\mathrm{Fe}(I I) / \mathrm{Fe}$ (total) ratio was determined with the aid of calibration curves. A sample of this calibration curve is shown in Appendix A.

\section{Cesium Content of Glass}

The glass samples were analyzed by SRS for cesium content. The glasses were digested using nitric acid, hydrofluoric acid, boric acid, and hydrochloric acid with microwave dissolution and the resulting digestate was analyzed using atomic adsorption. A Varian Spectra400 Atomic Adsorption spectrophotometer was used. 
The analysis was by flame emission at a wavelength of $852.1 \mathrm{~nm}$, with a slit width of $0.1 \mathrm{~nm}$, and using an air-acetylene flame

\section{Phase II: Operational Parameters}

A matrix of 12 trials for operating the melter was created allowing for different combinations of impeller height, impeller speed, melter temperature, slurry feed rate, and air feed rate. For each parameter, a high, middle, and low value were selected for testing. Following these initial 12 trials, 4 more trials were performed to refine the ranges. The parameters for the first 12 trials and the following 4 trials are shown in Table II. Trials were generally carried out for at least two hours except in cases where it was apparent after several minutes that the combination of parameter values for that trial would be unsuccessful such as those using high slurry feed rates. Qualitative observations were made during each trial.

\section{Phase 11: Oxygen Transfer Tests}

\section{Experimental Procedure}

Two of the oxygen transfer tests performed were batch type experiments úsing no feed slurry. The melter was first filled with a known amount of glass from the Phase Il tests. The impeller agitated the molten glass for several hours to assure that the molten glass was at equilibrium with the atmosphere. Next, a measured quantity of elemental carbon was added to the melt to increase the $\mathrm{Fe}($ III)/Fe(total) ratio. When it was felt that the carbon had been fully reacted with the melt as evidenced by the absence of flares, sparks, or the evolution of gases, samples were taken from the surface of the melt. Operational conditions for the test were then initiated. The operating conditions are shown in Table III for batch tests 1 and 2. Samples were then taken periodically for the next several hours. The operational values for the melter 
parameters such as melter temperature and impeller speed were based on results from Phase II observations.

Table 11

Phase II Operational Parameters Matrix

\begin{tabular}{cccccc}
\hline \hline Trial & $\begin{array}{c}\text { Melter T } \\
\text { (deg C) }\end{array}$ & $\begin{array}{c}\text { Imp Spd } \\
(\text { rpm) }\end{array}$ & $\begin{array}{c}\text { imp Ht } \\
\text { (inches) }\end{array}$ & $\begin{array}{c}\text { Slumy } \\
(\mathrm{mL} / \mathrm{min})\end{array}$ & $\begin{array}{c}\text { Air Feed } \\
\text { (mL/min) }\end{array}$ \\
\hline 1 & 1050 & 202 & 4 & 66 & 200 \\
2 & 1050 & 202 & 4 & 88 & 500 \\
3 & 1050 & 302 & 4 & 114 & 800 \\
4 & 1050 & 302 & 5 & 66 & 200 \\
5 & 1060 & 420 & 5 & 88 & 200 \\
6 & 1060 & 420 & 5 & 114 & 500 \\
7 & 1060 & 202 & 6 & 66 & 500 \\
8 & 1060 & 202 & 6 & 88 & 800 \\
9 & 1070 & 302 & 6 & 114 & 800 \\
10 & 1070 & 302 & 4 & 66 & 200 \\
11 & 1070 & 420 & 5 & 88 & 500 \\
12 & 1070 & 420 & 6 & 114 & 800 \\
13 & 1060 & 302 & 4 & 54 & 600 \\
14 & 1060 & 588 & 3.5 & 54 & 600 \\
15 & 1070 & 370 & 4 & 54 & 800 \\
16 & 1070 & 420 & 4 & 50 & 800 \\
\hline
\end{tabular}

The second type of oxygen transfer test was conducted using continuous slumy flow. The melter was first allowed to approach equilibrium as in the batch style test. Next, the slurry feed containing approximately 35 to 40 percent solids described earlier made up of frit, sludge, and PHA material was started at a rate of $50 \mathrm{~mL} / \mathrm{min}$ and an exit glass stream was established. Other operational values based on Phase II results for the continuous feed test are shown in Table III. When the melter was operating successfully under the slurry feed conditions, resin which had not been loaded with cesium, was batch fed in 30 to 100 gram portions to the melt to increase the $\mathrm{Fe}(\mathrm{II}) / \mathrm{Fe}$ (total) ratio. A total of 300 grams of resin were added in this manner. During 
the melter run, the redox state of the glass was monitored by two methods. First, samples of molten glass were taken periodically from the molten surface and of the exit glass. These samples were analyzed for the $\mathrm{Fe}(\mathrm{II}) / \mathrm{Fe}$ (total) ratio as an indication of the redox state of the glass. Second, the on-line redox analyzer utilizing a zirconium oxide probe was used which continuously monitored the redox state of the glass. A rough correlation was made between $\mathrm{Fe}(1 \mathrm{l}) / \mathrm{Fe}$ (total) ratio and EMF readings generated by the probe.

Table III

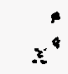

Operating Conditions for Phase III Oxygen Transfer Tests

\begin{tabular}{cccc}
\hline Parameter & Batch Test 1 & Batch Test 2 & Continuous Feed \\
\hline Melter Temperature & 1070 degrees Celsius & 1070 degrees Celsius & 1070 degrees Celsius \\
Auxiliary Temperature & 1055 degrees Celsius & 1055 degrees Celsius & 1055 degrees Celsius \\
Impeller Height & 3.25 inches & 2.75 inches & 4 inches \\
Impeller Speed & $405 \mathrm{rpm}$ & $405 \mathrm{spm}$ & $405 \mathrm{~mm}$ \\
Oxygen Flow & $0 \mathrm{~mL} / \mathrm{min}$ & $0 \mathrm{~mL} / \mathrm{min}$ & $1000 \mathrm{~mL} / \mathrm{min}$ \\
Water Feed Rate & $0 \mathrm{~mL} / \mathrm{min}$ & $35-40 \mathrm{~mL} / \mathrm{min}$ & $0 \mathrm{~mL} / \mathrm{min}^{\prime}$ \\
Slurry Feed Rate & $0 \mathrm{~mL} \mathrm{~min}$ & $0 \mathrm{~mL} / \mathrm{min}$ & $50 \mathrm{~mL} / \mathrm{min}$ \\
\hline
\end{tabular}

\section{Glass Sampling Procedure}

Glass was sampled from the surface of the melt during the batch type oxygen transfer tests. Inconel ${ }^{\mathrm{TM}}$ welding rod was inserted approximately 1.5 inches beneath the surface of the melt and removed. The glass was allowed to air quiench on the rod. It was removed from the rod by covering the glass with a paper towel and lightly tapping with a hammer. The glass samples were stored in a labelled plastic vials. 
Glass was sampled both from the surface of the melt and from the exit glass stream during the continuous type testing. Meit surface sampling was performed in the same way as the batch type testing. Pull samples were taken by allowing the exit stream to fall on a stainless steel plate. This glass was allowed to air quench and then stored in labelled plastic vials.

\section{$\mathrm{Fe}(I 1) / \mathrm{Fe}$ (total) Ratio Determination}

Redox determination of all glass samples was performed using the colorimetric analysis developed at SRS described eartier in Phase 1.

\section{Phase IV: Vitrification of lon Exchange Resin}

\section{Experimental Procedure}

The glass was filled to approximately 6 inches with nominal $8.6 \%$ iron glass made from Phase III tests. The melter and auxiliary temperature controllers were set to setpoints of $1070^{\circ} \mathrm{C}$ and $1045^{\circ} \mathrm{C}$, respectively. The oxygen sparger was then turned on at a rate of $1200 \mathrm{~mL} / \mathrm{min}$ at STP. The scrubber was filled with a known amount of tap water and turned on. The bubbler was allowed to fill with tap water to the level control tube. After the scrubber water was allowed to circulate through the packed column for approximately thirty minutes, three scrubber solution sample blanks were taken. Three bubbler tank solution sample blanks were also taken from the exit tube of the level controller. The bucket which held the slumy and resin mixture was then filled with $11.312 \mathrm{~L}$ of the slumy previously described as approximately 35 to 40 weight percent solids and 295 grams of the wet resin loaded with nonradioactive cesium. A small mixer kept the resin and other solids in suspension. Three feed samples were taken from this initial slurry mixture. When the glass melt had reached the setpoint temperatures, the slumy feed was added to the melter at a rate of $51 \mathrm{~mL} / \mathrm{min}$. During the course of the run, samples from the packed column scrubber and the bubbler 
solution were taken approximately every hour. Samples of exit glass were taken approximately every thirty minutes. Readings from the redox probe were recorded manually in a log book every few minutes during the course of the entire run. A data acquisition system recorded all other important data every one to five minutes. The bucket level was maintained by adding resin and slurry to the bucket in the same ratio as the initial amount during the run. When the melter had processed approximately 3 tank volumes of glass, samples of the off gas were taken using both the EPA Modified Method 5 Sampling Train (OSWER, 1986) and the EPA Multiple Metals Sampling Train (USEPA, 1990). After the off gas sampling was completed, final samples of the scrubber solution, bubbler solution, glass, and feed were taken.

\section{Sampling Procedure}

\section{Glass Sampling}

Glass was sampled from the exit stream in an identical manner as in the Phase III continuous type test.

\section{Bubbler Solution Sampling}

Samples of the bubbler solution were taken from the solution pumped from the bubbler tank through the level controller. Since the tank was required to be airtight at all times, no sample was taken directly from the tank. It was felt that enough bubbling and mixing was going on in the tank that the sample from the level controller was representative of the concentration in the tank.

\section{Scrubber Column Sampling}

Samples from the scrubber column were taken from the stream being pumped back into the scrubber solution reservoir immediately after leaving the scrubber column. Off Gas Multiple Metals Sampling Train

Sampling for metals in the off gas was performed using a modified version of the EPA Method 29 Sampling Train (USEPA, 1990). Since mercury was not present in the 
feed, the permanganate impingers normally used for sampling mercury were eliminated from the train. These impingers were replaced with additional $\mathrm{HNO}_{3} / \mathrm{H}_{2} \mathrm{O}_{2}$ impingers. The reason for this is that several of the metals of interest such as Cs were not on the list of metals for which Method 29 was designed. Thus, these additional impingers were analyzed separately to determine if the first impingers had caught all the additional metals. For example, if each impinger solution contained the same amount of a certain metal, it could be determined that the results for that metal were inconclusive since all the metal had apparently not been captured with the impingers. However, if the final impingers had much lower concentrations of a certain mețal than the first impingers, it could be concluded with reasonable certainty that the majority of that metal was captured.

\section{Off Gas Modified Method 5 Sampling Train}

The procedure used was as per EPA Modified Method 5 (OSWER, 1986).

\section{Phase IV Analytical Methods}

Feed and Glass Analysis

Glass and feed samples were analyzed by Corning Engineering Laboratory Services (CELS) in Coming, NY for the following elements: $\mathrm{Fe}, \mathrm{Na}, \mathrm{Ca}, \mathrm{Mg}, \mathrm{Cr}, \mathrm{Ni}, \mathrm{Cs}$, $B, S i, L i, K, M n$, and $A l$.

Glass samples were also analyzed by SRS for cesium. The procedure used was summarized earlier in the Phase I analytical methods section.

\section{Off Gas Analysis}

\section{Multiple Metals Sampling Train}

The components of the Multiple Metals Sampling Train were analyzed by Oxford Laboratories in Wilmington, $\mathrm{NC}$ for the following elements: $\mathrm{Cs}, \mathrm{Ni}, \mathrm{Si}, \mathrm{Pb}, \mathrm{Ba}, \mathrm{Fe}, \mathrm{Mn}$, $\mathrm{Mg}, \mathrm{Cr}, \mathrm{Na}, \mathrm{Ca}, \mathrm{Al}, \mathrm{Li}, \mathrm{K}$, and $\mathrm{B}$. 
Modified Method 5 Sampling Train

The XAD-2 resin module of the Modified Method 5 Sampling Train was analyzed by Triangle Laboratories in Raleigh, NC for semi-volatile organic compounds listed in the Clean Air Act and on Table 2 in SW-846 based on the guidelines of Method 8270 . The column for the gas chromatography analysis was a J\&W DB5-625, $30 \mathrm{~m} \times 0.32$ $\mathrm{mm} \times 1 \mu \mathrm{m}$. The carrier gas for the analysis was helium. The instruments used for performing the mass spectrophotometry were a Hewlett-Packard MSD, Chemsystem and Target data system. The parameters of the scan were 35-550 amu at $1.67 \mathrm{~s} / \mathrm{scan}$.

Bubbler and Scrubber Solution Analysis

Bubbler and scrubber solution samples were analyzed by SRS for total Cs content by SRS using a Varian Spectra400 Atomic Adsorption spectrophotometer. The analysis was by flame emission at a wavelength of $852.1 \mathrm{~nm}$, with a slit width of 0.1 $\mathrm{nm}$, and using an air-acetylene flame. 


\section{CHAPTER 5 \\ RESULTS AND DISCUSSION}

\section{Phase 1: Crucible Studies}

The basis for the design of the Phase I crucible test matrix was to vary the type of organic material and also to test what effects the addition of water and a sealed environment had on the resulting glass product. Seven combinations of these test conditions were explored. The basic matrix showing the different combinations is shown in Table IV. Within each combination, the amount of the respective reducing agent was varied. It was not felt that the addition of water would have an effect on an open crucible so that combination was not pursued.

Table IV

Basic Matrix for Phase I Crucible Study Experiments

\begin{tabular}{ccccc}
\hline Set & Reducing Agent & Reducing Agent $(\mathrm{g})$ & Water & Type of Environment \\
\hline A & Carbon & $0.125,0.25,0.29,0.34,0.375$ & No & 'Sealed \\
B & Carbon & $0.125,0.25,0.375$ & Yes & Sealed \\
C & Resin & $0.25,0.50,0.75$ & No & Sealed \\
D & Resin & $0.25,0.39,0.50,0.75,0.81$ & Yes & Sealed \\
E & Carbon & $0.125,0.25,0.375$ & No & Unsealed \\
F & Resin & $0.25,0.50,0.75$ & No & Unsealed \\
G & None & None & No & Sealed \\
\hline
\end{tabular}

Table $V$ shows the chemical contents of each crucible prior to melting and the type of environment (sealed vs. unsealed). As mentioned before, each crucible had the same base of glass forming materials. The glass frit was the primary glass forming material. It supplied the $\mathrm{SiO}_{2}$ for the final glass sample. The borax was added mainly 
because the actual glass frit used for the vitrification of HLW is a borosilicate glass. The $\mathrm{Fe}_{2} \mathrm{O}_{3}$ was added to serve as a redox determinant and to provide additional oxygen for the oxidation of carbon or resin. The $\mathrm{Fe}(\mathrm{II}) / \mathrm{Fe}$ (total) or ferrous to total iron ratio is a common indicator of the redox state of a glass. Ferric oxide can serve as a redox buffer by being reduced prior to other glass forming elements and thus providing oxygen for oxidation reactions. The soda ash was used as a fluxing agent so that the final glasses would become more homogeneous. Cesium carbonate was added to spike those crucibles containing carbon as the reducing agent. The masses listed in Table $V$ for each chemical were taken after the chemicals had been dried in a $101^{\circ} \mathrm{C}$ to $103^{\circ} \mathrm{C}$ oven for over 24 hours and then cooled in a desiccator.

\section{Visual Observations}

The crucibles were identified by a three section identification code. The first section is the page number of the log book issued to Dennis Bickford of SRS where they were first listed (Bickford, 1994). The second section is the lettér from Table IV which describes the combination of elements in the crucible. The third section is a number which distinguishes the crucibles with identical page numbers and combinations of elements from each other based on their different organic compound loading. For example, the crucible sample identified with $17-A-3$ means that this sample is described on page 17 of the log book, has carbon as the reducing agent, does not have water added, and is in a sealed environment.

Two of the crucible mixtures, $17-A-3$ and 13-D-2, described in Table $V$ did not form a homogeneous glass. These samples were discarded and underwent no further tests. Sample 17-A-3 contained 0.3749 grams of carbon. Two additional tests using set $A$ conditions were performed with slightly lower carbon loadings. These samples were $21-\mathrm{A}-1$ and $21-\mathrm{A}-2$ and had 0.2922 and 0.3383 grams of carbon respectively. 
Table V

Crucible Contents for Phase I Crucible Study Experiments

\begin{tabular}{|c|c|c|c|c|c|c|c|c|c|}
\hline $\begin{array}{c}\text { Crucible } \\
\text { ID }\end{array}$ & $\begin{array}{c}\text { Frit (g) } \\
\text { (grams) }\end{array}$ & $\begin{array}{l}\text { Borax }(g) \\
\text { (grams) }\end{array}$ & $\begin{array}{l}\text { Fe203 (g) } \\
\text { (grams) }\end{array}$ & $\begin{array}{l}\text { Carbon (g) } \\
\text { (grams) }\end{array}$ & $\begin{array}{c}\text { Cs2CO3 (g) } \\
\text { (grams) }\end{array}$ & $\begin{array}{l}\text { Resin }(g) \\
\text { (grams) }\end{array}$ & $\begin{array}{c}\mathrm{Na2CO3(g)} \\
\text { (grams) }\end{array}$ & $\begin{array}{l}\text { Water (mL) } \\
\text { (mL) }\end{array}$ & $\begin{array}{l}\text { Lid? } \\
\text { Y(N) }\end{array}$ \\
\hline $17-A-1$ & 20.0117 & 2.5005 & 2.5015 & 0.2489 & 0.0581 & & 2.5046 & & $Y$ \\
\hline $17-A-2$ & 20.0063 & 2.5000 & 2.5076 & 0.1278 & 0.0628 & & 2.5028 & & $\dot{Y}$ \\
\hline $21-A-1$ & 19.9970 & 2.4994 & 2.5078 & 0.2922 & 0.0696 & & 2.5094 & & $Y$ \\
\hline $21-A-2$ & 20.0040 & 2.5028 & 2.5033 & 0.3383 & 0.0735 & & 2.5100 & & Y \\
\hline $17-B-1$ & 20.0211 & 2.5059 & 2.4998 & 0.1261 & 0.0763 & & 2.5013 & 2.00 & $\dot{y}$ \\
\hline $17-B-2$ & 20.0004 & 2.5285 & 2.5078 & 0.2506 & 0.0543 & & 2.5303 & 2.00 & $Y$ \\
\hline $17-B-3$ & 20.0033 & 2.5160 & 2.5174 & 0.3801 & 0.0582 & & 2.5050 & 2.00 & $\dot{Y}$ \\
\hline $17-C-1$ & 20.0002 & 2.5023 & 2.4986 & & & 0.2529 & 2.5095 & & $\dot{Y}$ \\
\hline $17-C-2$ & 20.0000 & 2.5042 & 2.5178 & & & 0.5013 & 2.4968 & & $\dot{Y}$ \\
\hline $17-C-3$ & 20.0051 & 2.5260 & 2.5155 & & & 0.7535 & 2.5424 & & $\dot{Y}$ \\
\hline $13-D-1$ & . 19.9700 & 2.4900 & 2.5200 & & & 0.2526 & 2.5228 & 2.00 & $Y$ \\
\hline $13-D-3$ & 18.9500 & 2.5300 & 2.5000 & & & 0.7484 & 2.5700 & 2.00 & $\dot{Y}$ \\
\hline 21-D-1 & 20.0128 & 2.5050 & 2.5157 & & & 0.2496 & 2.5181 & 2.00 & $\dot{Y}$ \\
\hline $21-D-2$ & 20.0060 & 2.5197 & 2.5018 & & & 0.3936 & 2.5032 & 2.00 & $\dot{Y}$ \\
\hline $21-D-3$ & 20.0014 & 2.5113 & 2.5006 & & & 0.8127 & 2.5055 & 2.00 & $\dot{Y}$ \\
\hline 17-E-1 & 20.0000 & 2.5566 & 2.5162 & 0.1242 & 0.0743 & & 2.5477 & & $\dot{N}$ \\
\hline 17-E-2 & 18.8814 & 2.5236 & 2.5021 & 0.2500 & 0.0625 & & 2.4840 & & $\ddot{N}$ \\
\hline 17-E-3 & 20.0250 & 2.5024 & 2.4934 & 0.3772 & 0.0543 & & 2.5050 & & $N$ \\
\hline 13-F-1 & 20.0400 & 2.5100 & 2.5200 & & & 0.2502 & 2.5369 & & $N$ \\
\hline $13-F-2$ & 20.0200 & 2.5100 & 2.5000 & & & 0.5029 & 2.5651 & & $N$ \\
\hline $13-F-3$ & 20.0000 & 2.5400 & 2.5100 & & & 0.7541 & 2.5808 & & $N$ \\
\hline $13-G$ & 20.0000 & 2.5200 & 2.5100 & & & & 2.5000 & & $\dot{Y}$ \\
\hline
\end{tabular}


Both of these samples formed a homogeneous glass. Sample 13-D-2 contained 0.5039 grams of resin. This was anomalous because sample 13-D-3 which had a higher resin loading was processed at the same time and formed a homogeneous glass. Three additional tests were performed using both higher and lower resin loadings. Two of the samples, 21-D-1 and 21-D-2, had lower resin loadings and one sample, 21-D-3, had a higher loading. All three of these samples formed homogeneous glasses. It was not immediately clear why these two crucible mixtures failed to form a glass.

After powdering the glasses to approximately 100 mesh in an agate ball mill, the glass samples exhibited colors dependent on their final redox state. Glasses which had low $\mathrm{Fe}(\mathrm{II}) / \mathrm{Fe}($ total) ratios or were less reduced were yellow in color. Glasses which had higher ratios or were more reduced were green in color. For example, crucible 13-G which had no reducing agent addition was bright yellow. Crucibles such as 21-D-3 which had high reducing agent loadings were medium to dark green.

\section{Redox Ratio}

The final average redox values for each crucible as indicated by the $\mathrm{Fe}(\mathrm{II}) / \mathrm{Fe}$ (total) ratio are listed in Table VI. The values shown represent the average of at least two analyses performed at Clemson University and one analysis performed at SRS. The analysis provided by SRS served to check the Clemson values for accuracy. They were not used in the following correlations. Seven crucibles warranted an additional analysis because the first two analyses did not provide similar results. In these cases, all four values were averaged for the final result. In all cases, the SRS experimental values correlated well with the average Clemson University experimental values.

Equations were developed to correlate the redox results from the crucible study with the parameters which could affect the final redox state of the glass. These 
Table VI

Final Fe(II)/Fe(total) Values for Phase I Crucible Tests

\begin{tabular}{ccc}
\hline \hline Crucible & $\begin{array}{c}\text { Clemson University } \\
\text { Fe(II)/Fe(total) }\end{array}$ & $\begin{array}{c}\text { SRS Analysis } \\
\text { Fe(II)/Fe(total) }\end{array}$ \\
\hline $17-A-1$ & 0.675 & 0.722 \\
$17-A-2$ & 0.427 & 0.436 \\
$17-A-3$ & Did not form glass & Did not form glass \\
$17-B-1$ & 0.377 & 0.380 \\
$17-B-2$ & 0.603 & 0.599 \\
$17-B-3$ & 0.775 & 0.833 \\
$17-C-1$ & 0.244 & 0.250 \\
$17-C-2$ & 0.382 & 0.391 \\
$17-C-3$ & 0.427 & 0.502 \\
$13-D-1$ & 0.279 & 0.276 \\
$13-D-2$ & Did not form glass \\
$13-D-3$ & 0.549 & 0.558 \\
$17-E-1$ & 0.044 & 0.022 \\
$17-E-2$ & 0.050 & 0.051 \\
$17-E-3$ & 0.374 & 0.378 \\
$13-F-1$ & 0.088 & 0.073 \\
$13-F-2$ & 0.206 & 0.180 \\
$13-F-3$ & 0.273 & 0.293 \\
$13-G$ & 0.055 & 0.022 \\
$21-A-1$ & 0.686 & 0.658 \\
$21-A-2$ & 0.682 & 0.722 \\
$21-D-1$ & 0.202 & 0.204 \\
$21-D-2$ & 0.262 & 0.326 \\
$21-D-3$ & 0.515 & 0.574 \\
& & \\
& &
\end{tabular}

parameters included the type and amount of resin, the presence of water, and the presence of a lid.

The correlation based on the entire set of crucibles $\left(R^{2}=0.92\right)$ was determined to be,

$$
\mathrm{Fe}(\mathrm{II}) / \mathrm{Fe}(\text { total })=(1.28 * \mathrm{C})+(0.343 * \mathrm{R})+(0.0292 * W)+(0.159 * \mathrm{~L})
$$

and for only the sealed crucibles $\left(R^{2}=0.96\right)$ 


$$
\mathrm{Fe}(\mathrm{II}) / \mathrm{Fe}(\text { total })=(2.10 * \mathrm{C})+(0.530 * \mathrm{R})+(0.0255 * \mathrm{~W})
$$

where $C$ is the grams of carbon, $R$ is the grams of resin, $W$ is the $m L$ of water, and $L$ is the type of environment. A value of 1 was given to $L$ if a lid was used and 0 if there was no lid. The data for the set of unsealed crucibles were limited and did not generate an accurate correlation when analyzed separately.

The relative reducing ability of the two type of reducing agents can be calculated from the two correlations based on the ratio of their coefficients. In the correlation relating the entire set of crucibles the ratio of the carbon coefficient to the resin coefficient is approximately 3.7. This indicates that 1 gram of carbon and 3.7 grams of resin have the same capability as reducing agents under similar circumstances. For the correlation limited to the sealed crucibles, the ratio of the coefficients is closer to 4.0.

Since there was not a quantitative value that could be placed on whether the crucible environment was sealed or open, a value of 1 was used in determining the correlation if the environment was sealed and a value of 0 was used if the environment was open. This value system basically turns the variable on and off. The magnitude of this coefficient indicates that a difference of approximately 0.159 in the respective $\mathrm{Fe}(\mathrm{II}) / \mathrm{Fe}$ (total) ratios should be seen between two glass samples processed under otherwise identical conditions. This difference becomes significant when the $\mathrm{Fe}(I 1) / \mathrm{Fe}$ (total) ratio of 0.33 which SRS uses to define an acceptable glass is considered (Ramsey, 1991).

Since varying amounts of water were not used, the correlation is not meant to predict the result either qualitatively or quantitatively if more or less than $2 \mathrm{~mL}$ of water are used. Thus, the only comparisons that can be made involving water are those which compare $0 \mathrm{~mL}$ of water with $2 \mathrm{~mL}$ of water. Although there are not enough data 
to support any quantitative conclusions involving water, it seems that since the coefficient for water is positive, the presence of water hinders the reoxidation of the glass rather than assisting as an oxygen donor. This hindrance is only minor, however, since the magnitude of the coefficient for water is so small in relation to the other coefficients and the SRS guidelines for an acceptable glass.

A graphical comparison of the predicted $\mathrm{Fe}(11) / \mathrm{Fe}$ (total) redox ratios and the observed experimental values based on these correlations for the entire set of crucible data and the set of sealed crucibles are shown in Figures 5 and 6 respectively. An additional $45^{\circ}$ line has been added which represents a 100 percent correlation between the predicted redox ratios and the observed experimental results.

Figure 7 shows the effect of reducing agent loading on the final redox state of the glass as indicated by the $\mathrm{Fe}(\mathrm{II}) / \mathrm{Fe}$ (total) ratio. Since the same mass of resin and carbon behave differently and a slightly different amount of glass resulted in each crucible, the ratio of the coefficients in the correlation relating the entire set of crucibles was used to "normalize" the masses of reducing agents. The ratio used was 3.7. The normalization was performed by multiplying the masses of carbon in those crucibles with carbon as the reducing agent by the coefficient ratio. This normalized value is essentially the mass of reducing agent as resin. This value was then divided by the predicted mass of glass based on the crucible materials to get the mass of reducing agent as resin per gram of glass. It is apparent that the sealed crucibles follow a somewhat linear trend. The open crucible, on the other hand, do not follow any sort of trend and are therefore difficult to correlate.

Based on weight percentages given by Bibler (1991), the empirical formula for the organic portion of the resin is $\mathrm{C}_{2.96} \mathrm{H}_{5.80} \mathrm{O}_{2.84}$. Using this formula and assuming that the carbon combustion reaction proceeds 100 percent towards carbon dioxide $\left(\mathrm{CO}_{2}\right)$ and that the hydrogen combustion proceeds 100 percent towards water $\left(\mathrm{H}_{2} \mathrm{O}\right)$, the theoretical chemical oxygen demand can be calculated as 


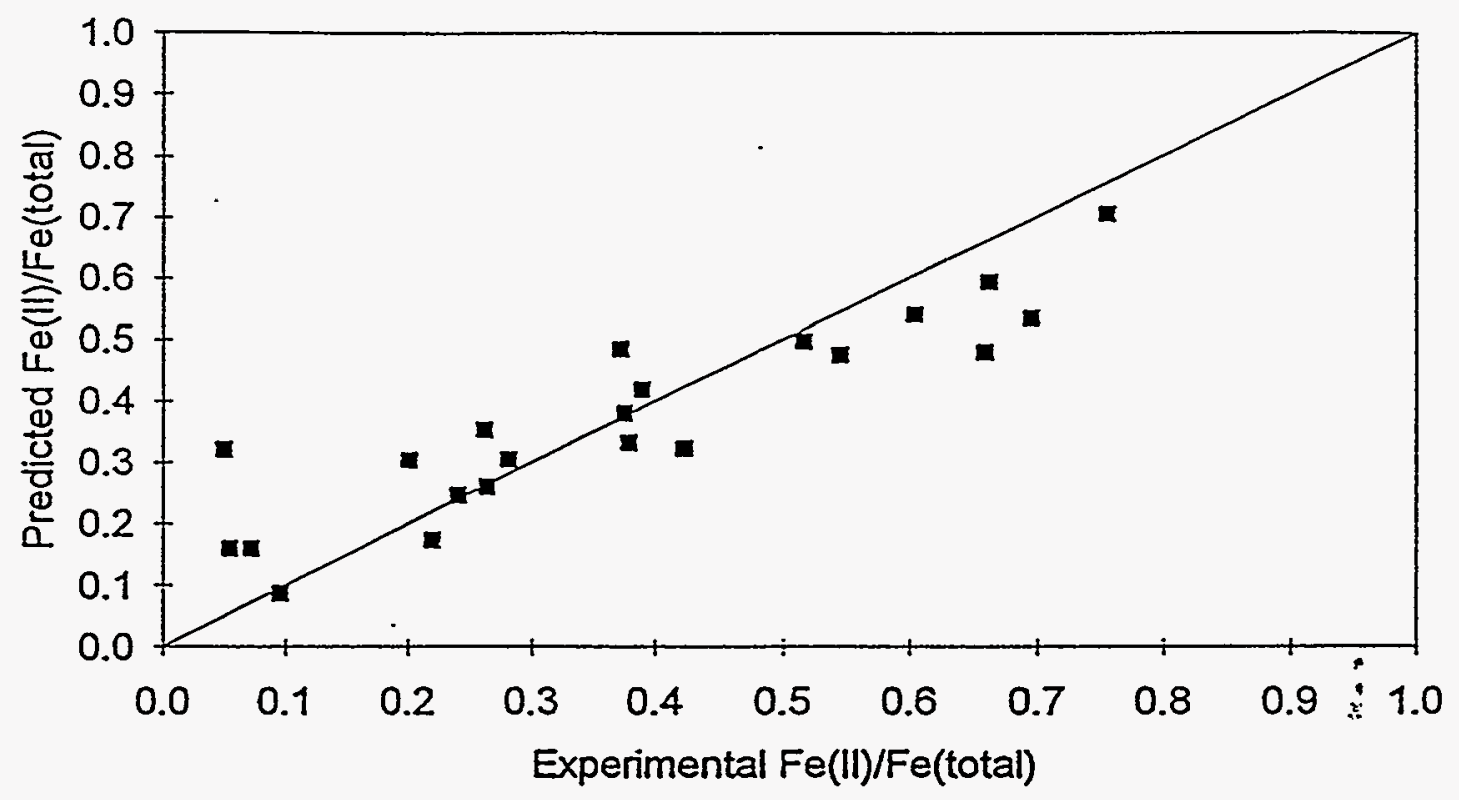

Figure 5. Comparison of Experimental Values with Predicted Values for the Entire Set of Crucibles in Phase I. Note: The solid line indicates perfect correlation.

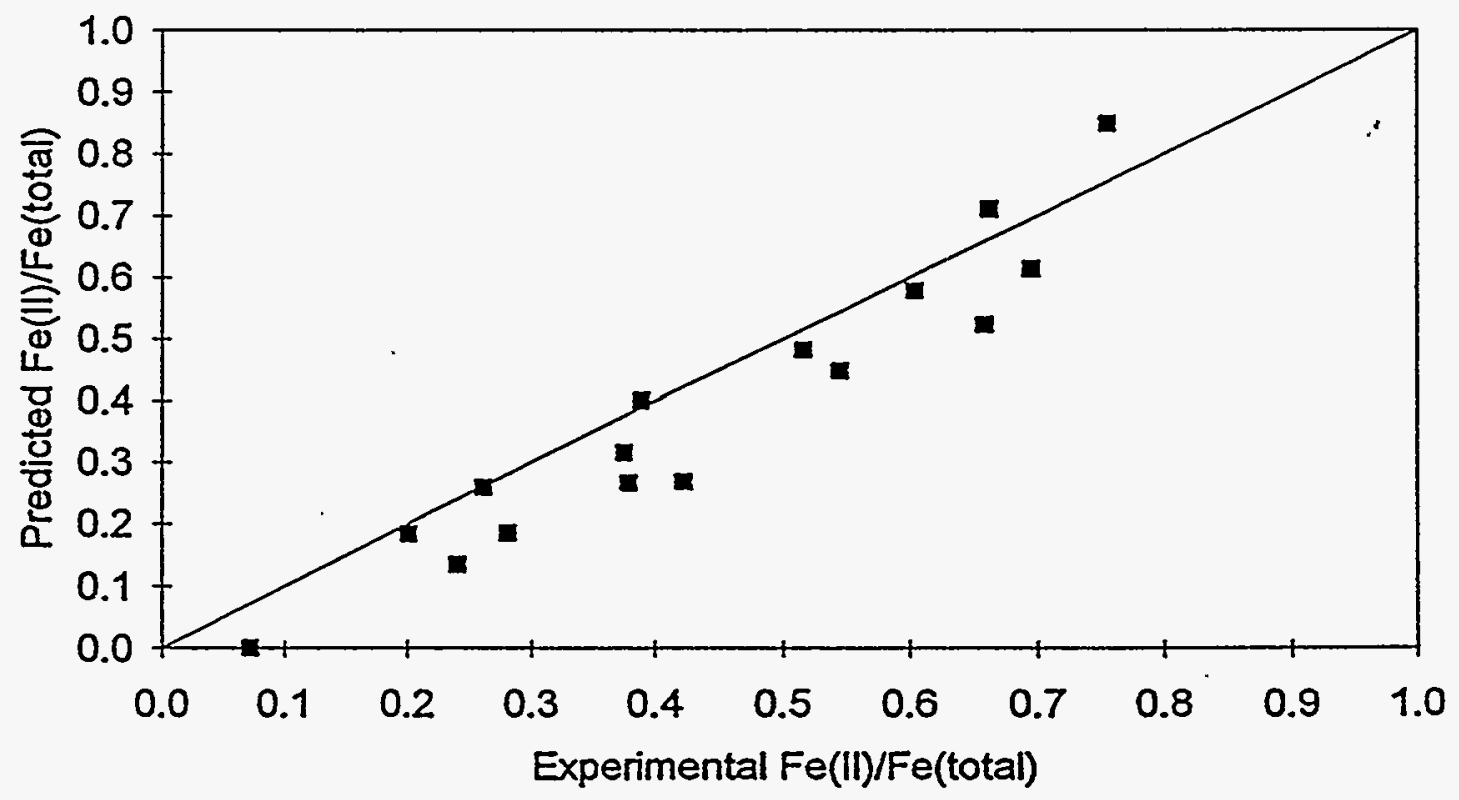

Figure 6. Comparison of Experimental Values with Predicted Values for the Sealed Set of Crucibles in Phase I. Note: The solid line indicates perfect correlation. 
2.99 moles $\mathrm{O}_{2} / 100$ grams resin. This value takes into account the existing oxygen in the resin molecule and ignores any oxygen demand attributed to the potassium, cesium, or sodium present as exchangeable elemental cations in the resin. If 100 grams of carbon are combusted and the same assumptions apply, the chemical oxygen demand is 8.33 moles $\mathrm{O}_{2} / 100$ grams carbon. Thus, the theoretical ratio of reducing effectiveness of carbon to resin can be calculated as 8.33 divided by 2.99 , or 2.79. This ratio is very similar to the experimental values of approximately 3.7 and 4.0 calculated earlier based on the crucible study correlations. If the combustion reactions of the resin were more correctly assumed to proceed 100 percent towards $\mathrm{CO}$, the theoretical chemical oxygen demand decreases to 1.51 moles $\mathrm{O}_{2} / 100$ grams of resin. In this case, the theoretical ratio of reducing effectiveness of carbon to resin can be calculated as 8.33 divided by 1.51 , or 5.52 . It is probable that during these crucible tests, the combustion of carbon did not proceed 100 percent towards either $\mathrm{CO}_{2}$ or $\mathrm{CO}$ indicating the theoretical ratios compare well with the experimental values.

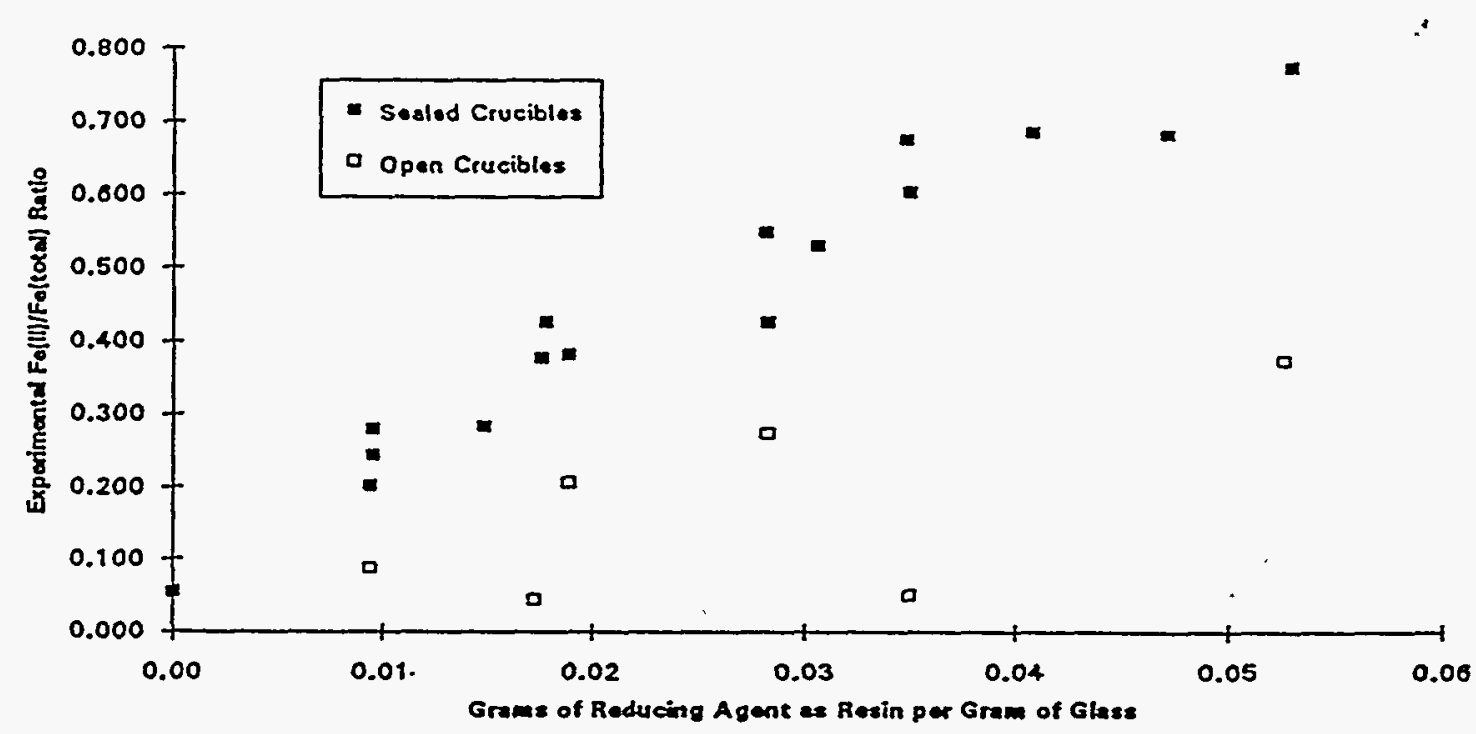

Figure 7. Correlation Between Grams of Reducing Agent as Resin and Final $\mathrm{Fe}($ II)/Fe(total) Ratio in Glass for Entire Set of Crucibles 
The crucible data can also give an early indication for the maximum level of resin loading in the glass that is operationally feasible. Preliminary assessments by SRS indicate a $\mathrm{Fe}(\mathrm{II}) / \mathrm{Fe}$ (total) of 0.33 in a glass as a maximum value to prevent nickel sulfide precipitation in the melter (Ramsey, 1991). These crucible studies indicate the organic loading giving this ratio is approximately 0.32 grams of reducing agent as carbon or 1.26 grams of reducing agent as resin per 100 grams of glass in a sealed environment. For the unsealed set of crucibles, the ratio increases to approximately 4.91 grams of reducing agent as resin or 1.23 grams of reducing agent as carbon per 100 grams of glass.

\section{Cesium Content}

Each crucible glass was intentionally loaded with one of two forms of nonradioactive cesium based on the type of organic material. The resin was preloaded with resin by SRS at a mass ratio of 0.16 grams of cesium per gram of dry resin. Those crucibles which used carbon as their reducing agent were spiked with cesium carbonate. The predicted cesium oxide weight percent was calculated based on the initial composition of raw chemicals. This value was compared to the experimental value to determine the retention of cesium in the crucible glass.

Table VII lists the final $\mathrm{Cs}_{2} \mathrm{O}$ weight percent in each crucible along with the predicted weight percent based on the initial composition of raw chemicals and the calculated cesium retention in the glass. The average cesium retention for the crucibles utilizing carbon as the reducing agent was 66.8 percent with a standard deviation of 4.9 percent. The average cesium retention for the crucibles utilizing resin as the reducing agent was 88.6 percent with a standard deviation of 6.6 percent. Thus, cesium retention was favored with the resin over that of the cesium carbonate, i.e., the intimate mixing of the cesium with the organic resin did not increase cesium volatility. 
Final redox ratio and mass of reducing agent did not seem to influence cesium retention.

Table VII

Cesium Retention in Phase I Crucible Study

\begin{tabular}{ccccccc}
\hline \hline $\begin{array}{c}\text { Crucible } \\
\text { ID }\end{array}$ & $\begin{array}{c}\text { Type of } \\
\text { Reducing Agent }\end{array}$ & $\begin{array}{c}\text { Predicted } \\
\text { (wt\% Cs20) }\end{array}$ & $\begin{array}{c}\text { Experimental } \\
\text { (wt\% Cs2O) }\end{array}$ & $\begin{array}{c}\text { Cs } \\
\text { Retention }\end{array}$ & $\begin{array}{c}\text { Final } \\
\text { Fe(II)/Fe(total) }\end{array}$ & $\begin{array}{c}\text { Reducing Agent } \\
\text { (grams) }\end{array}$ \\
\hline $17-C-2$ & Resin & $0.32 \%$ & $0.31 \%$ & $97.57 \%$ & 0.382 & 0.5013 \\
$13-D-3$ & Resin & $0.48 \%$ & $0.46 \%$ & $97.13 \%$ & 0.549 & 0.7484 \\
$13-D-1$ & Resin & $0.16 \%$ & $0.15 \%$ & $95.11 \%$ & 0.279 & 0.2526 \\
$17-C-3$ & Resin & $0.48 \%$ & $0.45 \%$ & $93.74 \%$ & 0.427 & 0.7535 \\
$17-C-1$ & Resin & $0.16 \%$ & $0.15 \%$ & $90.54 \%$ & 0.244 & 0.2529 \\
$13-F-1$ & Resin & $0.16 \%$ & $0.14 \%$ & $87.90 \%$ & 0.088 & 0.2502 \\
$13-F-3$ & Resin & $0.48 \%$ & $0.41 \%$ & $85.25 \%$ & 0.273 & 0.7541 \\
$13-F-2$ & Resin & $0.32 \%$ & $0.27 \%$ & $84.87 \%$ & 0.206 & 0.5029 \\
$21-D-1$ & Resin & $0.16 \%$ & $0.13 \%$ & $81.95 \%$ & 0.202 & 0.2496 \\
$21-D-2$ & Resin & $0.25 \%$ & $0.20 \%$ & $81.31 \%$ & 0.262 & 0.3936 \\
$21-D-3$ & Resin & $0.52 \%$ & $0.41 \%$ & $79.31 \%$ & 0.515 & 0.8127 \\
$17-E-3$ & Carbon & $0.18 \%$ & $0.13 \%$ & $72.60 \%$ & 0.374 & 0.3772 \\
$17-B-3$ & Carbon & $0.19 \%$ & $0.14 \%$ & $72.59 \%$ & 0.775 & 0.3801 \\
$17-E-1$ & Carbon & $0.24 \%$ & $0.17 \%$ & $70.26 \%$ & 0.044 & 0.1242 \\
$17-E-2$ & Carbon & $0.20 \%$ & $0.14 \%$ & $69.37 \%$ & 0.050 & 0.2500 \\
$21-A-1$ & Carbon & $0.23 \%$ & $0.16 \%$ & $69.02 \%$ & 0.686 & 0.2922 \\
$21-A-2$ & Carbon & $0.24 \%$ & $0.16 \%$ & $68.07 \%$ & 0.582 & 0.3383 \\
$17-B-2$ & Carbon & $0.18 \%$ & $0.11 \%$ & $63.35 \%$ & 0.603 & 0.2506 \\
$17-A-2$ & Carbon & $0.20 \%$ & $0.13 \%$ & $61.60 \%$ & 0.427 & 0.1278 \\
$17-B-1$ & Carbon & $0.25 \%$ & $0.15 \%$ & $61.51 \%$ & 0.377 & 0.1261 \\
$17-A-1$ & Carbon & $0.19 \%$ & $0.11 \%$ & $59.38 \%$ & 0.675 & 0.2489 \\
$13-G$ & None & $0.00 \%$ & $<0.0040 \%$ & Not Calc. & 0.055 & 0.0000 \\
\hline
\end{tabular}

\section{Phase 11: Establishing Operational Parameters}

The operating parameters chosen for the operational matrix in Phase II are critical in determining the success of a melter operation based on trials performed before this research. The melter temperature can establish the melt rate which in tum can determine the maximum feed rate. The impeller speed combined with the impeller height can influence the oxygen transfer rate as well as how rapidly the feed components are incorporated into the melt. The maximum slurry feed rate is a result of the chosen operating parameters. It is generally wise to set the operating parameters 
in order to maximize this rate. The air feed rate can influence the oxygen transfer rate but may hinder the success of a melter operation by lowering the melter temperature or increasing the volatilization of metals or entrainment of particulate matter.

\section{Operational Parameters}

Some of the operating parameters such as air sparger flowrate and auxiliary temperature varied during the Phase II work did not significantly influence the success of the melter operation. Some of the parameters, however, such as slurry feed rate and melter temperature were important in determining the operational stability of, the melter. The final melter operational settings chosen based on the 16 trials are listed in Table VIIl.

Table VIII

Phase II Final Operating Conditions

\begin{tabular}{cc}
\hline Parameter & Value \\
\hline Melter Temperature & 1070 degrees Celsius \\
Slumy Feed Rate & $50 \mathrm{~mL}$ min \\
Impeller Height & 4 inches \\
Impeller Speed & $405 \mathrm{rpm}$ \\
Auxiliary Temperature & 1055 degrees Celsius \\
Air Sparger Flowrate & $>800 \mathrm{~mL} / \mathrm{min} @$ STP \\
\hline
\end{tabular}

\section{Melter Temperature}

The operating temperatures of the melter were limited by the limits on the materials of construction. The upper limit of the inconel 601 was approximately $1070^{\circ} \mathrm{C}$ (Bickford, 1994). Based on previous melter operation, the lowest melter temperature which allowed acceptable melter operations was $1050^{\circ} \mathrm{C}$. This range was 
not large enough to provide a great deal of operational differences between the low and the high temperatures. The higher operational temperatures did, however, show some noticeable improvements in prevention of the formation of a cold cap. Impeller Speed and Height

The impeller speed was measured in $\mathrm{Hertz}(\mathrm{Hz})$ and converted to revolutions per minute (rpm) based on a correlation provided by the melter manufacturer. The impeller height was measured from the bottom of the vessel to the lower edge of the impeller blades. One restriction on the height of the impeller was that the blades must remain completely submerged in the molten glass in order to maintain the lowest current density across the impeller blades. If the blades are only partially submerged, the full amount of current is passed through a smaller area (the submerged area) and can increase the deterioration of the impeller. Therefore, in order to maintain an impeller height at 6 inches, for example, the additional glass height due to foaming would need to be the same height as the impeller blades, or approximately 2.25 inches. In a condition where the glass height was 6 inches (no foaming, full tank), the maximum impeller height would be approximately 3.75 inches measured from the bottom of the impeller to the bottom of the tank.

The impeller speed and height were important in determining the effectiveness of the vortex action in drawing the feed down into the melt. The relationship between the speed and height is an inverse relationship. If the impeller speed is increased, the impeller height must be decreased to prevent the exposure of the impeller within the vortex. If the impeller speed is decreased, the impeller height must be increased to create an effective vortex at the melt surface. During these trials, it was. not possible to set the impeller at heights above 4 inches measured from the bottom of the blades to the bottom of the vessel for extended periods of time because the molten level including glass and foam was not consistently over 6.25 inches. Since the impeller 
blades have a height of approximately 2.25 inches, it was necessary to maintain a molten level including glass and foam of at least 6.25 inches in order to completely cover the impeller blades. The final set of operational values set the impeller height at approximately 4 inches and the impeller speed at $25 \mathrm{~Hz}$ or $405 \mathrm{rpm}$.

\section{Air Sparger Feed Rate}

Nitrogen was used during Phase ll testing of the air sparger to test the influence of a separate gas stream on the operational feasibility of the melter system. There were no noticeable differences in melter operations at different gas flow settings. Under normal operating conditions, either oxygen or compressed air would be ușed as the sparging gas to assist in the combustion of the organic materials. The same results were expected for oxygen or compressed air that were found for nitrogen. The highest flow rate tested in Phase 11 was $800 \mathrm{~mL} /$ minute.

\section{Slumy Feed Rate}

The slurry feed rate was the most important of the five operating parameters in determining the melter operating stability. The three flowrates chosen in the initial matrix were too high for successful operation of the melter. Either the melt rate of the feed or the rate which feed was drawn down into the glass melt was too small to allow for successful operation of the melter. During the final refining trials, the feed rate was set at $50 \mathrm{~mL}$ slurry/minute or the equivalent of $1.36 \mathrm{~kg} / \mathrm{hour}$ of glass. This flowrate could be maintained continuously without operator assistance. In addition to problems associated with the melt rate and the incorporation of the feed into the melt, higher flowrates seemed to lead to periodic extreme foaming. Lower flowrates did not produce these foaming instances.

\section{Observation Categories}

The qualitative observations recorded during Phase II trials primarily fell into three categories. These categories were the formation of a cold cap, melter output, and 
foaming. Each of these categories was directly related to the successful operation of the melter.

\section{Formation of a Cold Cap}

The prevention of the formation of a cold cap was the most important category of observations. The melter occasionally developed a layer of unmelted feed on the surface. This occurred if the vortex action of the impeller was not sufficient to draw the feed contents under the melt surface or the melt rate was inadequate. Occasionally a cold cap would begin to form and then disperse without operator assistance. These instances were usually attributed to insufficient vortex action. If the cause of the cold cap formation was more severe such as grossly insufficient vortex action or a too high slurry feeding rate, a very sturdy cold cap layer was created. This layer was able to support the incoming slumy and would eventually cover the entire molten surface. Since one of the primary reasons for testing the stirred tank melter was to prevent the resin from forming a crust, it was necessary to change the operating conditions to prevent the slurry from forming a cold cap.

\section{Foaming}

Foaming is generally caused by the release of water vapor and other gases such as carbon dioxide from the melt. During these trials, the foaming was attributed primarily to the steam released from within the melt as water was pulled below the surface and also from combustion gases formed due to the addition of the small amounts of organic compounds in the feed. During Phase II operation, the melter exhibited periodic instances of extreme foaming. These instances generally occurred if the melter temperature dropped well below the setpoint and the joule heating circuit was forced on at high amperage. The foaming would quickly subside if the power to the joule heating circuit was tumed off. It was unclear as to the exact cause of these instances. Lower feed rates generally resulted in fewer occasions of extreme foaming. 


\section{Melter Output}

The overflow spout drain in the WV-0.25 was designed to allow for a steady output of glass as long as the molten glass level was above $15.24 \mathrm{~cm}$ (6. in). However, since the operating temperature is limited in the WV-0.25 melter and the drain diameter is so small, it was easy for the glass to cool as it traveled downward through the exit pipe of the melter. This sometimes caused a "nesting" effect, small strands of glass collecting on top of each other within the drainpipe, which led to clogging of the drain hole. It was therefore necessary from an operational standpoint to be able to operate the melter so that a steady stream exited the melter. In order to maintain a steady pull from the overflow drain, it was necessary to heat the lower two inches of the drain tube with a propane burner. The drain tube heating system effectively heated the entire drain tube except for these bottom few inches. There were no problems with maintaining a steady output from the melter when the propane burner was used as long as the feed system was operating properly as well. In cases of high slurry feed rates, the melter was unable to provide enough power to sufficiently melt all of the incoming slurry and therefore the melter pull or output rate was less than the expected based on the feed rate.

\section{Phase III: Oxygen Transfer Tests}

There were two types of oxygen transfer tests performed during the Phase III research. The first type was a batch type test. This type of test involved filling the melter with a known amount of glass containing a known amount of iron and then reducing the glass by adding a reducing agent such as carbon. Samples were then taken over the next several hours and analyzed for the $\mathrm{Fe}(1 \mathrm{l}) / \mathrm{Fe}$ (total) ratio. Two of these tests were performed with different operational conditions. Both tests used impeller agitation to assist in oxygen transfer. During one of the tests, water was fed to the melter during the course of the run. The second type of test was a continuous feed 
test. This test closely resembled operational conditions. Slurry was fed to the melter at approximately $50 \mathrm{~mL} / \mathrm{min}$ and reducing agent was added to the melt in order to increase the $\mathrm{Fe}(I I) / \mathrm{Fe}$ (total) ratio. Samples were taken over the next several hours and analyzed for the $\mathrm{Fe}(\mathrm{II}) / \mathrm{Fe}$ (total) ratio. A zirconium oxide redox probe was also used during this test to continuously measure the redox state of the glass.

It is assumed that the oxygen transfer rate can be approximated by the rate of oxidation of $\mathrm{FeO}$. This means that oxygen transfer rates can be estimated by observing the change in the $\mathrm{Fe}(\mathrm{II}) / \mathrm{Fe}$ (total) ratio and knowing the total amount of iron in the melt. In other words, the change from $\mathrm{FeO}$ to $\mathrm{Fe}_{2} \mathrm{O}_{3}$ uses the following : stoichiometry:

$$
4 \mathrm{FeO}+\mathrm{O}_{2} \rightarrow 2 \mathrm{Fe}_{2} \mathrm{O}_{3}
$$

Thus, the number of moles of oxygen entering the melt can be approximated by multiplying the moles of iron in the melt that change from $\mathrm{Fe}(\mathrm{II})$ to $\mathrm{Fe}$ (III) by the stoichiometric ratio of $\mathrm{Fe}(\mathrm{II})$ to $\mathrm{O}_{2}$ equal to 0.25 .

\section{Recovery Curve During Batch Test}

Data from the first batch type test that used only impeller agitation to assist in oxygen transfer is illustrated in Figure 8. A relatively weak $\left(R^{2}=0.76\right)$ equation describes this curve linearly. This equation is

$$
y=0.00230 \cdot t+1.400
$$

where $y$ is the moles of oxygen in the melt existing as $\mathrm{Fe}_{2} \mathrm{O}_{3}$ and $t$ is the elapsed time in minutes. 
This equation gives an approximation of the oxygen transfer rate as 0.00230 moles $\mathrm{O}_{2}$ per minute with the impeller running at approximately $405 \mathrm{rpm}$ and at a height of 2.25 inches from the bottom of the vessel.

In order to calculate the feed rate of resin which this oxygen transfer rate could accommodate, it is simpler to first look at carbon. The combustion of carbon follows the stoichiometry

$$
\mathrm{C}+\mathrm{O}_{2} \rightarrow \mathrm{CO}_{2}
$$

Thus, an oxygen transfer rate of 0.0023 moles $\mathrm{O}_{2} /$ min could accommodate 0.0023 moles $\mathrm{C} / \mathrm{min}$ or 0.0276 grams $\mathrm{C} / \mathrm{min}$. Since it was conclucled from Phase I research that approximately 4 grams of resin behaved the same as 1 gram of carbon, a resin flow rate of 0.1104 grams resin/min could be accommodated under these test conditions.

Data from the second batch test that used a combination of impeller agitation and water feed is illustrated in Figure 9. A stronger linear fit $\left(R^{2}=0.97\right)$ describes this curve. The linear equation is

$$
y=0.00153 * t+2.04
$$

where $y$ is the moles of oxygen in the melt existing as $\mathrm{Fe}_{2} \mathrm{O}_{3}$ and $t$ is the elapsed time in minutes. This equation gives an approximation of the oxygen transfer rate as 0.00153 moles $\mathrm{O}_{2}$ /minute. Using the same procedure as above, the equivalent flow rate of resin is $0.0734 \mathrm{grams}$ resin/min under otherwise similar test conditions.

The oxygen transfer rate was lower in the second batch test. The only difference between the two tests was the addition of the water stream. As seen in the crucible studies, the presence of water seemed to hinder the reoxidation of the melt. As 
mentioned earlier, it is not possible to make any definite conclusions concerning the effect of water on the redox state of a glass melt based on the amount of relevant data.

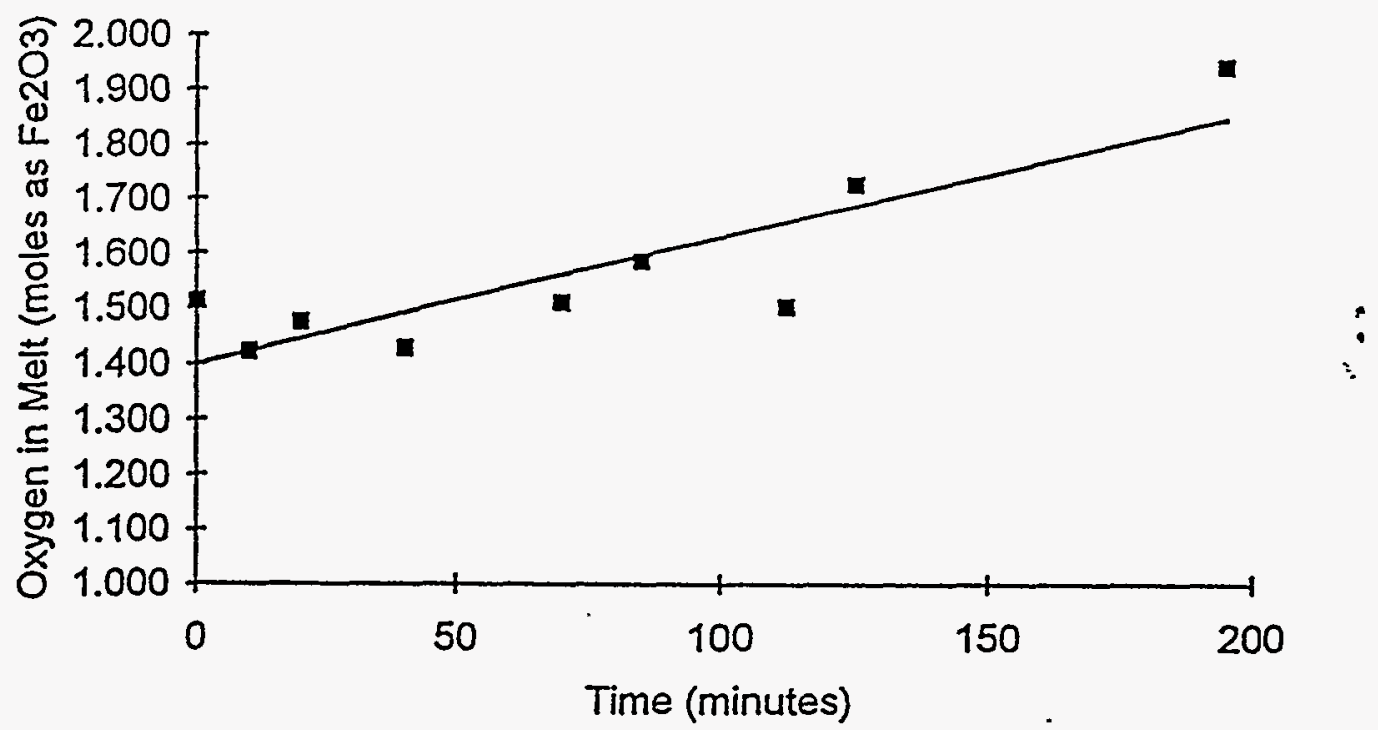

Figure 8. Recovery Curve for Phase III Batch Test One

Recovery Curve During Continuous Slurry Feed Test

The continuous feed test was performed in order to evaluate the oxygen transfer when slurry was being continuously fed to the melter which more closely resembled normal operating conditions. In addition to sampling exit glass for $\mathrm{Fe}(I I) / \mathrm{Fe}($ total) to evaluate the oxidation of $\mathrm{FeO}$, a zirconium oxide redox probe was used to continuously monitor the redox state of the glass.

After the full 300 grams of resin had been added batch style to the melt to reduce the $\mathrm{Fe}_{2} \mathrm{O}_{3}$ to $\mathrm{FeO}$, the melt was allowed to reoxidize. During the last 55 minutes of recovery, it was found that the $\mathrm{Fe}(\mathrm{II} / \mathrm{Fe}$ (total) ratio increased linearly. A linear equation $\left(R^{2}=0.98\right)$ can be used to describe the final 55 minutes of data shown in Figure 10. This equation is 


$$
y=0.00956 * t+2.54
$$

where $y$ is the moles of oxygen in melt existing as $\mathrm{Fe}_{2} \mathrm{O}_{3}$ and $t$ is the elapsed time in minutes. The approximate oxygen transfer rate under these test conditions was 0.00956 moles $\mathrm{O}_{2} / \mathrm{min}$. This oxygen transfer rate would accommodate a resin feed rate of 0.459 grams of resin/minute.

\section{Phase IV: Vitrification of lon Exchange Resin}

$\therefore$

A mixture of nonradioactive cesium-contaminated resin and the slumy described earlier in Chapter 4 composed of frit 202, metal oxide sludge, and PHA material was fed to the melter for 20 hours or the equivalent of roughly 3.1 tank volumes throughput. During the course of the run, samples of feed, exit glass, bubbler tank solution, and scrubber solution were taken in order to approximate a cesium mass balance on the melter and to determine the effect of the resin feed on the redox state of the glass. Samples of the off gas were also taken using a modified method 5 train and a multiple metals sampling train in order to characterize the off gas with respect to any semivolatile organic compounds present as products of incomplete combustion, volatile metals, and particulate matter.

\section{Overall Cesium Mass Balance}

A mass balance on cesium was performed around the melter system. This balance involved the feed stream, the exit glass, and the off gas. It covered the entire 20 hours (1385 minutes) of run time.

The following sections explain how each stream was analyzed for the total cesium content. 


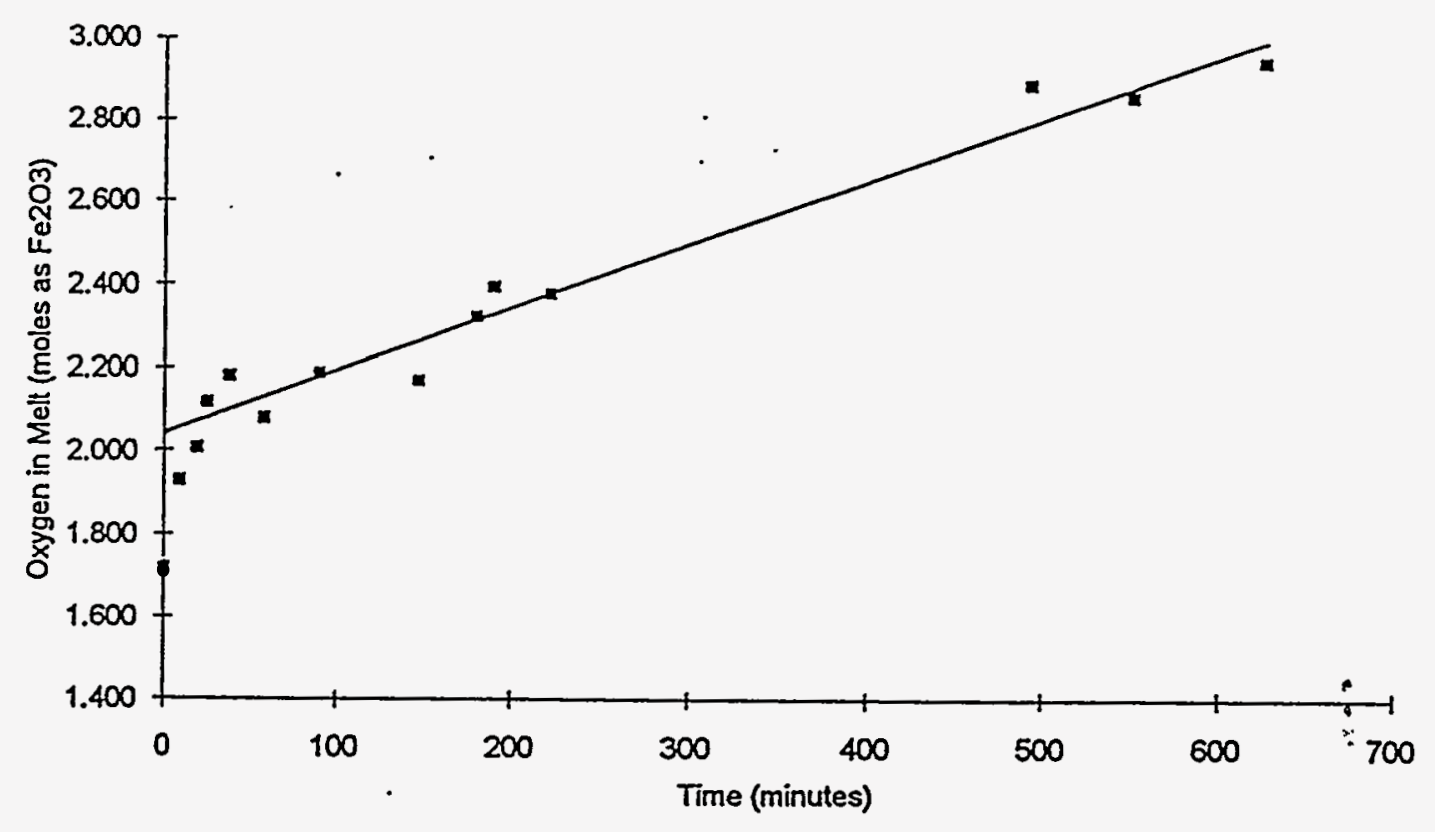

Figure 9. Recovery Curve for Phase III Batch Test Two

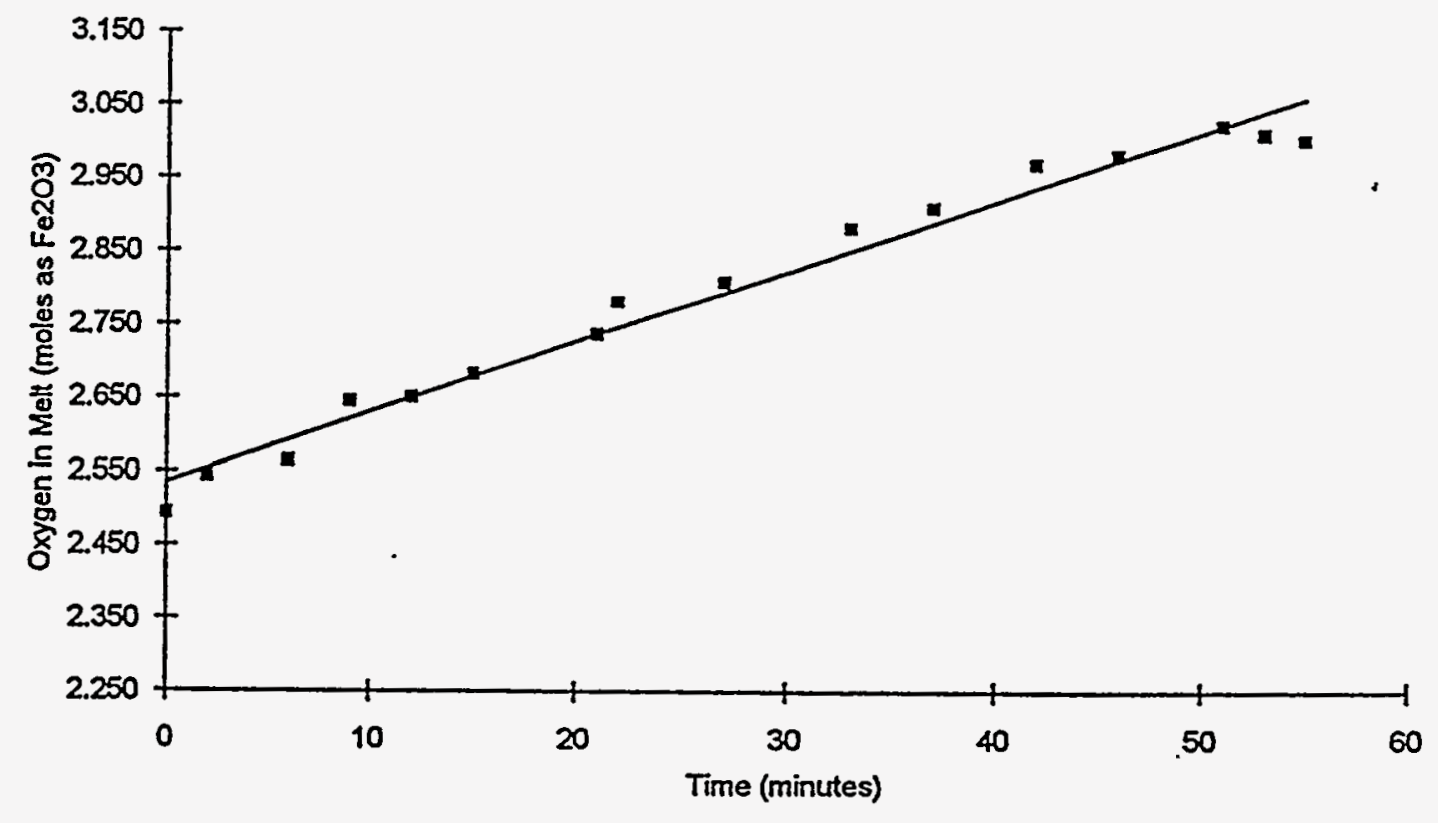

Figure 10. Recovery Curve for Phase III Continuous Feed Test 


\section{Feed Stream}

The feed slurry mixture was prepared in a 5 gallon bucket during the course of the run. When the slurry level dropped in the bucket, more of the resin and slurry mixture was added in the same ratio as existed in the initial batch. This ratio was approximately 1.302 grams of wet resin per $50 \mathrm{~mL}$ of slurry. Duplicate samples were taken from the initial batch and the final batch mixtures. The samples were taken as the slumy was pumped from the slurry feed nozzle so they would be an accurate representation of what was actually being fed to the melter.

The samples taken at the beginning and at the end of the test were analyzed by CELS for certain oxides and loss on ignition (LOI) at $850^{\circ} \mathrm{C}$. The results of thes: analyses are shown in Table IX. It is apparent from the results that the composition of the slurry being fed to the melter changed over the course of the run. Based on the predicted composition of the mixture, the weight percent of $\mathrm{Cs}_{2} \mathrm{O}$ in the dry slurry solids should be approximately. $0.396 \mathrm{wt} \%$. Neither of the sample analyses reflect this predicted amount. One possible reason why the initial results are much lower than the predicted results could reflect the method of analysis by CELS. Each sludge sample was dried at $850^{\circ} \mathrm{C}$. The high volatility at this drying temperature could result in a lower measured weight percent. One possible reason why the measured weight percent of cesium in the final sample analysis is much higher than the predicted amount is inadequate mixing in the bucket. Each of the measured oxide weight percents in the final slurry increase from the initial sample analysis result except silicon, magnesium, lithium, and boron. These are 4 of the 5 oxides which constitute frit 202. Sodium is the other oxide in the frit but it is also present in large amounts in the PHA material and the oxide sludge so a decrease in frit 202 would not significantly affect the final weight percent of sodium. Since no evidence of settling was seen during the Phase IV operation by visual inspection or by probing the bottom of the bucket with a rod, no corrective action was taken during the test. 
In addition to the oxide analysis and LOI test, a semi-quantitative inspection was done on the glass to determine why the oxide weight percentages did not equal 100 percent. This type of chemical analysis gives weight percentage ranges for each oxide. The results of this analysis are shown in Table $X$. It appears that the oxides of titanium, lead, copper, and zirconium which were not analyzed for by CELS probably make up the difference between the sum of the weight percentages and 100 percent.

In order to calculate the total amount of cesium fed to the melter, the total amount of cesium used in making up all of the slurry/resin batches for the full 20 hours and the amount of cesium remaining in the bucket after the test was complete must be known. The difference between these two values is the total amount of cesium fed to the melter. The total amount of wet resin used in making the slurry and resin mixture was 2036 grams. Based on the resin being $38.40 \%$ solids and loaded with cesium at a mass ratio of 0.16 to 1 , the total amount of cesium used in making the entire amount of feed mixture was 125.09 grams. The full 125.09 grams of cesium was not fed to the melter, however, because there was $20.18 \mathrm{~kg}$ of feed mixture remaining in the bucket after the testing was complete. The amount of cesium remaining in the bucket after testing was completed is difficult to accurately define because the CELS oxide analysis results do not agree with what would be predicted based on the quantities of resin and slurry used in making the batch. Both the predicted value for the weight percent of $\mathrm{Cs}_{2} \mathrm{O}$ in the final slumy and the final CELS analysis value were used in the cesium mass balance calculations to provide a cesium retention range. If the calculations are done based on the predicted $0.396 w \% \mathrm{Cs}_{2} \mathrm{O}$ in the residual feed mixture and an LOI of 64.75 percent, the total amount of cesium which remained in the bucket was 25.26 grams. Therefore, the total amount of cesium fed to the melter is calculated as 99.83 grams. If the CELS analysis value of 0.550 wt\% $\mathrm{Cs}_{2} \mathrm{O}$ is used in the same calculation, the total amount of cesium which remained in the bucket was 35.08 grams. This results in a total amount of cesium fed to the melter of 88.18 grams. 
Table IX

Phase IV CELS Feed Analysis Results

\begin{tabular}{ccc}
\hline Oxide & $\begin{array}{c}\text { Ánalysis of } \begin{array}{c}\text { Onitial Sample } \\
(w t \%)\end{array} \\
\text { Analysis of Final Sample } \\
(w+\%)\end{array}$ \\
\hline $\mathrm{Cs}$ & 0.26 & 0.55 \\
$\mathrm{~K}$ & 2.39 & 2.90 \\
$\mathrm{Li}$ & 4.85 & 4.50 \\
$\mathrm{Na}$ & 6.46 & 6.54 \\
$\mathrm{Al}$ & 2.95 & 3.35 \\
$\mathrm{~B}$ & 7.77 & 7.60 \\
$\mathrm{Ca}$ & 1.02 & 1.26 \\
$\mathrm{Cr}$ & 0.13 & 0.16 \\
$\mathrm{Fe}$ & 12.05 & 14.20 \\
$\mathrm{Mg}$ & 1.55 & 1.48 \\
$\mathrm{Mn}$ & 2.63 & 3.12 \\
$\mathrm{Ni}$ & 1.11 & 1.30 \\
$\mathrm{Si}$ & 54.35 & 50.75 \\
TOTAL & 97.51 & 97.68 \\
Loss on lgnition & $63.00 \%$ & $66.50 \%$ \\
\hline
\end{tabular}

Table $X$

Phase IV Semi-Quantitative Analysis of Feed

\begin{tabular}{cc}
\hline Range (wt\%) & Element \\
\hline$>30$ & $\mathrm{Fe}, \mathrm{Si}$ \\
$10-30$ & $\mathrm{Al}, \mathrm{Na}$ \\
$3-10$ & $\mathrm{~B}, \mathrm{~K}, \mathrm{Mg}, \mathrm{Mn}$ \\
$1-3$ & $\mathrm{Ca}, \mathrm{Cu}, \mathrm{Ni}, \mathrm{Zr}$ \\
$.3-1$ & $\mathrm{~Pb}, \mathrm{Ti}$ \\
$.1-.3$ & $\mathrm{Ba}, \mathrm{Cr}$ \\
$.03-.1$ & $\mathrm{Sr}$ \\
$.01-.03$ & $\mathrm{Mo}$ \\
$.003-.01$ & \\
$.001-.003$ & $\mathrm{Ag}$ \\
$<0.001$ &
\end{tabular}




\section{Glass Stream}

The glass was collected in large graphite crucibles during the course of the run. Samples of the exit glass were collected on a stainless steel plate approximately every thirty minutes. Four of the glass samples were sent to CELS for oxide analysis. Table $\mathrm{XI}$ shows the final analysis results. As seen in Figure 11, the temporal changes in cesium concentration resemble what would be expected in a continuously stirred tank reactor (CSTR).

In order to calculate the total amount of cesium retained in the glass, it is necessary to know the average weight percent of $\mathrm{Cs}_{2} \mathrm{O}$ in the glass collected in the crucibles and also the weight percent of $\mathrm{Cs}_{2} \mathrm{O}$ in the glass remaining in the vessel after the run was completed. The sum of the cesium in the collected glass and the glass remaining in the crucible is the total cesium retained in the glass.

The total amount of cesium in the glass collected in the crucibles can be calculated by dividing the area of the curve in Figure 11 by the total run time to get an average concentration. A second order polynomial was used as a basis in order to calculate the area. This polynomial was

$$
C=-1.427 E-07 t^{2}+4.47 E-04 t+2.19 E-04
$$

where $\mathrm{C}$ is the concentration in the exit glass in wt\% $\mathrm{Cs}_{2} \mathrm{O}$ and $\mathrm{t}$ is the time in minutes. If this curve is integrated from $t=0$ to $t=1385$ minutes, the area under the curve is calculated as $302.65 \mathrm{wt} \% \mathrm{Cs}_{2} \mathrm{O} \cdot \mathrm{min}$. If the area is divided by the total time, the result is the average concentration or $0.218 w t \% \mathrm{Cs}_{2} \mathrm{O}$. If the average concentration is multiplied by the total glass collected in the crucibles, the result is the total amount of $\mathrm{Cs}_{2} \mathrm{O}$ collected in the exit glass. Since the total amount of glass collected in the crucibles was $25.87 \mathrm{~kg}$, the total amount of cesium in the collected glass of 53.20 grams. 
The cesium in the glass remaining in the vessel after the testing was completed can be calculated by multiplying the final weight percent of $\mathrm{Cs}_{2} \mathrm{O}$ in the exit glass by the total amount of glass remaining in the vessel. Table XI shows the average last measured weight percentage of $\mathrm{Cs}_{2} \mathrm{O}$ to be 0.347 . The total amount of glass remaining in the vessel was $8.85 \mathrm{~kg}$ giving a total amount of cesium remaining in the vessel after the test was complete of 28.97 grams. The total amount of cesium retained in the glass is the sum of these two values or 82.17 grams. This is between 82.3 percent and 93.2 percent of the total cesium fed to the melter.

\section{Off Gas Deposits}

The off gas deposits were taken from the stainless steel piping immediately exiting the melter and the 2 inch riser. The deposits were dark brown to black in color and had the texture of fine soot. There were some very small yellow particles mixed in with the soot like material. A total of 12.70 grams of deposit were collected. The analysis of these solids provided by CELS is shown in Table XII. CELS also performed a semi-quantitative spectrographic analysis on the deposits. These results provided estimates of the oxide weight percent of all elements present in the sample. Five elements were not analyzed for in the quantitative analysis which showed up in : significant amounts in the semi-quantitative analysis. These elements were copper, zirconium, titanium, barium, and lead. Estimated weight percentages provided by CELS for these five oxides are also shown in Table XII.

A loss on ignition test at 850 degrees Celsius was performed on the solids collected from the bubbler solution. These solids were similar to the solids collected as deposits on the off gas piping in appearance. The average loss on ignition of these solids was 8.96 weight percent.

The sum of the weight percentages based on the quantitative analysis, the semiquantitative analysis and the loss on ignition using the bubbler solution solids was 98.0 
Table XI

Phase IV CELS Analysis of Exit Glass

Samples Taken at Different Times

\begin{tabular}{ccccc}
\hline wt\% oxide & 0 minutes & .627 minutes & 920 minutes & 1385 minutes \\
\hline $\mathrm{Cs}$ & 0.00 & 0.24 & 0.30 & 0.35 \\
$\mathrm{~K}$ & 2.43 & 2.70 & 2.76 & 2.76 \\
$\mathrm{Li}$ & 4.75 & 4.79 & 4.82 & 4.80 \\
$\mathrm{Na}$ & 6.69 & 6.69 & 6.73 & 6.76 \\
$\mathrm{Al}$ & 3.09 & 3.05 & 3.04 & 3.07 \\
$\mathrm{~B}$ & 7.90 & 7.75 & 7.76 & 7.80 \\
$\mathrm{Ca}$ & 1.70 & 1.24 & 1.23 & 1.24 \\
$\mathrm{Cr}$ & 0.19 & 0.17 & 0.17 & 0.17 \\
$\mathrm{Fe}$ & 12.00 & 12.25 & 12.50 & 12.57 \\
$\mathrm{Mg}$ & 1.56 & 1.53 & 1.56 & 1.56 \\
$\mathrm{Mn}$ & 2.64 & 2.74 & 2.80 & 2.80 \\
$\mathrm{Ni}$ & 1.15 & 1.18 & 1.20 & 1.21 \\
$\mathrm{Si}$ & 54.10 & 52.70 & 53.55 & 53.67 \\
Total & 98.19 & 97.01 & 98.38 & 98.73 \\
\hline
\end{tabular}

Note: The analysis results shown for 1385 minutes are the average of two analysis resuits.

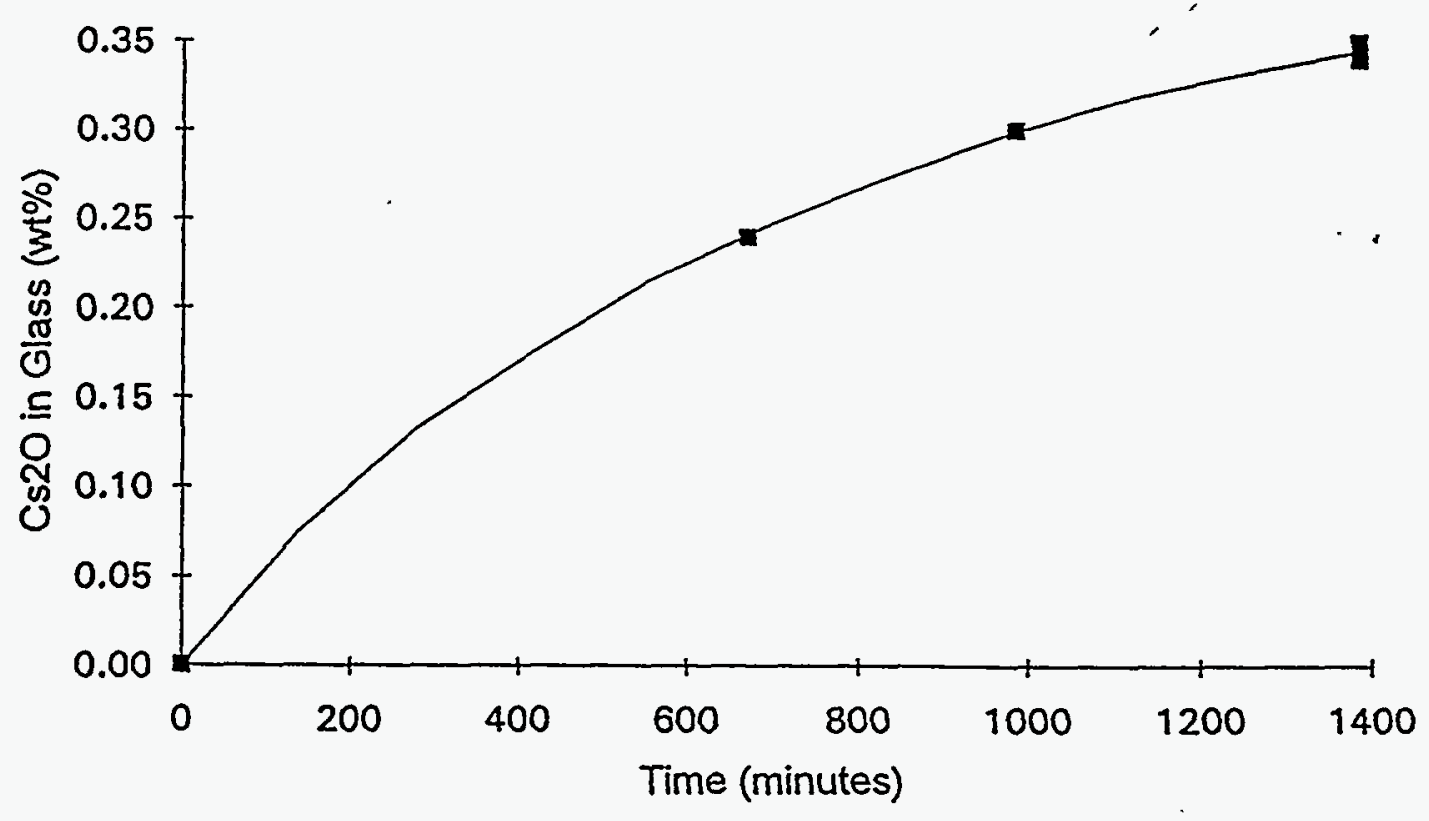

Figure 11. Phase IV CELS Analysis Results for $\mathrm{Cs}_{2} \mathrm{O}$ in Glass 
percent. Since estimates were used for copper, zirconium, titanium, barium, lead, and carbon, the 2.0 percent which is not accounted for based on these analyses is not significant.

Based on the CELS value for the weight percentage of $\mathrm{Cs}_{2} \mathrm{O}$ and the total mass of solids collected, the total amount of cesium existing in the off gas deposit is 0.14 grams. This is between 0.14 and 0.16 percent of the total cesium fed to the melter. Bubbler Solution

The purpose of the bubbler tank in combination with the venturi scrubber and spray quencher was to remove the larger particles from the off gas stream and also to $\mathrm{cool}$ the off gas stream enough to condense most of the volatile metals. Samples of the bubbler solution were taken from the liquid leaving the bubbler tank through the level controller. Four of these samples were filtered and sent to SRS for analysis. The results of the analyses are listed in Table XIII and shown graphically in Figure 12.

In order to calculate the amount of volatile cesium captured in the bubbler solution, it is necessary to know the total amount of cesium leaving the bubbler tank through the level controller and the total amount of cesium remaining in the bubbler tank after the testing was complete.

The total amount of cesium that was captured in the bubbler solution which exited the bubbler tank through the level controller can be calculated by multiplying the area of the curve in Figure 12 by the average flow rate. A second order polynomial was used as a basis in order to calculate the area. This polynomial was

$$
C=-1.157 E-06 t^{2}+3.192 E-03 t+4.763
$$

where $\mathrm{C}$ is the concentration in the exit bubbler solution in $\mathrm{mg} \mathrm{Cs} / \mathrm{L}$ and $\mathrm{t}$ is the time in minutes. If this curve is integrated from $t=0$ to $t=1385$ minutes, the area under the 
Table XII

Phase IV CELS Oxide Analysis, Semi-Quantitative Analysis, and Loss on Ignition Results of Off Gas Deposits

\begin{tabular}{cc}
\hline Oxide & $\begin{array}{c}\text { Final Analysis } \\
\text { wt\% as oxide }\end{array}$ \\
\hline $\mathrm{Cs}$ & 1.17 \\
$\mathrm{~K}$ & 6.49 \\
$\mathrm{Li}$ & 0.77 \\
$\mathrm{Na}$ & 7.25 \\
$\mathrm{Al}$ & 6.53 \\
$\mathrm{~B}$ & 7.67 \\
$\mathrm{Ca}$ & 3.00 \\
$\mathrm{Cr}$ & 0.61 \\
$\mathrm{Fe}$ & 32.10 \\
$\mathrm{Mg}$ & 0.50 \\
$\mathrm{Mn}$ & 6.82 \\
$\mathrm{Ni}$ & 2.89 \\
$\mathrm{Si}$ & 6.16 \\
$\mathrm{Cu}$ & $1.25(\mathrm{a})$ \\
$\mathrm{Zr}$ & $4.00(\mathrm{a})$ \\
$\mathrm{Ti}$ & $1.20(\mathrm{a})$ \\
$\mathrm{Ba}$ & $0.30(\mathrm{a})$ \\
$\mathrm{Pb}$ & $0.30(\mathrm{a})$ \\
$\mathrm{C}$ & $8.96(\mathrm{~b})$ \\
\hline
\end{tabular}

(a) - These results are estimated based on the semi-quantitative spectographic analysis provided by CELS

(b) - The result is based on a loss on ignition at 850 degrees

Celsius of the solids collected in the bubbler solution.

Table XIII

Phase IV SRS Results of Bubbler and Scrubber Solution Analyses for Cesium

\begin{tabular}{ccc}
\hline $\begin{array}{c}\text { Time } \\
\text { (minutes) }\end{array}$ & $\begin{array}{c}\text { Bubbler Solution } \\
\text { (mg Cs/L) }\end{array}$ & $\begin{array}{c}\text { Scrubber Solution } \\
\text { (mg Cs/L) }\end{array}$ \\
\hline 0 & 0.0046 & Not Detected \\
670 & 2.6942 & 0.2271 \\
1075 & 2.1131 & 0.4518 \\
1281 & 2.1617 & 0.5491 \\
1385 & 2.2278 & 0.6615 \\
\hline
\end{tabular}


curve is calculated as $2043.727 \mathrm{mg} \mathrm{Cs \bullet min/L.} \mathrm{Since} \mathrm{the} \mathrm{average} \mathrm{flowrate} \mathrm{of} \mathrm{bubbler}$ solution exiting the bubbler solution tank was approximately $0.916 \mathrm{~L} / \mathrm{min}$, the total amount of cesium in the exiting bubbler solution was 1.87 grams.

The cesium in the glass remaining in the vessel after the testing was completed can be calculated by multiplying the final concentration of cesium in the bubbler solution by the total amount of bubbler solution remaining in the tank. The final concentration of cesium in the bubbler solution was $2.23 \mathrm{mg} \mathrm{Cs} / \mathrm{L}$. The total amount of solution remaining in the tank was 91.77 liters giving a total amount of cesium remaining in the tank after the test was complete of 0.205 grams. The total amount of cesium captured in the bubbler solution is the sum of these two values or 2.07 grams. This is between 2.1 and 2.4 percent of the total cesium fed to the melter.

The particulate form of cesium captured in the off gas treatment system was not quantified. When the samples were being pulled from the level controller tube, there were small quantities of solids present in the solution. The total particulate cesium in the off gas was hard to accurately quantify for two primary reasons. First, the solids captured in the bubbler solution were not analyzed. Since there was a significant amount of solids present in the bubbler tank at the beginning of the run, it was felt that an analysis of these solids would not be valuable. Most of the solids were removed from the tank prior to the run but some residual solids remained. Second, the samples were not filtered immediately. The solids were allowed to settle in the sample container and cesium attached to the particulate could have desorbed into solution.

\section{Scrubber Column Solution}

Scrubber solution samples were taken from the solution immediately after it left the scrubber column. These samples had no visually detectable solids present. Four of these samples were sent to SRS for analysis. The results of these analyses are listed in Table XIIl and showed graphically in Figure 13. The total amount of cesium 
captured by the scrubber column solution can be calculated by multiplying the total volume of solution in the scrubber tank by the concentration of the solution after the run was completed. Based on a final scrubber solution volume of 325.4 liters and a final concentration of $0.662 \mathrm{mg} / \mathrm{L}$, the total cesium captured in the scrubber solution was 0.215 grams. This represents between 0.22 and 0.24 percent of the total cesium fed to the melter.

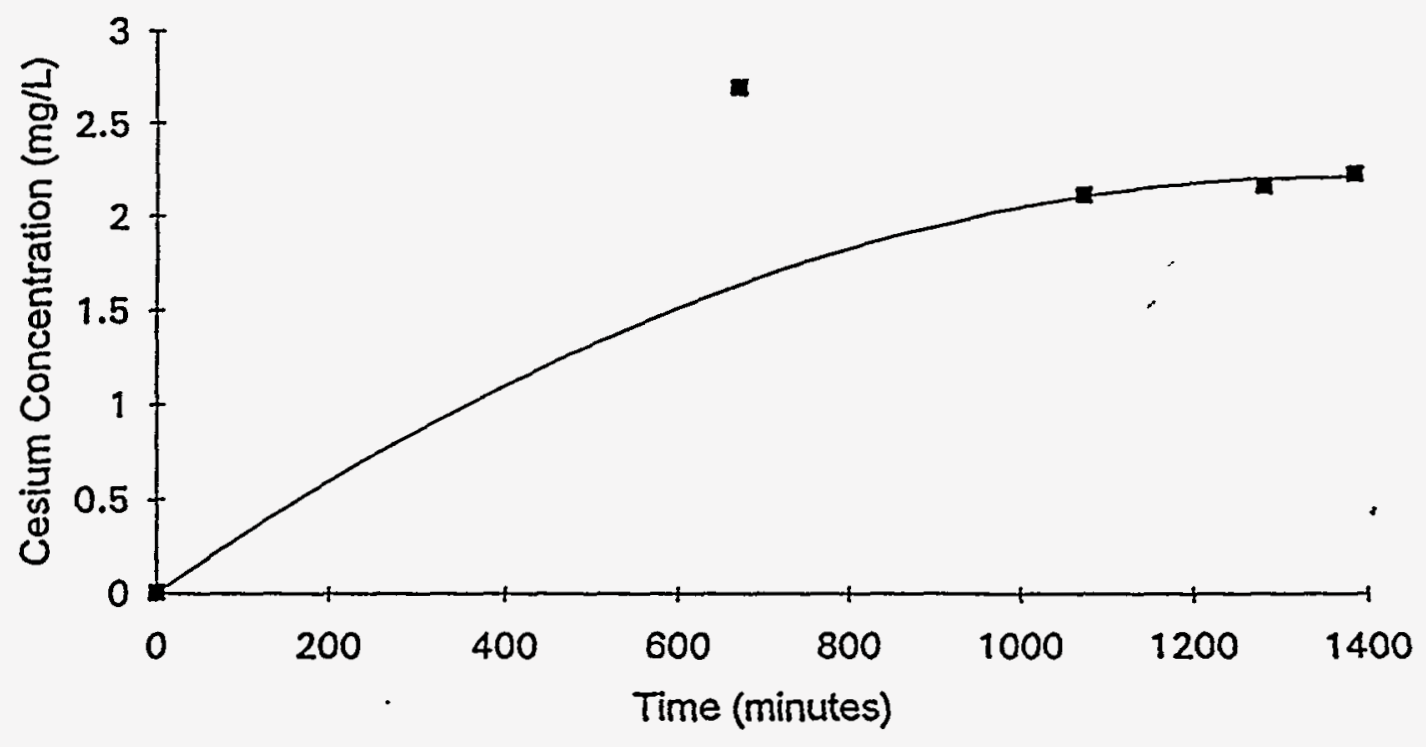

Figure 12. Phase IV Results from Bubbler Solution Analysis 


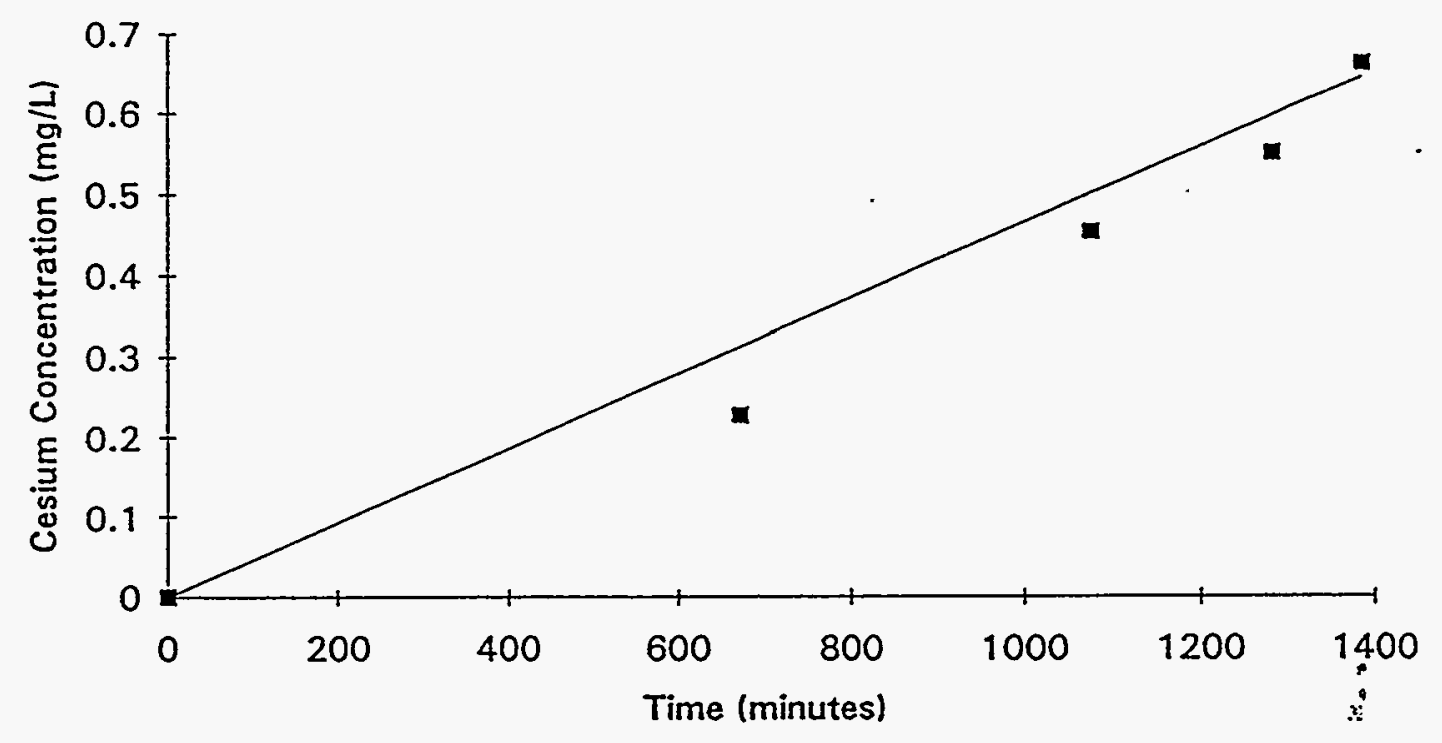

Figure 13. Phase IV Results from Scrubber Solution Analysis

Summary of Results from the Mass Balance

A summary of the results from the cesium mass balance is shówn in Table XIV. Between 84.7 and 96 percent of the cesium that entered the melter system was accounted for in the exit glass stream and the off gas treatment system. A cesium retention efficiency in the glass was calculated as between 82.3 and 93.2 percent. Between 2.4 and 2.8 percent of the cesium was found in the off gas treatment system.

There are several reasons for having a fraction of cesium unaccounted for in the mass balance. First, it was already mentioned that the calculations for the total amount of cesium fed to the melter were probably inaccurate because it was unclear on the total amount of cesium remaining in the bucket after the test was complete. Second, cesium present in the particulate form captured in the bubbler solution was not included. If the tank had been cleaned thoroughly before the test and samples could be filtered quickly, the results from this sampling could be valuable. Third, the underlying assumption that all of the cesium was captured in the off gas system has not 
been confirmed. It is possible that some of the cesium could have passed through the scrubber column and therefore not been included in the mass balance. Chapter 6 lists some of the recommendations which could possibly improve the accuracy of this type of analysis.

\section{Analysis of Off Gas}

The off gas stream was sampled for metals and semi-volatile organic compounds using a multiple metals sampling train and a modified method 5 sampling train, respectively. The field data sheet for each of these sampling runs is presented in Appendix B.

Table XIV

Phase IV Cesium Mass Balance Summary

\begin{tabular}{ccc}
\hline Location & Grams of Cesium & Percent of Total Cesium \\
\hline Feed Stream & $88.18-99.83$ & \\
Exit Glass & 82.17 & $82.3-93.2$ \\
Off Gas Deposits & 0.14 & $0.14-0.16$ \\
Bubbler Solution (Particulate) & Not Calculated & Not Calculated \\
Bubbler Solution (Nolatile) & 2.07 & $2.1-2.4$ \\
Scrubber Solution & 0.22 & $0.22-0.24$ \\
Unaccounted Cesium & $15.23-3.58$ & $4.00-15.24$ \\
\hline
\end{tabular}

\section{Multiple Metals Sampling Train}

The multiple metals sampling train was operated for one hour. It was run in accordance with the proposed method 29 with some minor additions. The two impingers normally containing a permanganate solution contained additional nitric acid and hydrogen peroxide. This was done since some of the metals which were sampled for were not on the list of metals for which the sampling train was designed. By adding the additional impingers at the end, the efficiency of removing the metals from the off gas was increased. The final two impingers were also analyzed separately from the 
first three impingers so the metals removed across the train of impingers could be seen by examining the concentration gradient.

During the multiple metals sampling run the feed stopped for approximately 10 minutes due to a blockage in the feed nozzle. This problem was corrected as quickly as possible but still significantly affected the results.

The total particulate loading was not performed on this sampling run because the samples of filter and front end washes were sent to the outside laboratory. The concentration of water vapor in the off gas stream was 71.0 grams per cubic meter at an average stack temperature of $636^{\circ} \mathrm{C}$. The sampling rate was approximately $y_{z} 130$ percent of isokinetic. This means that the average velocity pulled through the sample nozzle was 1.3 times the velocity of the off gas in the pipe.

The results from the analysis of the multiple metals sampling train components are shown in Table XV. These results are in total micrograms of a specific metal found in each component of the sampling train. It was practically impossible to make any quantitative conclusions based on this data because of the feeding problem. The analyses were divided into two main parts, the front end and the back end. The front end analysis involves a combined sample of the quartz filter, the acetone wash of the probe liner, nozzle, and filter bell inlet, and the nitric acid wash of the same three components. The back end analyses include the five impingers. The first impinger is a knock out impinger and serves to remove water from the sampled gas stream. The following four impingers contain a nitric acid/hydrogen peroxide mixture which serves to remove volatile metals from the sampled gas. The first, second, and third impingers were analyzed together. The fourth impinger and fifth impinger were each analyzed separately.

The front end and the last two impingers were not analyzed for silicon and boron. . : According to the laboratory which performed the analyses, conclusions concerning particulate silicon are almost impossible because of the silicon present in the quartz 
filter. Boron analyses are also difficult because much of the boron is lost through volatilization during the filter digestion step. The final two impingers were not analyzed for silicon and boron due to an ireversible mistake by the lab.

Some important qualitative observations can be made from the multiple metals sampling train analysis. First, the partitioning of the cesium shows that less than half of the cesium present in the off gas exists in the volatile form. Any quantitative observations drawn from the results of this analysis are inconclusive due to the feed system malfunction. Approximately 34 percent of the total cesium which was captured in the multiple metals sampling train was found in the impingers (volatile) rather than on the filter (particulate). Second, there were several other metals which partitioned significantly into the volatile form. Other elements which partitioned more than 10 percent in the volatile form include lead $(15.2 \%)$, chromium $(25.4 \%)$, sodium $(14.5 \%)$, calcium (10.7\%), lithium (15.0\%), and potassium (18.5\%).

The amount of volatile cesium collected in the volatile form in the bubbler and scrubber solutions can be roughly checked by the amount of volatile cesium collected in the Multiple Metals Sampling Train. The total amount of volatile cesium collected in one hour using the Multiple Metals Sampling Train was 2362 micrograms through a 0.375 inch diameter orifice. If this value is corrected to what passed through the 2 inch pipe, the approximate cesium flowrate is 0.0672 grams Cs per hour. Thus, during a trial lasting 1385 minutes, the total amount of volatile cesium that would be expected is 1.55 grams. The total amount of cesium in the bubbler and scrubber solution from Table XIV was 2.29 grams. Although these values are not identical and the amount captured is more than the amount predicted through a rough estimation, this comparison shows that the values calculated for the amount of volatile cesium in the bubbler and scrubber solutions is at least reasonable. 


\section{Modified Method 5 Sampling Train}

Table XVI lists the six predominant semi-volatile organic compounds found in the. off gas based on results from the modified method 5 sampling train analysis. They were benzoic acid $\left(\mathrm{C}_{6} \mathrm{H}_{5} \mathrm{CO}_{2} \mathrm{H}\right)$, naphthalene $\left(\mathrm{C}_{10} \mathrm{H}_{8}\right)$, phenanthrene $\left(\mathrm{C}_{14} \mathrm{H}_{10}\right)$, fluorene $\left(\mathrm{C}_{13} \mathrm{H}_{10}\right)$, fluoranthrene $\left(\mathrm{C}_{16} \mathrm{H}_{10}\right)$, and pyrene $\left(\mathrm{C}_{16} \mathrm{H}_{10}\right)$. Each of these are feasible since they are all based on an aromatic or ring structure. Since the resin is a polymer based on resorcinol which is also an aromatic, it makes sense that the major products of incomplete combustion would also be aromatics.

The modified method 5 sampling train also provided results for particulate loading calculations. The particulate loading was $433 \mathrm{mg}$ per cubic meter of off gas at an average temperature of $664^{\circ} \mathrm{C}$. The major components of these solids based on the analysis of the multiple metals sampling train solids and the off gas deposits were boron, iron, sodium, manganese, potassium, calcium, aluminum, and carbon.

The total mass of particulate captured in one hour of sampling through a 0.375 inch orifice was 0.5059 grams. If this value is corrected to what passed though the 2 inch pipe, the estimated total particulate emissions is 14.39 grams of particulate per hour. The slurry feed rate used during the trial was approximately $50 \mathrm{~mL} / \mathrm{min}$. . Assuming a specific gravity of 1.2 and an LOI of 64.75 percent, the solids feed rate into the melter was approximately 1215 grams per hour. Thus, the amount of particulate captured in the off gas accounts for approximately one percent of the total solids fed to the melter. 
Table XV

Phase IV Multiple Metals Sampling Train Results

\begin{tabular}{|c|c|c|c|c|c|c|}
\hline Element & $\begin{array}{l}\text { Front End } \\
\text { Wash Blank } \\
\text { (micrograms) }\end{array}$ & $\begin{array}{l}\text { Back End } \\
\text { Wash Blank } \\
\text { (micrograms) }\end{array}$ & $\begin{array}{l}\text { Front End } \\
\text { Analysis } \\
\text { (micrograms) }\end{array}$ & $\begin{array}{c}\text { Impingers } \\
1,2, \text { and } 3 \\
\text { (micrograms) }\end{array}$ & $\begin{array}{c}\text { Impinger } \\
4 \\
\text { (micrograms) }\end{array}$ & $\begin{array}{c}\text { Impinger } \\
5 \\
\text { (micrograms) }\end{array}$ \\
\hline Cesium & $<1.00$ & $<1.00$ & 4510 & 2020 & 174 & 167 \\
\hline Nickel & 1.79 & 2.11 & 7880 & 530 & 2.75 & 2.82 \\
\hline Silicon & NA & $N A$ & NA & 548 & NA & NA \\
\hline Lead & 1.49 & $<1.00$ & 1130 & 174 & 14.5 & 13.8 \\
\hline Barium & 4.86 & $<1.00$ & 601 & 57.5 & $<1.00$ & $<1.00$ \\
\hline Iron & 325 & 6.01 & 72200 & 4750 & 31.2 & 14.8 \\
\hline Manganese & 1.38 & $<1.00$ & 15000 & 1080 & 2.41 & 2.15 \\
\hline Magnesium & 10.3 & $<6.25$ & 788 & 62 & $<6.25$ & $<6.25$ \\
\hline Chromium & 1.4 & 5.4 & 395 & 113 & 10.9 & 10.6 \\
\hline Sodium & 128 & 18.7 & 22200 & 3280 & 283 & 223 \\
\hline Calcium & 47 & $<12.5$ & 3980 & 427 & 28.2 & .22 \\
\hline Aluminum & 100 & 6.21 & 8720 & 775 & 19 & 10 \\
\hline Lithium & $<1.00$ & $<1.00$ & 2370 & 381 & 20.6 & 19.3 \\
\hline Potassium & 32.5 & 16.5 & 23700 & 4700 & 342 & 332 \\
\hline Boron & $N A$ & NA & NA & 8320 & NA & NA \\
\hline
\end{tabular}

Table XVI

Phase IV Modified Method 5 Sampling Train Results

\begin{tabular}{cccc}
\hline Compound & $\begin{array}{c}\text { Analysis One } \\
\text { (micrograms) }\end{array}$ & $\begin{array}{c}\text { Analysis Two } \\
\text { (micrograms) }\end{array}$ & $\begin{array}{c}\text { Blank } \\
\text { (micrograms) }\end{array}$ \\
\hline Benzoic Acid & 348.87 & 304.73 & 17.36 \\
Napthalene & 297.44 & 495.30 & 5.14 \\
Fluorene & 11.65 & 9.50 & $(1.43)$ \\
Phenanthrene & 113.82 & 130.11 & $(1.07)$ \\
Fluoranthene & 52.50 & 71.87 & $(0.84)$ \\
Pyrene & 83.21 & 81.55 & $(0.90)$ \\
\hline
\end{tabular}

Note: Numbers in Parenthesis Indicate Detection Limit 


\section{Redox Ratio}

Samples of the glass were taken periodically from the exiting glass stream and analyzed for the $\mathrm{Fe}(\mathrm{II}) / \mathrm{Fe}$ (total) ratio. The results of this analysis are shown in Figure 14. Redox measurements using the zirconium oxide redox probe were also taken but did not correlate with the corresponding $\mathrm{Fe}(\mathrm{II}) / \mathrm{Fe}$ (total) ratio so these probe results were not used in the redox analysis. None of the samples analyzed exceeded 0.3 for the $\mathrm{Fe}(\mathrm{II}) / \mathrm{Fe}$ (total) ratio. The average $\mathrm{Fe}(\mathrm{II}) / \mathrm{Fe}$ (total) ratio after approximately one hour of operating time was 0.176 .

At a feed rate of 0.50 grams of dry resin per minute, it appears that there would be no significant problems associated with an over reduced melt.

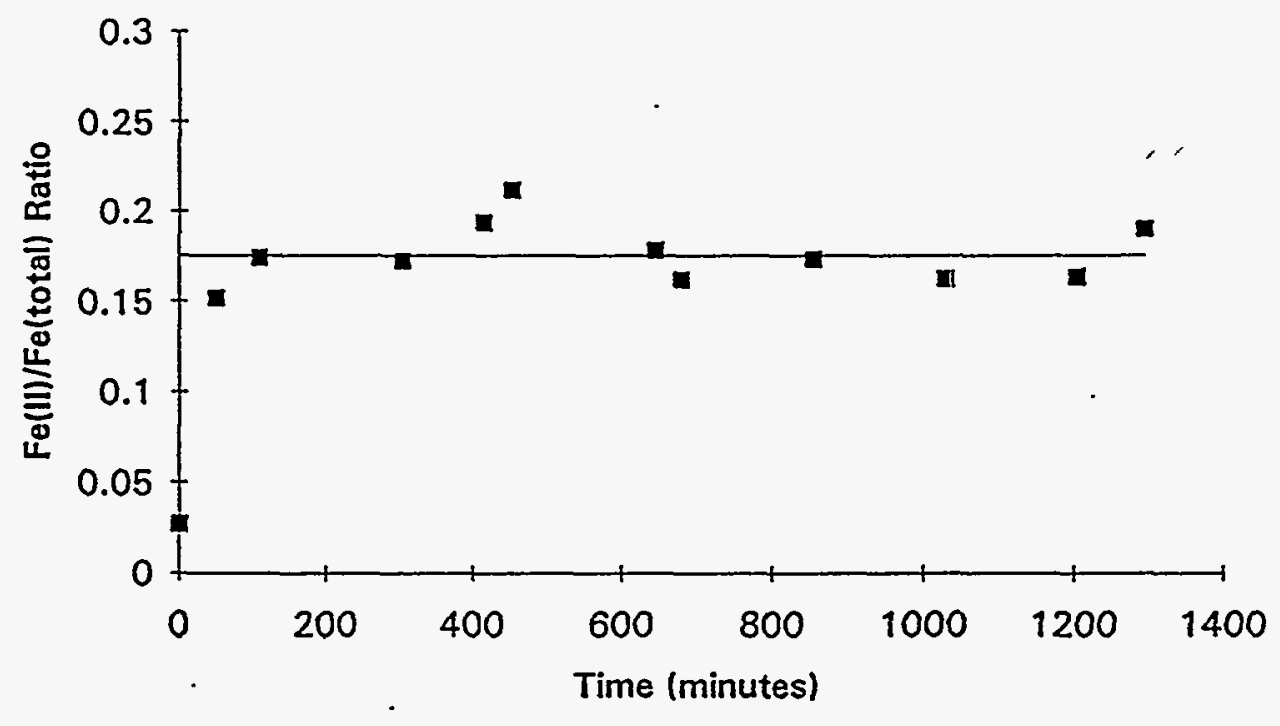

Figure 14. Phase IV Fe(II)/Fe(total) Ratio Results 


\section{CHAPTER 6}

\section{CONCLUSIONS AND RECOMMENDATIONS}

The following conclusions were reached after completing the four phases of research.

1. The reducing effectiveness of the organic resin used in this research is approximately four times less than elemental carbon on a mass basis.

2. During the crucible study, the average cesium retention for those : glass samples which had resin as a reducing agent was 88.6 percent with a standard deviation of 6.6 percent. The average cesium retention for those glass samples which had elemental carbon as a reducing agent and cesium added as cesium carbonate was 66.8 percent with a standard deviation of 4.9 percent.

3. There was no. apparent correlation between the final redox state of a glass and the cesium retention based on the crucible study data.

4. Based on the limited amount of data, the addition of watér seemed to result in a more reduced final glass sample.

5. A set of operating conditions which allowed for successful operation of the melter were defined. Slurry feed rate and melter temperature : were the two most important operational parameters in achieving successful melter operation.

6. The oxygen transfer rate under batch type conditions using only the impeller agitation was 0.0023 moles $\mathrm{O}_{2} /$ min for a $0.25 \mathrm{ft}^{2}$ melter. When water was fed to the melter under similar operating conditions, the oxygen transfer rate dropped to 0.00153 moles $\mathrm{O}_{2} / \mathrm{min}$ for a 0.25 $\mathrm{ft}^{2}$ melter.

7. The oxygen transfer rate with a slurry feed rate of $50 \mathrm{~mL} / \mathrm{min}$, an oxygen sparging rate of $1000 \mathrm{~mL} / \mathrm{min}$ at STP, and using impeller agitation was 0.00956 moles $\mathrm{O}_{2} / \mathrm{min}$. This is the equivalent of approximately 0.50 grams of dry resin/min.

8. During Phase IV, the melter was successfully operated for 20 hours using a feed mixture of slurry and resin contaminated with nonradioactive cesium. There were no significant operational problems during the course of the run. 
9. Between 82.3 and 93.2 percent of the cesium fed to the melter during Phase IV was retained in the glass. Between 4 and 15.5 percent of the cesium was unaccounted for in the mass balance.

10. There were six primary semi-volatile organic compounds found in the off gas sampling. They were benzoic acid, naphthalene, fluorene, phenanthrene, fluoranthene, and pyrene.

11. The multiple metals sampling train results were used as a qualitative check on the form, particulate or volatile, elements took in the off gas. Elements which were found to be at least 10 percent in the volatile form during the Phase IV experiment include lead (15.2\%), chromium $(25.4 \%)$, sodium (14.5\%), calcium (10.7\%), lithium (15.0\%), and potassium (18.5\%).

12. The particulate loading during the Phase $I V$ experiment was approximately $433 \mathrm{mg}$ per cubic meter of off gas at an average temperature of $664^{\circ} \mathrm{C}$. The primary elements found in these solids were carbon, boron, iron, sodium, manganese, potassium, calcium, and aluminum.

The following recommendations should also be considered when additional work is performed dealing with the vitrification of ion exchange resin or other organic compounds in a stirred tank melter.

1. The dilution air pulled through the off gas treatment system should be minimized in order to allow for accurate calculations of off gas components. Accurate off gas sampling results can assist in performing a mass balance.

2. More oxygen transfer tests should be performed in order to define a set of parameters which maximize the rate of oxygen transfer into the glass melt so that the corresponding feed rate of resin can also be maximized.

3. Another test similar to the Phase IV study should be performed for a longer period of time in order to assure steady-state operation.

4. Methods and equipment should be developed so that reproducible results can be acquired without having to send samples to a third party for analysis. This would eliminate any financial boundaries on the number of samples that can be analyzed and greatly increase the amount of data. 
5. Off gas sampling should be done at other locations along the off gas treatment system such as downstream from the scrubber and between the bubbler solution tank and the scrubber in order to calculate other values such as scrubber efficiencies.

6. Attempts should be made to incorporate a redox probe such as the one used in these experiments into all phases of research.

7. A better and more reliable feed system should be established which is able to feed the slurry and resin mixture homogeneously at metered rates. 
$\therefore:$

APPENDICES 


\section{Appendix A}

Sample Calibration Curve from $\mathrm{Fe}(\mathrm{II}) / \mathrm{Fe}$ (total)

Redox Analysis

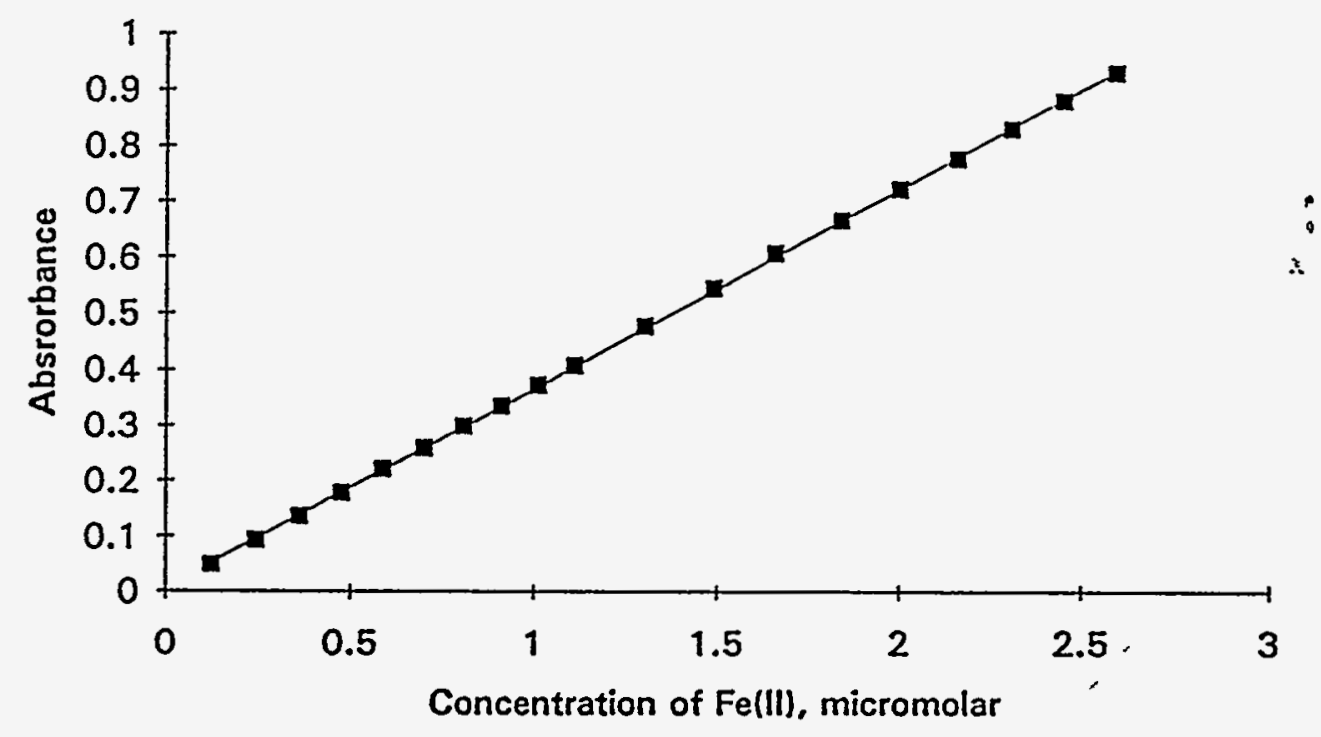

Figure A-1. Sample Calibration Curve from Fe(II)/Fe(total) Redox Analysis 
Appendix B

Field Data Sheets from Off Gas Sampling

\section{Table B-1}

Field Data Sheet for Multiple Metals Sampling Train

\begin{tabular}{cccccccccccc}
\hline \hline $\begin{array}{c}\text { Time } \\
\text { (min) }\end{array}$ & $\begin{array}{c}\text { Volume } \\
\text { (cub ft) }\end{array}$ & $\begin{array}{c}\text { Vacuum } \\
\text { (in } \mathrm{Hg} \text { ) }\end{array}$ & $\begin{array}{c}\text { Pitot del P } \\
\text { (in H2O) }\end{array}$ & $\begin{array}{c}\text { Orifice del P } \\
\text { (in H2O) }\end{array}$ & $\begin{array}{c}\text { Probe } T \\
\text { (F) }\end{array}$ & $\begin{array}{c}\text { Stack } T \\
\text { (F) }\end{array}$ & $\begin{array}{c}\text { Meter In } \\
\text { (F) }\end{array}$ & Meter Out & Filter T & Exit T \\
\hline 0 & 288.20 & 2.5 & 0.10 & 1.50 & 259 & 655 & 67 & 67 & 239 & 59 \\
5 & 292.39 & 2.5 & 0.10 & 1.50 & 251 & 640 & 71 & 67 & 246 & 53 \\
10 & 295.83 & 2.5 & 0.10 & 1.50 & 248 & 636 & 73 & 68 & 250 & 55 \\
15 & 299.30 & 2.5 & 0.10 & 1.50 & 250 & 632 & 76 & 68 & $250^{\circ}$ & 59 \\
20 & 302.80 & 3.5 & 0.10 & 1.60 & 248 & 635 & 77 & 68 & 250 & 59 \\
25 & 306.37 & 3.5 & 0.10 & 1.60 & 248 & 631 & 78 & 69 & 250 & 59 \\
30 & 309.92 & 3.5 & 0.10 & 1.60 & 250 & 625 & 79 & 69 & 250 & 59 \\
35 & 313.46 & 3.5 & 0.10 & 1.60 & 248 & 615 & 79 & 69 & 250 & 59 \\
40 & 316.93 & 3.5 & 0.10 & 1.50 & 247 & 618 & 79 & 69 & 250 & 58 \\
45 & 320.38 & 3.5 & 0.10 & 1.50 & 248 & 628 & 78 & 69 & 250 & 59 \\
50 & 324.00 & 3.5 & 0.10 & 1.50 & 247 & 642 & 78 & 69 & 250 & 58 \\
55 & 327.19 & 3.5 & 0.10 & 1.50 & 248 & 667 & 78 & 69 & 250 & 57 \\
60 & 330.63 & 3.3 & 0.10 & 1.50 & 250 & 651 & 77 & 69 & 250 & 57 \\
\hline
\end{tabular}

Table B-II

Field Data Sheet for Modified Method 5 Sampling Train

\begin{tabular}{|c|c|c|c|c|c|c|c|c|c|c|}
\hline $\begin{array}{l}\text { Time } \\
(\min ) \\
\end{array}$ & $\begin{array}{l}\text { Volume } \\
\text { (cub ft) }\end{array}$ & $\begin{array}{l}\text { Vacuum } \\
\text { (in } \mathrm{Hg} \text { ) }\end{array}$ & $\begin{array}{l}\text { Pitot del P } \\
\text { (in } \mathrm{H2O} \text { ) }\end{array}$ & $\begin{array}{l}\text { Orifice del P } \\
\text { (in } \mathrm{H} 2 \mathrm{O})\end{array}$ & $\begin{array}{c}\text { Probe } T \\
\text { (F) }\end{array}$ & $\begin{array}{c}\text { Stack T } \\
\text { (F) }\end{array}$ & $\begin{array}{c}\text { Meter In } \\
\text { (F) }\end{array}$ & $\begin{array}{l}\text { Meter Out } \\
\text { (F) }\end{array}$ & $\begin{array}{c}\text { Filter } T \\
\text { (F) }\end{array}$ & $\begin{array}{c}\text { Exit T } \\
\text { (F) }\end{array}$ \\
\hline 0 & 246.85 & 6 & 0.10 & 1.50 & 266 & 675 & 67 & 66 & 247 & 42 \\
\hline 5 & 250.00 & 7.5 & 0.10 & 1.50 & 267 & 671 & 69 & 67 & 242 & 41 \\
\hline 10 & 253.35 & 7.5 & 0.10 & 1.50 & 266 & 667 & 73 & 67 & 242 & 42 \\
\hline 15 & 256.61 & 7.5 & 0.10 & 1.50 & 266 & 664 & 75 & 68 & 243 & 42 \\
\hline 20 & 259.98 & 7.5 & 0.10 & 1.50 & 266 & 664 & 76 & 69 & 242 & 42 \\
\hline 25 & 263.31 & 7.5 & 0.10 & 1.50 & 265 & 665 & 78 & 69 & 242 & 43 \\
\hline 30 & 266.68 & 7.5 & 0.10 & 1.50 & 266 & 663 & 79 & 70. & 247 & 43 \\
\hline 35 & 270.17 & 8 & 0.10 & 1.50 & 265 & 670 & 80 & 70 & 248 & 43 \\
\hline 40 & 273.50 & 8.5 & 0.12 & 1.75 & 265 & 664 & 80 & 71 & 248 & 43 \\
\hline 45 & 277.15 & 8.5 & 0.12 & 1.70 & 264 & 658 & 81 & 72 & 248 & 44 \\
\hline 50 & 280.80 & 8.5 & 0.12 & 1.75 & 266 & 656 & 82 & 72 & 248 & 45 \\
\hline 55 & 284.32 & 8.5 & 0.12 & 1.75 & 265 & 656 & 82 & 72 & 249 & 45 \\
\hline 60 & 288.07 & 8.5 & 0.12 & 1.75 & 265 & 654 & 82 & 72 & 247 & 45 \\
\hline
\end{tabular}




\section{REFERENCES}

Arculos, R.J. and Delano, J.W. (1981) Geochemica et Cosmochemica Acto. 45, 899913.

Armstrong, K.M. and Klingler, L.M. (1985) "Evaluation of a Unique System for the Thermal Processing of Radioactive and Mixed Wastes," MLM-3340, EG\&G Mound Applied Technologies, Miamisburg, $\mathrm{OH}$.

Asano, M. and Yasue, $\mathrm{Y}(1985)$ "Vapor Species over $\mathrm{Na}_{2} \mathrm{O}-\mathrm{B}_{2} \mathrm{O}_{3}-\mathrm{SiO}_{2}-\mathrm{Cs}_{2} \mathrm{O}$ Glass," J. Nucl. Sci. Technol., 22, pp. 1029-1032.

Baumann, E., Coleman, C.J., Karraker, D.G., and Scott, W.H. (1987) "Colorimetric Determination of $\mathrm{Fe}$ (II)/Fe(III) Ratio in Glass," DP-MS-87-18, E.l. du Pont: Nemours \& Co., Aiken, SC.

Bibler, J.P. and Wallace, R.M. (1987) "Preparation and Properties of a Cesium Specific Resorcinol-Formaldehyde Ion Exchange Resin", DPST-87-647, E.l. du Pont Nemours \& Co., Aiken, SC.

Bibler, N.E., Bibler, J.P., Andrews, M.K., and Jantzen, C.M. (1991) "Initial Demonstration of the Vitrification of Nuclear Waste Sludge Containing an Organic Cs-Loaded lon Exchange Resin," WSRC-MS-91-465, Westinghouse Savannah River Co., Aiken, SC.

Bickford, D.F. and Choi, A.S. (1991), "Control of High Level Radioactive Waste-Glass Melters, Part 5: Modelling of Complex Redox Effects," Proceedings of the Fifth International Symposium on Ceramics in Nuclear and Hazardous Waste Management," Cincinnati, $\mathrm{OH}$, pp. 267-280:

Bickford, D.F. (1994) Log Book Issued to Dennis Bickford by Westinghouse Savannah River Site.

Bickford, D.F. (1994) Westinghouse Savannah River Site, Personal Communication.

Bickford, D.F. and Diemer, R.B. (1986) "Redox Control of Electric Melters with Complex Feed Compositions: I. Analytical Methods and Models," Joumal of NonCrystalline Solids, 84, pp. 276-284.

Burns, G.W., Scroger, M.G., Strouse, G.F., Croarkin, M.C., and Guthrie, W.F. (1993) "Temperature-Electromotive Force Reference Functions and Tables for the Letter-Designated Thermocouple Types Based on the ITS-90," National Institute of Standards and Technology Monograph 175.

Federal Register (1990), 55 (106), p. 22627. 
Kamizono; H., Kikkawa, S., Togashi, Y., and Tashiro, S. (1989) "Volatilization of Cs-137 and Ru-106 from Borosilicate Glass Containing Actual High-Level Waste," J. Am. Ceram. Soc., 72 [8], pp. 1438-1440.

Klingler, L.M. and Abellera, P.L. (1989) "Joule-Heated Glass Furnace Processing of a Highly Aqueous Hazardous Waste Stream," MLM-3577, EG\&G Mound Applied Technologies, Miamisburg, $\mathrm{OH}$.

Odoi, R. (1979) "Volatility of Alkali Fission Products During Solidification Processes," IAEA-SM-236/23, International Atomic Energy Agency.

Office of Solid Waste and Emergency Response (1986), "Test Methods for Evaluating Solid Waste, Vol. Il: Field Manual/Chemical Methods," SW-846.

Pearson, W.D. (1991) "Savannah River Site High Level Waste Program and the Defense Waste Processing Facility," Proceedings of the Fifth International Symposium on Ceramics in Nuclear and Hazardous Waste Management" Cincinnati, OH, pp. 3-10.

- Ramsey, W.G., Jantzen, C.M., and Bickford, D.F. (1991), "Redox Analyses of SRS Melter Feed Slumy; Interactions Between Nitrate, Formate, and Phenol Based Dopants," Proceedings of the Fifth International Symposium on Ceramics in Nuclear and Hazardous Waste Management," Cincinnati, OH, pp. 259-266.

Richards, R.S. and Lacksonen, J.W., (1991) "Stir-Melter'm Vitrification of Simulated Radioactive Waste, Fiber Glass Scrap, and Municipal Waste Combustor Fly Ash," Proceedings of the Fifth International Symposium on C'eramics in Nuclear and Hazardous Waste Management," Cincinnati, OH, pp. 309-320.

Sanders, D.M. and Haller, W.K. (1977) "The Effect of Water Vapor on Sodium Volatilization in Two Silica Based Glasses," Joumal of the American Chemical Society.

Schumacher, R.F. (1991) "DWPF Batch 1, Waste Glass Investigations," Proceedings of the Fifth international Symposium on Ceramics in Nuclear and Hazardous Waste Management," Cincinnati, OH, pp. 453-463.

Spalding, B.P. and Jacobs, G.K. (1989) "Evaluation of an In Situ Vitrification Field Demonstration of a Simulated Radioactive Liquid Waste Disposal Trench," ORNLTM-10992, Oak Ridge National Laboratories, Oak Ridge, TN.

USATHMA, (1988), "Bench Scale Glassification Test on Rocky Mountain Arsenal Soil," AMXTH-TE-CR-88015, U.S. Army and Toxic and Hazardous Materials Agency.

USEPA (1990) Methods Manual for Compliance with the BIF Regulations," EPAV530SW-91-010, PB-91-120-006, U.S. Environmental Protection Agency.

USEPA (1992) Handbook: Vitrification Technologies for Treatment of Hazardous and Radioactive Waste, EPA/625/R-92/002, U. S. Environmental Protection Agency. 
Wallace, R.M. and Bibler, J.P. (1988) "An Improved Method for Decontaminating Soluble High-Level Waste Using lon Exchange," DPST-88-789, E.I. du Pont Nemours \& Co., Aiken, SC.

Wicks, G. and Bickford D. (1989) "Doing Something About HLW," Technology Review, $92(6)$. 
D.F. Bickford, 773-A

G.S. Bumgarner, 773-41A

D.A. Crowley, 773-23A

E.F. Duhn, 773-A

J.R. Harbour, 773-43A

D.B. Helton, 773-41A

E.W. Holtzscheiter, 773-A

L.E. Landon, 704-T

M.J. Plodinec, 773-A

C.T. Randall, 704-T

H.F. Sturm, 773-A

GT Files

TIM 703-43A 